\title{
THE REPTILIAN VESTIBULAR AND CEREBELLAR GRAY WITH FIBER CONNECTIONS
}

\author{
JEAN K. WESTON \\ Laboratory of Comparative Neurology, Department of Anatomy, \\ University of Michigan ${ }^{2}$ \\ TWENTY-SEVEN FIGURES
}

(Accepted for publication September 21, 1935)

CONTENTS

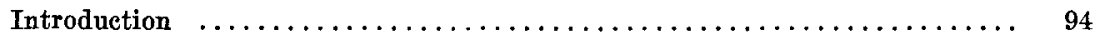

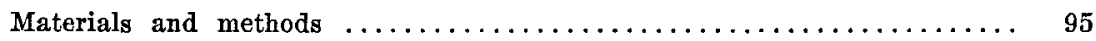

General survey of the literature $\ldots \ldots \ldots \ldots \ldots \ldots \ldots \ldots \ldots \ldots \ldots \ldots \ldots, 95$

Cytoarchitectonic structure of the vestibular region $\ldots \ldots \ldots \ldots \ldots \ldots \ldots .96$

General introduction $\ldots \ldots \ldots \ldots \ldots \ldots \ldots \ldots \ldots \ldots \ldots \ldots \ldots \ldots$

General survey and descriptions of vestibular subdivisions as based on

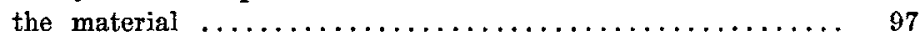

Nucleus vestibularis ventrolateralis $\ldots \ldots \ldots \ldots \ldots \ldots \ldots \ldots \ldots . . \ldots 8$

Nucleus vestibularis tangentialis $\ldots \ldots \ldots \ldots \ldots \ldots \ldots \ldots \ldots \ldots \ldots$

Nucleus vestibularis ventromedialis $\ldots \ldots \ldots \ldots \ldots \ldots \ldots \ldots \ldots \ldots . \ldots 6$

Nucleus vestibularis descendens $\ldots \ldots \ldots \ldots \ldots \ldots \ldots \ldots \ldots \ldots . \ldots . \ldots 109$

Nucleus vestibularis dorsolateralis $\ldots \ldots \ldots \ldots \ldots \ldots \ldots \ldots \ldots \ldots . \ldots \ldots$

Nucleus vestibularis superior $\ldots \ldots \ldots \ldots \ldots \ldots \ldots \ldots \ldots \ldots \ldots \ldots, 115$

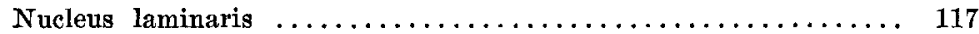

Cytoarchitectonic structure of the cerebellum $\ldots \ldots \ldots \ldots \ldots \ldots \ldots \ldots \ldots .120$

General introduction $\ldots \ldots \ldots \ldots \ldots \ldots \ldots \ldots \ldots \ldots \ldots \ldots \ldots \ldots \ldots \ldots$

Description of cerebellar nuclei $\ldots \ldots \ldots \ldots \ldots \ldots \ldots \ldots \ldots \ldots \ldots \ldots, 121$

Nucleus lateralis cerebelli $\ldots \ldots \ldots \ldots \ldots \ldots \ldots \ldots \ldots \ldots \ldots \ldots \ldots \ldots, 121$

Nucleus medialis cerebelli $\ldots \ldots \ldots \ldots \ldots \ldots \ldots \ldots \ldots \ldots \ldots \ldots \ldots 125$

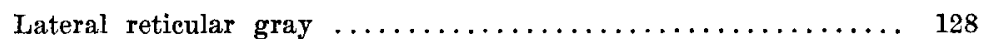

Description of cerebellar cortex $\ldots \ldots \ldots \ldots \ldots \ldots \ldots \ldots \ldots \ldots \ldots \ldots . \ldots \ldots$

Fiber connections of the vestibular region $\ldots \ldots \ldots \ldots \ldots \ldots \ldots \ldots \ldots \ldots 131$

Direct root fibers of the acoustico-facial complex $\ldots \ldots \ldots \ldots \ldots \ldots \ldots 131$

Sensory root of the VIIth nerve $\ldots \ldots \ldots \ldots \ldots \ldots \ldots \ldots \ldots \ldots$

Motor root of the VIIth nerve $\ldots \ldots \ldots \ldots \ldots \ldots \ldots \ldots \ldots \ldots$

${ }^{1}$ A dissertation submitted in partial fulfillment of the requirements for the degree of doctor of philosophy. 
Acoustic nerve ............................. 134

Dorsal (cochlear) root of the VIIIth nerve ........... 134

Ventral (vestibular) root of the VIIIth nerve ........ 138

Trigeminal root fibers to the cerebellum $\ldots \ldots \ldots \ldots \ldots \ldots \ldots \ldots \ldots \ldots, 142$

Secondary afferent connections of the vestibular region $\ldots \ldots \ldots \ldots \ldots, 144$

Tractus cerebello-vestibularis $\ldots \ldots \ldots \ldots \ldots \ldots \ldots \ldots \ldots \ldots \ldots, 144$

Tractus spino-vestibularis $\ldots \ldots \ldots \ldots \ldots \ldots \ldots \ldots \ldots \ldots \ldots \ldots . \ldots \ldots$

Certain other secondary afferent connections $\ldots \ldots \ldots \ldots \ldots \ldots \ldots 145$

Secondary efferent connections of the vestibular region $\ldots \ldots \ldots \ldots \ldots, 145$

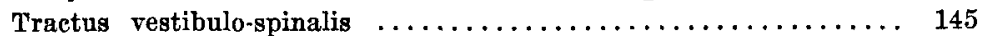

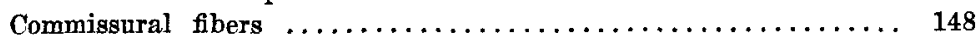

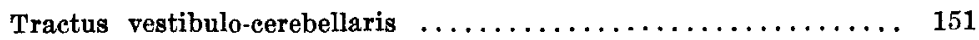

Fiber connections of the cerebellum $\ldots \ldots \ldots \ldots \ldots \ldots \ldots \ldots \ldots \ldots \ldots \ldots, 153$

Afferent cerebellar connections $\ldots \ldots \ldots \ldots \ldots \ldots \ldots \ldots \ldots \ldots \ldots \ldots, 153$

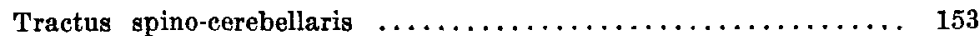

Nucleo-cerebellar system $\ldots \ldots \ldots \ldots \ldots \ldots \ldots \ldots \ldots \ldots \ldots \ldots \ldots$

Ventral superficial arcuates $\ldots \ldots \ldots \ldots \ldots \ldots \ldots \ldots \ldots \ldots \ldots \ldots$

Olivo- and reticulo-cerebellar fibers $\ldots \ldots \ldots \ldots \ldots \ldots \ldots \ldots 157$

Certain other nueleo-cerebellar connections $\ldots \ldots \ldots \ldots \ldots \ldots 158$

Tractus trigemino-cerebellaris $\ldots \ldots \ldots \ldots \ldots \ldots \ldots \ldots \ldots \ldots \ldots \ldots . \ldots \ldots$

Tractus tecto-cerebellaris $\ldots \ldots \ldots \ldots \ldots \ldots \ldots \ldots \ldots \ldots \ldots \ldots . \ldots \ldots$

Efferent cerebellar paths $\ldots \ldots \ldots \ldots \ldots \ldots \ldots \ldots \ldots \ldots \ldots \ldots \ldots \ldots, 163$

Cerebello-tegmental sgstem ..................... 163

Tractus cerebello-motorius et tegmentalis mesencephali ..... 164

Tractus cerebello-motorius et tegmentalis bulbaris ....... 167

Tractus cerebello-spinalis (et cerebello-vestibularis) $\ldots \ldots \ldots \ldots \ldots 169$

Connections of the cerebellar plate $\ldots \ldots \ldots \ldots \ldots \ldots \ldots \ldots \ldots \ldots, 171$

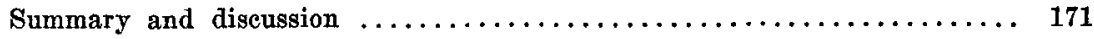

\section{INTRODUCTION}

The aim of this contribution is to present a detailed, comparative study of the vestibular and cerebellar nuclei and fiber paths in various reptilian forms. These two regions are considered together since they are so intimately associated structurally, functionally, and in their phylogenetic and ontogenetic development that such joint consideration seemed to be warranted. Thus far no investigator has presented, as a unit, a detailed study of these regions in reptiles, and it was felt that such a study, in a vertebrate class of such fundamental importance to comparative neurology and one which offers so wide a degree of variation among its members, could be pursued with profit, and would help bridge a rather obvious gap in our knowledge of the detailed structure of the brain stem in these forms. 
This study, pursued by anatomic methods, is subject to the limitations of all comparative neurological studies carried on by such means, but, while not all the problems encountered have been brought to final solution, it is felt that sufficient new data have been uncovered to warrant the presentation of this study and to incite the interest of other workers in this field.

This study carries a step caudalward the work of Huber and Crosby ('26 and '33) on the reptilian thalamus, midbrain, and tectum.

I am indebted to Dr. G. Carl Huber and Dr. Elizabeth C. Crosby for the opportunity to undertake this problem, for continued help and supervision while pursuing it, and for constructive criticism freely given; to them I gratefully acknowledge my indebtedness.

\section{MATERIALS AND METHODS}

The material available for study embraces brain series cut in cross, sagittal, and frontal planes, and respectively prepared by the modified pyridine-silver (Huber and Guild, '13) and tigroid methods (Huber, 27) used at Michigan, and by a modified Weigert's medullary sheath stain. The series studied are the same as those listed by Huber and Crosby '33).

\section{GENERAL SURVEY OF THE LITERATURE}

Since neither the reptilian cerebellum nor vestibular region has been studied exhaustively by very many investigators, so that most of the references quoted will be from papers which have considered these regions more or less incidentally, it is scarcely deemed desirable or profitable to present a complete review of the literature. It is rather the intention to refer to the literature at those points in this study where such references are directly pertinent to the structures under consideration. 
In addition to the literature directly pertaining to the problem, numerous other researches by various investigators and based on other vertebrates have been consulted. While in many cases they have had but an indirect bearing on this investigation, they have been found both suggestive and stimulating in the interpretation of the material herein considered. All of these will obviously not be referred to in the text of this paper despite the fact that they have undoubtedly had no small effect upon the evaluation of the material. Chief among these were the contributions of Larsell and Herrick on the amphibian cerebellum and associated regions.

\section{CYTOARCHITECTONIC STRUCTURE OF THE VESTIBULAR REGION}

\section{General introduction}

The discussion of the region in which the vestibular nuclei are located will be initiated by presenting briefly certain general observations based on the most generalized order available, the Chelonia or turtles.

Most of the lateral limb of the medulla oblongata in reptiles, which forms a large part of the lateral wall of the IVth ventricle, has been generally recognized as being primarily concerned with the reception, elaboration, and projection of vestibular and acoustic impulses. Ventrally and anteriorly the vestibular area extends to the chief sensory nucleus and entering roots of the $V$ th nerve. More caudally it is delimited ventrally by the descending root and nucleus of the Vth nerve, its ventral boundary throughout being approximately at the level of the inferolateral angle of the IVth ventricle. Caudally it grades over into the sphere of the vagus, and cephalically and dorsally, though more imperceptibly, into the cerebellum. Dorsally it reaches the cochlear region. Through this area pass the fibers of the VIIth and VIIIth nerves, together with other fibers of passage, most of which are concerned with the cerebellum. The above relations are illustrated in figures 2 to 7 and 17 to 26 . 
In Lacertilia, accompanying the eversion (figs. 8 and 26) of the cerebellum (possibly as a result of it), with the increased development of the trigeminal complex (fig. 26) and with the advent of a large nucleus tangentialis, the vestibular region becomes relatively more broadened mediolaterally and shortened dorsoventrally (figs. 9, 10, 25 and 26), with a concomitant narrowing of the IVth ventricle; this together with a variable degree of development of the cochlear region (Holmes, '03; figs. 9, 10, 25, see p. 118). This latter region is relatively smaller than in the turtle (at least in the forms studied), though in position and differentiation (particularly in the larger lizards) it evidently foreshadows the conditions found in Crocodilia.

In Ophidia the shape of the vestibular region resembles that in lizards, although the ventricle is relatively narrower (figs. 11, 12 and 25). The cochlear region (Holmes, '03) is very poorly developed (figs. 12 and 25). In this connection it is interesting to note that Ditmars ('10, p. 199) observed that snakes have no external ear and that their tongue is sensitive to vibrations, i.e., they hear with their tongue.

It is among Crocodilia that the cochlear region becomes best developed (Holmes, '03). In the alligator it assumes almost equal size with the vestibular region (figs. 14, 15 and 25) - provided one considers the nucleus laminaris to be cochlear-and the IVth ventricle is further encroached upon through this development (see especially fig. 15).

General survey and descriptions of vestibular subdivisions as based on the material

The terminology of Sanders ('29) for the sparrow is largely used in this account, chiefly because that terminology is more directly applicable to the conditions observed in the forms studied, both by reason of their morphologic appearance and their comparative anatomic relationships. Where her terminology does not fully conform with the localization in reptiles, this is duly mentioned. It should be stated that the plans of subdivision of the region advanced earlier 
by Stieda (1875), C. L. Herrick (1890), Köppen (1892, 1894), Holmes ('03), Beccari ('12), van Hoevell ('16), and others deserve recognition and may be quite as correct and permissible as that which follows. One must recognize that all plans of subdivision present individual interpretations of the same structures, and are biased in part by the material at the disposal of the respective observer.

According to the Sanders' ('29) nomenclature, the vestibular region is here subdivided as follows: 1) nucleus vestibularis ventrolateralis (nucleus of Deiters); 2) nucleus vestibularis tangentialis; 3 ) nucleus vestibularis ventromedialis ; 4) nucleus vestibularis descendens (inferior of Beccari); 5) nucleus vestibularis dorsolateralis (superior of Beccari; anterior of van Hoevell; see p. 113);6) nucleus vestibularis superior ; 7) nucleus laminaris.

Nucleus vestibularis ventrolateralis. This nucleus, very evident and relatively constant in position throughout this vertebrate class, forms an excellent approach to the more detailed consideration of this region. The nucleus vestibularis ventrolateralis is particularly large and obvious in Chrysemys, being the most conspicuous cell mass in the vestibular region (figs. $3,4,6,7,19,22$ to 24 ), and it is practically impossible to confuse its characteristically large, deeply staining, multipolar cells with those of any other cell mass in this region.

In the literature this large celled nucleus is commonly referred to as Deiters' nucleus or the lateral vestibular nucleus, either as a whole (Köppen, 1892; Holmes, '03; van Hoevell, '16; Ariëns Kappers, '21 and '29; Larsell, '26 and '32 ; Shanklin, '30; Frederikse, '31; and others) or in part (Beccari, '12, central group), these observers considering its large celled part homologous with the mammalian Deiters' or lateral vestibular nucleus. Hindenach ('31, fig. 5) figured this nucleus in Sphenodon punctatum, where its relations appear essentially similar to those in the turtle. Deiters' nucleus is but a part of the nucleus ventralis of the older workers, which was often referred to as a whole as Deiters' nucleus. 
The nucleus vestibularis ventrolateralis lies somewhat medially (figs. 3 and 4), having a rostrocaudal extent a trifle greater than that of the entering VIIIth roots (figs. 22 and 24). It passes over rostrally into the nucleus vestibularis dorsolateralis (figs. 6, 22, 23) and continues caudally into the nucleus vestibularis descendens (figs. 7,22 to 24 ; see also fig. 470 in Ariëns Kappers, Huber and Crosby, '36). Medially and dorsally (figs. 3 and 4) the periventricular gray intercalated among the dorsal arcuate fibers separates it from the ependymal lining of the IVth ventricle; medially and ventrally the nucleus vestibularis ventromedialis serves the same purpose. Laterally it lies against the long ascending tracts to the cerebellum (figs. 19 and 23). Dorsally it borders upon the cochlear nuclei (figs. 3 and 4) and the nucleus laminaris, where that is present, and ventrally it is limited by the nucleus and descending root of the Vth nerve (figs. $4,5,19,23$ to 25 ). Longitudinally coursing fibers of passage and the root fibers of the VIIth and VIIIth nerves aid in causing the rather broken up appearance of this nucleus (figs. 19, 22, 23 to 25 ).

Beccari ('12), in Lacerta, and Ariëns Kappers ('21), in the crocodile, have noted a fairly consistent grouping of these large cells into a central (which Beccari, '12, p. 678, considers probably the only one homologous to Deiters' nucleus of mammals), a dorsal, and a ventrocaudal (Beccari; posterior of Ariëns Kappers) group (figs. 3 and 4). These three divisions are readily observed in the turtle material, the central and ventrocaudal being rather intimately connected and together making up the pars ventralis of this account (figs. 3 and 4). These are also figured but not labeled by Larsell ('32, fig. 13, p. 313). In addition there is found, at some levels, a fairly well-defined lateral group (see figs. 3 and 4). The shape of the nucleus is quite inconstant throughout. At certain levels, where all the groups are more or less interconnected, the nucleus might be considered as having the shape of a rough, broken, shallow $\mathrm{C}$, the thicker closed portion (the central group of Beccari) lying toward the ventricle, 
and the open part (bounded dorsally by the dorsal group; ventrally by the ventrocaudal group of Beccari) embracing most of the entering vestibular portion of the VIIIth roots and the scattered cells intercalated among these fibers (this relation shows better in the lizard, fig. 9). Where the lateral group is present it closes the $\mathrm{C}$ laterally. One of the factors responsible for the quasi-separation between dorsal and ventral groups is the entering sensory root of the VIIth nerve (fig. 25). The ventral (ventrocaudal and central of Beccari, '12) group continues somewhat farther caudally than does the dorsal, and is usually more distinct, better delimited, and larger than the others. This grouping varies but little among the turtles, the chief difference being in the relative compactness and size of the cell masses.

The cells characterizing this nucleus are relatively large, deeply staining, and multipolar in appearance (figs. 3 and 4), resembling the ventral horn cells of the spinal cord of mammals (Spitzka, 1880). This is the only one of the vestibular nuclei in turtles presenting a distinctly efferent type of cell (Malone, '10), and hence it is logical to assume that it is probably principally concerned with vestibular reflex paths (doubtless largely to the neck and extremities in this form where the trunk is immovable). These large cells possess several thick processes (seven having been noted in some cases) and abundant Nissl substance grouped most heavily around a large, centrally placed nucleus. Scattered among these large cells are both medium sized and small multipolar and spindle-shaped varieties, which stain fairly deeply (figs. 3 and 4 ), as well as some very small, lightly staining, pearshaped and bipolar cells. Certain of these latter cells may be representative of Beccari's nucleus tangentialis, which is not distinct in the turtles. The above description agrees essentially with the accounts of this cell group in the literature and shows little variation among all the turtles examined.

In lizards, Beccari ('12; see his figs. 7, 8, 9, 12 and 18) gave a very complete description of this nucleus, based on silver series of embryos of Lacerta muralis, and all the lizard material examined accords with his description, and is very 
similar to that of the turtle (figs. 9 and 10). In Anolis carolinensis the nucleus vestibularis ventrolateralis varies from the above description chiefly as follows: 1) its large cells appear actually and relatively smaller in size; 2) the nucleus as a whole is smaller in size, both actually and relatively; 3) relatively, it does not have so great a rostrocaudal extent; 4 ) the lateral group noted above is not so constant nor so well developed; 5) it reaches its greatest development slightly rostral to the most cephalic entrance of the roots of the VIIIth nerve. It must be remembered that Anolis is a very small, swift moving, active form, while Chrysemys is much larger and more clumsy (except possibly in water); possibly the size of this efferent nucleus may be to some extent a function of the amount of muscle present.

Beccari noted that the ventrocaudal group lies close to the chief sensory nucleus of the Vth nerve and is difficult to delimit therefrom. This is not true for the turtle, where the relatively much greater size of the cells of Deiters' nucleus could permit of no confusion with cells of the chief sensory nucleus of the Vth nerve. Also, the most anterior level at which Deiters' nucleus is found is caudal, in turtles, to the most caudal pole of the chief sensory nucleus of $V$, depending, of course, on where one stops calling it the chief sensory nucleus and begins calling it the nucleus of the descending root of V. Neither could Beccari's statement be verified in the majority of the lizards observed, though in Varanus there was a small group of Deiters' cells (part of the ventrocaudal group of Beccari) which seemed to lie rather far ventrally, quite close to certain cells of the $V$ th which appeared large and efferent in type, though quite apparently a part of the nucleus of the descending root.

Shanklin ('30, see figs. 30, 33 and 34) also figured and described this nucleus in Chameleon vulgaris as a nucleus ventralis (nucleus magnocellularis of Deiters). His brief description is in perfect accord both with that of Beccari and with the one presented here for Anolis. Frederikse ('31, figs. 28 and 29) showed this nucleus in photomicrographs of 
the brain of Lacerta vivipara, where its appearance is in agreement with the above account. Larsell ('26, figs. 4 and 23) figured and labeled this nucleus in Anniella and Gerrhonotus.

Of all the reptiles studied, snakes seem to have received least attention from the viewpoint of the comparative anatomy of the vestibular system. Hence the general work of Rabl Rückhard (1894), who barely touched on the vestibular region, a figure of Larsell ('26, fig. 17), and the brief mention by Papez ('29) of this nucleus, which he labeled in his figure 226 , include all the relevant literature.

In Thamnophis the nucleus vestibularis ventrolateralis is in most respects very similar to the nucleus of that name as described for Anolis. This comparison concerns two individuals in which the brains are of about the same size and in which the degree of activity is on the same general plane. The chief differences are that the individual cells of the nucleus are actually much larger in the snake (fig. 12), in fact being somewhat larger than the homologous neurons in Chrysemys, and that the nucleus has relatively fewer cells. Here, again, there can be little possibility of confusion with the chief sensory nucleus of $V$. However, in Natrix, where the cells are slightly smaller, some large cells are noted in the chief sensory nucleus and the nucleus of the descending root of $\mathrm{V}$, which are very close to the nucleus vestibularis ventrolateralis pars ventralis (see p. 101) of this account (possibly being aberrant Deiters' cells), and here Beccari's ('12) observation on Lacerta muralis can be confirmed, although his rather generalized interpretation is open to question, since this relationship appears more in the nature of an individual variation. The other snakes studied were very similar to Thamnophis, except that the cells were slightly smaller and the distinctness of the grouping, as in turtles, was somewhat variable.

In crocodiles the nucleus under consideration has been discussed, in the majority of cases in a very general way, by many observers (Rabl Rückhard, 1878; Holmes, '03; van 
Hoevell, '16; de Lange, '16; Ariëns Kappers, '21 and '29; Huber and Crosby, '26; and others). For Alligator mississippiensis, a large and, on land, a rather lethargic animal, the brains of young specimens were studied, but even so they were larger than the brains of adult individuals of the other reptilian forms available. In them the nucleus vestibularis ventrolateralis (fig. 14) is very well developed, resembling more closely the turtle as to the size of its cells, although these cells are relatively somewhat larger. While the grouping described by Ariëns Kappers ('21) for the crocodile is present in the alligator, it is often masked by the distinct concentration of these cells in the lateral portion of this region (fig. 14), apparently a rather distinct development of the variable lateral group noted in the turtle.

The nucleus presents its most marked development anterior to the level at which the nucleus tangentialis is well developed and it does not extend so far caudally in relation to the most caudal entering roots of the VIIIth nerve as is the case in the turtle. The concentration of the smaller elements of this nucleus is much more pronounced than in the other forms studied (fig. 14).

The relations of the ventrolateral vestibular nucleus (fig. 14) are essentially the same as in the turtle, except that dorsally it is in contact with the pronounced band of longitudinally coursing fibers which lies ventral to the nucleus laminaris (fig. 14), and that laterally and caudally a welldeveloped nucleus tangentialis is present. Here, also, there is no question of delimitation from either of the sensory nuclei of the Vth nerve.

Nucleus vestibularis tangentialis. The literature seems to contain no reference to the presence of a nucleus vestibularis tangentialis in the turtle other than Beccari's ('12, p. 691) general statement that it is probably present throughout the vertebrate series. Chrysemys certainly presents no welldeveloped nucleus tangentialis, its only representative consisting of a few small, spindle-shaped cells lying intercalated in the course of the entering vestibular fibers (figs. 4 and 19), 
unless certain of the medium-sized cells of the nucleus vestibularis ventrolateralis can be considered as its functional equivalent. With the exception of one series of Emys, which exhibited a more marked concentration of cells in the typical position of the nucleus tangentialis, the other turtle material observed resembled Chrysemys in this respect.

The relatively distinct nucleus tangentialis distinguishes the vestibular region of lizards from that of turtles, and it was in Lacerta muralis that Beccari ('12) first described this cell group in reptiles. Shanklin's ('30) paper on Chameleon vulgaris does not consider this nucleus nor do his figures show it labeled. The photomicrographs of Frederikse ('31, figs. 28 and 29), based on Lacerta vivipara, show this nucleus, although it is not labeled.

Beccari's excellent and most detailed description of this nucleus, based on silver preparations of embryos, leaves little to be added; the following brief description is chiefly for the convenience of the reader, and is based on Anolis carolinensis.

The nucleus tangentialis is the well-marked collection of small and medium-sized cells found intercalated among the entering vestibular root fibers (figs. 9 and 10). Anteriorly it passes over gradually into the lateral part of the nucleus vestibularis dorsolateralis, although at times this relation may be obscured by an especially well-developed lateral extension of the anterior portion of the nucleus vestibularis ventrolateralis. Caudally it gradually merges, along with the small celled component of Deiters' nucleus, into the nucleus vestibularis descendens; this caudal to the most caudally entering vestibular roots. Medially it borders on the nucleus vestibularis ventrolateralis (in many cases being practically continuous with the small celled portion of this latter mass, figs. 9 and 10), and more caudally, where that mass is not well developed, it approaches the dorsal areuate fibers and the periventricular gray (figs. 9 and 10). Ventrally it comes close to the chief sensory nucleus and the nucleus of the descending root of $V$, more laterally, and the nucleus vestibularis ventromedialis, more medially (fig. 10). 
It is often difficult to delimit the nucleus tangentialis from the chief sensory nucleus and the nucleus of the descending root of $\mathrm{V}$, since their cells are of practically the same size and lie quite close together in certain planes, although the motor root of the VIIth nerve (fig. 10), the ventralmost entering vestibular fibers (fig. 9), and a fairly constant blood vessel separating these areas (as Köppen, 1892, noted in the turtle and which is frequently encountered among all the reptiles; see fig. 25D) are very helpful in orientation. Laterally the tangential nucleus is scattered among the entering vestibular roots and the longitudinally coursing tracts; dorsally, it reaches the cochlear gray (figs. 9 and 10).

Beccari ('12) has noted four groupings; he designated them as anterior, posterior, central, and lateral, with the added note that cross sections show more a dorsal and a ventral division, due to the manner of entrance of the vestibular fibers. All these groups can be identified to a variable degree at various levels, and this distribution can probably be ascribed to fiber paths ramifying through this region; hence such grouping is of doubtful functional significance.

The cells of this nucleus are of small and medium size, and stain rather deeply. They are much smaller than the large Deiters' cells (fig. 9), and, although certain of them resemble the cells of all the other contiguous gray areas, they usually differ enough en masse to be readily recognizable. Many of them, especially the larger, more deeply staining cells, are multangular, though at first glance they appear round; others are more nearly oval (racket-shaped, as Beccari termed them); still others are spindle-shaped and appear very similar to the smaller elements of the nucleus vestibularis ventrolateralis. The nucleus appears best developed at the more caudal levels of the entering vestibular roots (fig. 10), and at these levels there are usually few of the large Deiters' cells in the plane of section (fig. 10).

Only minor variations were noted among the lizards available for study. Varanus and the Gila monster present little evidence of grouping and the latter appeared to exhibit a 
relative diminution in the size of this cell mass, with its cells apparently more scattered among the cells of the nucleus vestibularis ventrolateralis.

No description or labeled figure of this nucleus has been encountered anywhere in the literature on snakes, it apparently having been included under the general term of the vestibular or Deiters' nucleus. However, in the garter snake the nucleus tangentialis is very similar to Anolis (fig. 12) in all respects, although the grouping of its cells is more irregular and inconstant than in lizards, and its boundaries are not very distinct. In the other snake material studied (possibly because less satisfactorily stained), the nucleus does not exhibit quite so marked a development.

Ariëns Kappers ('21) appears to have been the only observer who has mentioned a nucleus tangentialis for Crocodilia, and he does not consider it very fully. It is quite well developed in Alligator mississippiensis, although not to nearly the same relative extent as has been noted in lizards or snakes. Its relations are very similar to those described in Anolis, except that its dorsal boundary is formed by the cross cut fibers ventral to the nucleus laminaris (fig. 15), and it has no distinet and constant subgrouping of its cells. The cells of the nucleus vary chiefly in that here the more deeply staining elements are spindle- or lancehead-shaped and very numerous, being relatively and actually smaller than the more oval or pear-shaped, deeply staining cells of the lizard (compare figs. 10 and 15) and snake.

Nucleus vestibularis ventromedialis. This rather ill-defined mass has evidently not been named in the literature consulted dealing with reptilian forms, probably being included under the general term of Deiters' nucleus or the nucleus ventralis. However, in the sparrow Sanders ('29) designated a mass of small cells by the name 'nucleus vestibularis dorsomedialis,' which certainly possesses similar relations to the nucleus under consideration, although in reptiles the term ventromedialis is more nearly accurate, topographically considered, and this mass is referred to here as the nucleus 
vestibularis ventromedialis (figs. 3 to 5). Sanders ('29) also suggested that this mass is homologous with the medial vestibular nucleus of mammals.

In Chrysemys this nucleus is preeminently a small celled mass, intermingled with which are a variable number of medium sized, multangular cells (figs. 3 to 5), which stain rather lightly and are pear- or spindle-shaped. However, they usually can be readily differentiated from contiguous cell masses by reason of their relatively much smaller size, although the whole nucleus is often almost totally eclipsed at some levels by the invasion of the large cells of the nucleus vestibularis ventrolateralis.

The rostrocaudal limits of this nucleus are very indefinite and purely arbitrary. Here its cephalic limit is considered as being at the level of the cephalic end of the nucleus vestibularis ventrolateralis, since in this region it presents first a fairly definite concentration of cells, although it is quite possible to trace such cells somewhat farther rostralward than this, more or less as periventricular gray scattered rather thinly among the dorsal arcuate and cerebello-tegmental fibers. Followed caudally it becomes better developed, tending to assume a rather triangular outline in cross section (fig. 5), keeping the same relative position just lateral and inferior to the inferolateral angle of the IVth ventricle, and can be followed through the whole extent of the vestibular region caudal to the above noted point of origin. It is split up considerably by the dorsal arcuates, the vestibular fibers, and the secondary Vth fibers coursing through it, which factors probably partially explain its variable cell density from section to section. Dorsolaterally it is bounded by the ventrolateral vestibular nucleus and more caudally by the inferior vestibular nucleus, certain of the cells of this latter nucleus practically becoming a part of the nucleus vestibularis ventromedialis (fig. 5). Ventrolaterally it lies fairly close to the nucleus of the descending root of the Vth almost throughout its extent (figs. 3 to 5), and at some levels there appears to be cell continuity between them. Dorsally and 
medially it stretches toward the cochlear gray by means of scattered cells intercalated in the course of the dorsal arcuate fibers (periventricular gray, figs. 3 to 5). Ventrally and medially it is similarly elongated around the inferolateral angle of the ventricle toward the medial longitudinal fasciculus by small, scattered cells; medially it is limited by the ependyma of the IVth ventricle (figs. 3 to 5). Its caudal boundary is difficult to fix. However, somewhere between the entrance of the IXth and Xth nerves it becomes dominated by these nerves, especially the latter, and quite definitely can no longer be thought of as being in any relation to vestibular fibers. This point coincides essentially with the caudal pole of the acoustic nuclei and of the nucleus vestibularis descendens, all of which are difficult to delimit caudally with any degree of certainty. The extent to which this cell mass is in reality vestibular is questionable (see p. 175). Excepting in some very young specimens of Pseudoemys, where this nucleus is much better developed as a compact mass than in the adult forms, the nucleus vestibularis ventromedialis shows little variation in the turtle.

The relations of the nucleus vestibularis ventromedialis in lizards differ but little from those in Chrysemys, except that in Anolis the nucleus appears to be slightly better developed (figs. 9 and 10). More anteriorly it comes into relation ventrally with the dorsomedial motor nucleus and root of the Vth nerve. More caudally and laterally it is in contact with the nucleus tangentialis, which, as observed above, is here much more developed than in the turtle (fig. 10). Also, due to the broadening and flattening of this region, as previously noted, it lies quite near to the cell masses on the dorsolateral side of the medial longitudinal fasciculus (figs. 9 and 10), thus resembling in position the nucleus intercalatus of more caudal levels. The larger lizards, such as Varanus and Gila monster, resemble the turtle more closely in the development of this nucleus, while the smaller lizards resemble Anolis more closely. 
In snakes the relations of the nucleus vestibularis ventromedialis are similar to those in Anolis. However, the nucleus here is relatively much larger (fig. 12), though whether this may be due to a considerable invasion of the smaller elements of surrounding cell masses is uncertain, particularly since the lateral boundary of the nucleus under consideration is a very indefinite and hence an arbitrary one. Dorsally and medially it is well developed, and seemingly becomes directly continuous with the cells of the cochlear region, which are very similar to the cells of this nucleus in size and type (fig. 12). Laterally, in addition to the boundaries noted in the turtle and the lizard, the nucleus is limited at some levels by a rather conspicuous bundle of what appear to be secondary acoustic fibers, which swing down into the region of the nucleus of the descending root of the Vth.

In Crocodilia is found the best relative development of the nucleus vestibularis ventromedialis among the reptiles, although there is not much difference in its relative development when compared with that of the garter snake (compare fig. 12 with figs. 14 and 15). With the exceptions 1) that the dorsal extension of the nucleus into the cochlear region is not present here, due to the well-developed nucleus laminaris (figs. 14 and 15), 2) that the cells of this nucleus appear slightly larger, and 3) that more of the multangular type of cells are present, the description for the snake can be applied to Alligator mississippiensis.

Nucleus vestibularis descendens. The nucleus vestibularis descendens has usually been included with Deiters' nucleus or nucleus ventralis. Ariëns Kappers ('21) stated that in reptilian forms there is no caudal extension of Deiters' nucleus, as in mammals, to the level of entrance of the IXth nerve.

In general, the nucleus vestibularis descendens may be thought of as the more diffuse, caudal, medium sized and small celled continuation of the nucleus vestibularis ventrolateralis and the nucleus tangentialis (figs. 5, 7, 22 to 24). It represents a fairly well-delimited nucleus of variable shape 
extending from the caudal limits of Deiters' nucleus, cephalically, to a rather indistinct, purely arbitrary, caudal limit, which lies somewhere between the entrance of the IXth and of the Xth nerves, its most caudal part apparently running over into the nuclei funiculi posterioris. It lies in close relation throughout to the descending vestibular root (figs. 22 to 24). Ventrolaterally it is limited by the descending root of the Vth and its nucleus; ventromedially, by the nucleus vestibularis ventromedialis. Medially it is bounded by the dorsal arcuate fibers; dorsally, by the cochlear gray; and laterally, by the ascending fibers to the cerebellum. The delimitation from the cochlear gray and from the nucleus vestibularis ventromedialis is not very distinct at some levels, there being cell continuity between all three of these masses.

The constituent cells are essentially of the medium sized and small varieties previously noted for the surrounding nuclei, the medium sized, multangular variety predominating, particularly more rostrally. Throughout its extent the mass appears most dense around and among the descending vestibular fibers.

Beccari ('12) noted that in Lacerta muralis the nucleus vestibularis descendens is very indistinct. Frederikse ('31, figs. 30 and 55) labeled this nucleus in Lacerta vivipara, where it seems to be quite comparable to its homologue in the turtle.

In the smaller lizards examined, such as Anolis and Holbrookia, the above statement of Beccari seems to apply, and this may be ascribed, at least in part, to the very great development caudally of the nucleus tangentialis which apparently occurs at the expense of the nucleus vestibularis descendens (and as a consequence of the development of the nucleus tangentialis, the nucleus under consideration no longer exhibits the same intimate relationship to the nucleus vestibularis ventrolateralis as was noted in the turtle). Also, the fact that there appear to be many fiber bundles coursing through this region and converging upon the cochlear area, which tend to split up the gray of the whole region 
into columns, serves to effectually mask the nucleus vestibularis descendens in these forms, the more so since the cells of the nucleus vestibularis descendens are very similar to those of the surrounding cell masses. However, in the larger lizards, notably in Gila monster, this nucleus resembles the homologous cell mass in Chrysemys, with the exception of the above noted relation to the nucleus tangentialis.

Papez ('29) figured the nucleus vestibularis descendens and mentioned it very briefly in his consideration of the brain of Natrix sipedon. From his figures it appears that in position, relations, and extent, it resembles closely the foregoing description for Chrysemys, although a few of his figures suggest that he includes with it a portion of what here is ascribed to the cochlear nuclear complex. However, since his illustrations are based on fiber material it is difficult to be certain of a sharp delimitation of a nuclear mass such as this, the more so since such delimitation is practically impossible even in toluidin blue material. In the garter snake, as well as in the other species studied, the relations of this nucleus are so similar in all respects to the conditions in the larger lizards, that no further description is deemed necessary.

In Alligator mississippiensis the relations of the nucleus vestibularis descendens are very similar to those in the turtle. However, in the alligator the nuclear mass is a trifle more condensed and much better delimited from the cochlear region, dorsally, the nucleus vestibularis ventromedialis, medially, and the nucleus of the descending root of the Vth ventrally, and appears to fade out at about the level of entrance of the Xth roots. It is notable that a greater number of larger cells are present at the cephalic pole of this nucleus, while caudally it is almost entirely small celled.

Nucleus vestibularis dorsolateralis. As with the other vestibular nuclei, Deiters' nucleus (or nucleus ventralis) has also included the nucleus vestibularis dorsolateralis of this report. The nucleus under consideration is the same as the nucleus vestibularis superior of Beccari ('12, Lacerta), and 
undoubtedly forms a large part of van Hoevell's ('16) nucleus vestibularis anterior in Caiman sklerops (pp. 113 and 115). Ariëns Kappers ('21) verified this nucleus in the crocodile, and considered it homologous to Bechterew's nucleus of higher forms. It is the same cell mass which Larsell ('26, figs. 21 and 23) and Hindenach ('31, Sphenodon) have labeled as the nucleus vestibularis superior.

Between the levels of the nucleus vestibularis ventrolateralis, caudally, and the cerebellar nuclei, cephalically, practically the whole of the lateral limb of the medulla oblongata is taken up by the nucleus vestibularis dorsolateralis (figs. $3,6,22$ and 23). These boundaries are purely arbitrary, since caudally there is little difference between the cells of the caudal part of this nucleus and the smaller cells of the nucleus vestibularis ventrolateralis, and rostrally the same is true of this nucleus in relation to the cerebellar and superior vestibular nuclei. In the turtle, the most cephalic limit of the nucleus vestibularis dorsolateralis (likewise the most caudal limit of the cerebellar nuclei) is approximately at the rostralmost level of entrance of the Vth roots (figs. 6 and 23).

The mass is very irregular in shape and rather diffuse throughout, appearing most dense caudally and medioventrally (fig. 3). Medially it lies against the cerebello-tegmental fibers, anteriorly, and the dorsal arcuates and their intercalated periventricular gray, more posteriorly. Dorsally the cochlear gray (and the nucleus laminaris), which is best developed more caudally, serves as a rather indefinite boundary, and rather more rostrally the cerebello-oblongata junction, with its attendant fiber masses sweeping up into the cerebellum, answers the same purpose. Laterally the long ascending tracts to the cerebellum limit the nucleus (fig. 22), and ventrally it is usually very poorly delimited from the chief sensory nucleus of the Vth (figs. 3 and 6).

The cells of this nucleus are predominantly medium-sized, multangular, and stain fairly darkly. However, many smaller cells of various shapes are scattered among them, particularly caudally. As van Hoevell ('16) has noted for the nucleus 
vestibularis anterior (see p. 112) of Caiman (incorrectly designated Alligator sklerops; private communication from Amsterdam), the medium sized multangular type predominates caudally resembling the vestibular variety, while more rostrally there are more of the medium sized spindle-shaped or pear-shaped cells, which resemble those of the cerebellar nuclei, although the extent to which this tendency is manifested depends upon where one draws the line between the vestibular and the cerebellar nuclei (see p. 115). In other words, here is a rather undifferentiated transition area between the strictly vestibular and the strictly cerebellar regions. The diffuse nature of the nucleus is largely due to the fact that it is broken up by the vestibular fibers passing through it, and these are also very likely responsible for the inconstant clumping observed at all levels. With the exception of Emys, where this mass appears more compact throughout, there is little evidence of variation in any of the other turtles studied.

In the lizards the nucleus vestibularis dorsolateralis is formed, as in turtles, by the fusion caudally of the cerebellar nuclei, which occurs slightly anterior to the caudalmost part of the cerebello-oblongata junction-and hence slightly anterior to the rostralmost entrance of the Vth roots. The nucleus is very diffuse here and occupies a greater dorsoventral extent than in the turtle. Its rostralmost level is usually relatively farther cephalad than the same in the turtle. However, in Varanus it is placed much farther caudalward than in the turtle, appearing at about the middle of the rostrocaudal extent of the entering $V$ th roots. To some extent this variation is undoubtedly due to a difference in the plane of section, but it is unquestionable that such variation is in part dependent upon the degree of eversion in these forms. Caudally it is arbitrarily considered as bounded by the entrance into the picture of Deiters' cells, which, being farther forward than in turtles, make it appear that in all the lizards (except Gila monster) there has been a relative, if not an actual shortening of this portion of the vestibular area. 
There is, rather consistently, an indefinite grouping, especially more caudally, into a medioventral group and a dorsolateral group. The smaller lizards, such as Anolis, presented a denser cell arrangement, the cells appearing relatively more numerous than in the turtle, while in the larger lizards, such as Gila monster, they are more exactly comparable to those of the turtle. The sizes and types of cells are relatively very similar to those of the turtle, though actually the cells appeared slightly smaller.

The nucleus vestibularis dorsolateralis represents the $\mathrm{nu}$ cleus which Beccari ('12) and Larsell ('26) in lizards, and Hindenach ('31), have labeled the nucleus vestibularis superior. Beccari's brief description of this nucleus, as a mass of stellate cells smaller than those of Deiters' and lying in that portion of the brain stem corresponding to the juxtarestiform body of mammals, along the course of the ascending VIIIth root, is more true of the lateral than of the medial portion of this mass. Beccari also questioned whether this mass corresponded to the superior vestibular nucleus of Cajal ('00) in Amphibia, and stated that if its neuraxes do not add to the medial longitudinal fasciculus, by reason of its position it could be considered to correspond to the nucleus vestibulo-cerebellaris. Frederikse ('31), in his figures 26 and 27 , has labeled this nucleus more caudally and in its ventral portion as nucleus vestibularis adscendens, and more anteriorly, apparently, as a part of his nucleus vestibulo-cerebellosus; his nucleus principalis vestibularis (fig. 27) is probably a part of the chief sensory nucleus of $V$.

Papez ('29) mentioned the nucleus vestibularis dorsolateralis under the term nucleus vestibularis superior, and considered it as the place of origin for his vestibulo-mesencephalic tract, and this apparently constitutes the only reference to this mass in the literature on snakes. The description of this nucleus in the lizard is applicable, for the most part, to snakes. The chief differences are that in the garter snake the cells of the nucleus seem actually larger than in the lizard and more densely arranged (fig. 11). There is no differentiable cochlear gray bounding this nucleus dorsally, the 
cerebello-oblongata junction occupying that position throughout the cephalocaudal extent of the nucleus.

The nucleus vestibularis dorsolateralis has been figured and described by van Hoevell ('16) for Caiman sklerops (pp. 112 and 125) under the name of the anterior vestibular nucleus, and his descriptions are applicable to the conditions observed in Alligator mississippiensis, where, although somewhat larger, this nucleus resembles closely the condition in Chrysemys. However, according to van Hoevell's figures, the name of anterior vestibular nucleus is applied to a large part of what is here considered the nucleus lateralis cerebelli.

Nucleus vestibularis superior. Among reptiles, only turtles present a distinct nucleus vestibularis superior which has a position similar to that mass as described by Sanders ('29) for the sparrow. Even here, sagittal series suggest that this nucleus might well be considered the direct rostroventral continuation of the nucleus vestibularis dorsolateralis (fig. 6). Where present this mass corresponds only to the most anterior portion of the nucleus vestibularis superior of Beccari ('12), Ariëns Kappers ('21), Larsell ('26 and '32), and others, their nucleus vestibularis superior being largely the nucleus vestibularis dorsolateralis of this account.

In transverse series of the turtle, the nucleus vestibularis superior (figs. $2,6,17$ ) is continuous caudally with the nucleus vestibularis dorsolateralis. It first becomes clearly evident slightly rostral to the most rostral limits of the chief sensory nucleus of $V$, just ventral to the nucleus lateralis cerebelli and but poorly delimited from this latter mass, being composed of morphologically similar cells. Ventral to it is the reticular gray, from which it is also poorly delimited. Medially lie the cerebello-tegmental fibers and their intercalated periventricular gray. Laterally the afferent cerebellar tracts are found. Followed forward it becomes larger, becoming somewhat round in cross section. Its relations remain nearly the same throughout, except that anteriorly it appears more directly continuous with the reticular gray, ventrally, and with the lateral cerebellar nucleus, dorsally (fig. 6), while 
medially it is in relation with the mesencephalic root of the Vth nerve and the scattered cells accompanying that tract (which are labeled the nucleus loci cerulei by van Hoevell, '16, in a similar relation to the mesencephalic root of the Vth nerve in Caiman sklerops). It finally passes over cephalically, caudal to the large celled portion of the nucleus isthmi, into a smaller-celled reticular gray mass (see p. 128), rather broken up by fiber tracts running to the cerebellum, which swings around the lateral angle of the IVth ventricle (fig. 1), and is here in direct continuity with the most anterior part of the cerebellar nuclei.

The cells of the superior vestibular nucleus resemble in size both those of the lateral cerebellar nucleus and those of medium size found in the nucleus vestibularis dorsolateralis, although the multangular variety predominates, resembling, in this respect, the vestibular rather than the cerebellar nuclei (fig. 2). Smaller cells of various shapes and sizes are also present. The cells are rather compactly arranged and the whole mass stains relatively deeply. It is not a very large nucleus (fig. 2).

While in certain of the other forms studied (fig. 8) it is possible to make out faintly' a nucleus similar to the above, its delimitation is so indefinite that it would force the issue were the attempt made to locate such a nucleus in all the different orders. In lizards (especially the smaller ones) and snakes, the small size of the area, and, especially in lizards, the marked eversion or tendency toward it, probably constitute a sufficient anatomic basis to explain the absence of this nucleus as a distinct mass. In alligators there is also a tendency toward eversion in that portion of the cerebellum most closely attached to the medulla oblongata probably sufficient to explain in part the absence of this nucleus. Probably a functionally homologous group is present in all these forms, although morphologically it may constitute a part of either the nucleus vestibularis dorsolateralis, the nucleus cerebelli lateralis, or even the dorsalmost portion of the reticular gray of this region, or it may be distributed 
among these three masses, being submerged until the whole region reaches fuller phylogenetic development in birds.

Nucleus laminaris. There still is not unanimity of opinion as to whether the nucleus laminaris is to be considered purely vestibular, purely cochlear, or mixed in its function. Holmes ('03) first considered this nuclear mass under the above name (although it had been known previously by the older workers such as Edinger and Köppen as part of the tuberculum acusticum) and described it rather completely in the alligator, noting that it was variously developed in all the other Reptilia examined by him. This nuclear mass was seen in Caiman (van Hoevell, '16), in Crocodilia (de Lange, '16; Ariëns Kappers, '21 and '29), in Alligator (Huber and Crosby, '26), and in Chameleon (Shanklin, '30).

At about the middle of the rostrocaudal extent of the nucleus vestibularis ventrolateralis (figs. 4, 5, 7, 21, 24), Chrysemys series show a nucleus dorsal to this latter mass, which is unquestionably the nucleus laminaris of Holmes ('03; Testudo and Chelone midas) although there is no definite lamina. Followed frontally it becomes more and more diffuse, and before the most anterior level of the nucleus vestibularis ventrolateralis is reached, it can no longer be delimited from the cochlear gray of this region as a definite nuclear mass. Caudally, considerably behind the nucleus vestibularis ventrolateralis, the nucleus laminaris seems gradually to become invaded by the larger oval cells (figs. $5,7,21,24$ ) of the nucleus dorsalis magnocellularis (pars posterior of the nucleus laminaris of Holmes, '03). Ventrally the nucleus is separated from the vestibular nuclei by a fairly well-marked mass of cross cut and longitudinally cut fibers. Medially it abuts against the ependyma of the IVth ventricle, and laterally and dorsally it lies among the longitudinally coursing fibers to the cerebellum.

The characteristic cells (figs. 5, 7, 24) are medium sized and are rather spindle-shaped or multangular in form, although there is some admixture of smaller cells. For the most part, these cells appear to be oriented so that one of 
their two main processes courses dorsally and the other ventrally.

Beccari ('12), in Lacerta muralis, was unable to establish a nucleus laminaris comparable to Holmes' description, though he would not affirm that it was lacking. Shanklin ('30), in Chameleon, identified this nucleus as that portion of the cochlear mass having the same relations as the nucleus laminaris of crocodiles, and noted that the cells are medium sized and small, multipolar or round in form, and further stated that they are not lined up in a row but are separated into groups by means of fiber fasciculi. It is difficult to harmonize Shanklin's description of this mass with the labeling of the same in certain of his figures. Frederikse ('31) did not attempt to subdivide the cochlear region in Lacerta vivipara.

In smaller lizards, the present observations are in accord with the negative results of Beccari as concerns this nucleus. Certainly there is cochlear gray throughout this region (figs. 9 and 10), but this resembles the nucleus laminaris only in position-and even that tends to become atypical at many levels, where this gray moves more laterally and seems to have a position more analogous to that of the avian nucleus angularis. It is apparently the more caudal part of this cochlear gray that Shanklin described as the nucleus laminaris (and so it may be functionally). No very definite nucleus dorsalis magnocellularis can be clearly recognized in these forms, the cells throughout appearing smaller and more diffuse than those composing the nucleus laminaris in turtles.

When the larger lizards are examined, the results of Holmes ('03) can be verified, since a nuclear mass similar to the nucleus laminaris of Chrysemys can be readily located, although it is apparently not so well developed. It may be noted, parenthetically, that in this order, where the nucleus laminaris shows the greatest variability of development, the development of the cochlea also shows its greatest variability, and this would constitute a major argument for considering the nucleus laminaris to be chiefly cochlear in function. 
Holmes ('03) mentioned having examined Boa, Python, Tropidonotus, and Zamenis, but made no comment concerning the presence of the nucleus laminaris in these forms. It is not possible to delimit a definite nucleus laminaris in the snakes studied, which is not surprising since the whole acoustic region is relatively greatly reduced. If a functional nucleus laminaris is present, it has either migrated medioventrally or has become a part of the dorsal cochlear mass, the only cochlear nuclear mass sufficiently developed here to deserve consideration, which by reason of its topographic relations is more homologous to the nucleus angularis of higher forms (fig. 12).

It is in Crocodilia, concomitant with the extraordinarily great development of the cochlear portion of the ear and the consequent relative enlargement of the acoustic portion of the VIIIth nerve, that there is an unmistakable and highly developed nucleus laminaris, another argument for its being primarily cochlear in function. In these forms, the descriptions of Holmes ('03) for Alligator, of van Hoevell ('16) for Caiman, and of Ariëns Kappers ('21) for Crocodilia are quite complete and the material available is in essential agreement with them. A glance at figures 14, 15 and $25 \mathrm{~A}$ shows the relations of this very evident cell mass. However, just dorsal to the fiber mass bounding the nucleus laminaris dorsally, there is found a second nuclear mass having the same linear type of arrangement but being somewhat more broken (figs. 14, 15, 25A), the cells of which are similar to those of the nucleus laminaris, but less darkly stained. Laterally this mass is directly continuous with the nucleus laminaris by means of a fairly well-defined, semilunar band of cells, the concavity of this band being directed medially (figs. 14 and 15). This appears not to have been noted by Holmes or subsequent observers of this region in reptiles. This band is best shown caudally (fig. 15), and it is also observed to continue ventrally, apparently in direct continuity with the smaller cells of the vestibular region. This apparent connection is definitely intercalated among secondary cochlear 
fibers. This second, more dorsal row of cells probably represents portions of the nucleus laminaris split off by the longitudinally coursing tracts which bound it dorsally.

The nucleus laminaris passes over caudally, as Holmes ('03) has noted, into a large celled nucleus (the nucleus dorsalis magnocellularis of van Hoevell, '16, Ariëns Kappers, '21, and Huber and Crosby, '26; pars posterior of the nucleus laminaris of Holmes, '03), which here seems to be composed of a larger celled mediodorsal portion and a smaller celled ventrolateral portion, although these respective portions may possibly be accentuated by the plane of section and the manner in which the fibers pass through this mass, and hence have relatively little functional significance.

CYTOARCHITECTONIC STRUCTURE OF THE CEREBELLUM

\section{General introduction}

The reptilian cerebellum may be considered as a plate of nervous tissue, attached laterally to the medulla oblongata and rostrally to the anterior medullary velum, which diverges from this attachment in a variety of ways and which shows a variable amount of folding, depending upon the species under consideration. With such attachments it follows that the cerebellar plate forms a variable portion of the roof of the IVth ventricle, and serves in all cases as a place of attachment for the tela choroidea of the IVth ventricle.

Embryologically, Herrick and Liarsell have shown for amphibians (although this had been known earlier for man; see His, 1891, and Streeter, '12; the work of Reese, '08 and '15, on the alligator is also of interest) that the cerebellum "appears to be derived from two bilaterally paired sets of primitive coordinating centers, namely the auricular lobes and the corpora cerebelli'' (Larsell, '32, p. 340); and Larsell ('32) considers it to have a similar origin in reptiles.

So far as the gross morphology is concerned, it will receive little attention here, since it is fully realized that this phase of the reptilian cerebellum has received adequate attention from other investigators (for example, Ingvar, '19, and Larsell, '26 and '32). 


\section{Description of cerebellar nuclei}

Edinger ('00) and Banchi ('03) considered briefly a reptilian cerebellar nucleus. Since the work of van Hoevell ('16), this mass has been generally recognized as consisting of two groups of cells, usually referred to as the nucleus lateralis cerebelli and the nucleus medialis cerebelli. However, it should be added, and with emphasis, that these two nuclei are very intimately connected morphologically in all the forms studied, probably being parts of the same slightly folded gray mass. In Sphenodon punctatum, Hindenach ('31) has noted no anatomic separation into two nuclear masses, but found that such a separation may be made on the basis of the fiber connections.

Nucleus lateralis cerebelli. The nucleus lateralis cerebelli has received brief consideration in turtles from Larsell ('32) where it appears to agree with the same mass as described by van Hoevell ('16) in Caiman sklerops (see pp. 115 and 125), by Ariëns Kappers ('21 and '29) in Crocodilia, by Larsell ('26) in lizards and snakes, and by Shanklin ('30) in Chameleon vulgaris (with some exceptions, see p. 123).

In Chrysemys marginata (and with but slight differences in the other turtles studied) the nucleus lateralis cerebelli (figs. 1, 2, 6, 17, 23, 24) is continuous caudally with the nucleus vestibularis dorsolateralis, and ventrally with the nucleus vestibularis superior. It is difficult to separate the nucleus lateralis cerebelli from the nucleus vestibularis dorsolateralis but for convenience the caudal pole of each of the cerebellar nuclei is considered here to be at the rostralmost level of entrance of the Vth nerve. At this level (figs. 2 and 6) the nucleus lateralis cerebelli is a rather dense cell group lying about in the middle of the lateral limb of the medulla oblongata, just lateral to the IVth ventricle (fig. 2). Ventrally lies the nucleus vestibularis superior (as yet poorly developed) and dorsally, the nucleus medialis cerebelli. Laterally it is limited by fiber bundles to the cerebellum. Followed rostralward it keeps practically the same relative position except that it is crowded more dorsalward. At about the 
middle of its caudorostral extent, it attains a position dorsal to the lateral angle of the IVth ventricle (Larsell's, '32, "lateral extension of the rostral region of the ventricle"), where ventrally a reticular gray mass takes the place of the nucleus vestibularis superior and where medially it appears continuous with the periventricular gray above the IVth ventricle (van Hoevell's nucleus brachium conjunctivum; considered here merely as a well-developed portion of the periventricular gray), as well as with those swinging around the lateral angle of the ventricle and running ventromedially (fig. 1). Here, also, it is in more evident continuity with the nucleus medialis cerebelli, although this connection is variably developed throughout its extent, as is its continuity with the superior vestibular nucleus and the reticular gray ventrally. There is doubt as to the relations of this nucleus as figured by Larsell ('32, fig. 15). His figure does not present relations observed in Chrysemys or other turtle material, but does appear to represent the relations observed in snake material, leaving the supposition that it was inadvertently accredited to turtle when it should have been labeled snake (compare with figs. 1, 2, 11 and 12 of this account).

Farther forward this nucleus has become more medial, lying entirely dorsal to the IVth ventricle, closely interconnected with the nucleus medialis cerebelli (fig. 1), and forming practically the most medial portion of the reticular gray mass which swings up around the lateral angle of the IVth ventricle. At this level the nucleus lateralis cerebelli has reached its most rostral extent. Thus the lateral cerebellar nucleus is more distinct from the medial one laterally and caudally, and more intimately connected with it medially and rostrally (figs. 1, 2,6).

The cells are chiefly medium sized and stain fairly dark, being quite densely packed throughout (figs. 1, 2,6). Many small cells are also noticeable. Apparently oval and bipolar types predominate, although certain multangular cells can be observed, as well as a few scattered, large cells of the type characteristic of the nucleus medialis cerebelli. 
Larsell ('26) described a nucleus lateralis cerebelli rather generally in the legless, subterranean, burrowing form, Anniella nigra. He observed that there the lateral nucleus is considerably larger than the medial, noting that the nuclei are both small and that the separation between them is not so evident as in the larger reptilian forms. In Gerrhonotus principis (a less active, more generalized lizard), he found the cerebellar nuclei very similar to those of Anniella but larger, and his figure of this form (fig. 21) appeared to illustrate conditions quite similar to those found in Chrysemys at more rostral levels of this nucleus. This apparent similarity, in part at least, is probably due to the fact that in Gerrhonotus there is a much less extreme eversion than is found in Anolis, Holbrookia, and certain other lizards.

Shanklin ('30) considered this nucleus in Chameleon vulgaris. From his brief description of the cerebellar nuclei, it appears that they are completely at variance with those masses as Larsell ('26) described them in lizards and as they are considered and identified in this paper, and such of his figures as illustrate these masses do not seem to materially clarify them, at least insofar as it is permitted to interpret such figures. It seems most probable that his nucleus lateralis is the nucleus medialis of this report, or both the cerebellar nuclei in some of the figures, and that his nucleus medialis may be the periventricular cells corresponding to the nucleus of the brachium conjunctivum of van Hoevell ('16).

In the smaller lizards the available material accords with Larsell's observations. Here it is very difficult to delimit a well-defined nucleus lateralis cerebelli (fig. 8) because of the relatively much smaller size of these lizards and because the eversion seems to have tended to pull the cerebellar nuclei dorsalward. As a result the lateral cerebellar nucleus becomes very diffusely organized and less clearly delimited from the medial cerebellar nucleus and the granular layer of the cerebellum. However, its main relations are very similar to those in Chrysemys, particularly anteriorly. Ventrally, there being here no observable superior vestibular 
nucleus, the lateral cerebellar nucleus is directly continuous with the reticular gray throughout its course. The cells are similar to those in the homologous nucleus of the turtle, although they seem to be somewhat smaller (fig. 8).

In the larger lizards the nucleus is more nearly comparable to those found in the turtle and the alligator; Gila monster being more comparable to the turtle and Varanus to the alligator.

The nucleus lateralis eerebelli appears relatively smaller than the medial cerebellar nucleus in the smaller lizards, which fact does not agree with the condition noted by Larsell ('26); in the larger specimens, there is little difference in the size of these two nuclei.

Larsell ('26) has noted that the cerebellar nuclei in Thamnophis are similar to those in Gerrhonotus, and his figure 18 (of an embryo of Thamnophis) illustrates in general the conditions encountered among the various snakes studied. In these forms there is relatively much less of a separation of the nucleus lateralis cerebelli from the nucleus medialis cerebelli, medially, and from the nucleus vestibularis dorsolateralis, laterally and ventrally, than in any of the reptiles studied, indicating, as others have suggested, that perhaps here there is a regressive, rather than a specialized, condition of the cerebellum. The relations of this nucleus are most similar to those found in the smaller lizards, although here it is more truly lateral in relation to the medial nucleus than in any of the lizards examined (fig. 11) and appears to be the larger of the two, as Larsell ('26) noted (see fig. 11).

In Alligator mississippiensis the nucleus lateralis cerebelli has relations very similar to those found in turtles (fig. 13). It differs, of course, in its somewhat larger size, and also by extending farther rostralward than does the medial nucleus.

Van Hoevell ('16) described this nucleus very briefly in Caiman sklerops, considering it as lying "lateral and ventrolateral' from the cells of the medial cerebellar nucleus. With this description our observations are in full accord. However, it is difficult to homologize the figures of van Hoevell 
('16) with similar levels of the brains of either the turtle or the alligator. With his figure 9 the available material is in agreement, so far as the cerebellar nuclei are concerned. With his figure 8 this is not the case. The cell mass he has labeled nucleus vestibularis anterior probably is the caudal part of the lateral cerebellar nucleus, and the cells he has labeled the nucleus lateralis cerebelli are merely a part of the smaller celled component of the medial cerebellar nucleus, which component at most levels is in direct (though often masked) continuity with the same sort of cells of the lateral cerebellar nucleus. The same criticism applies to his figure 7, although here it appears that quite possibly the ventralmost portion of what is labeled the nucleus vestibularis anterior is actually that mass due to the tilt of the section; however, the same criticism as above holds for his nucleus lateralis cerebelli and the more dorsal part of his nucleus vestibularis anterior. His figure 6 is in agreement with this account insofar as the nucleus vestibularis anterior (here nucleus vestibularis dorsolateralis) is concerned. This figure appears to be about at the level of the transition from the cerebellar nuclei to the vestibular nuclei (which occurs relatively farther rostralward than in the turtle). Since the nucleus lateralis cerebelli merges caudally more directly with the nucleus vestibularis dorsolateralis (or van Hoevell's nucleus vestibularis anterior), it would appear consistent to consider that what van Hoevell has labeled in his figure 6 as the nucleus lateralis cerebelli, is the diffuse, caudal pole of the nucleus medialis cerebelli, at least in its more dorsal portion. Ariëns Kappers ('21) identified the two cerebellar nuclei in the crocodile and used van Hoevell's figure 7 to illustrate them.

Nucleus medialis cerebelli. The literature on the medial cerebellar nucleus seems to be in quite general agreement as to its location and relations, and has been contributed by the same workers as those referred to in the account of the lateral cerebellar nucleus. 
The nucleus medialis cerebelli as described by Larsell ('32) is strictly comparable with the homologous mass in the material available for study, with the reservations previously noted (p. 122) regarding his figure 15. He said (p. 317): "The more rostral part of the medial nucleus in Chrysemys extends nearly to the midplane, but farther caudad it lies more laterally, in transverse series. It has, therefore, an oblique position in the deep part of the cerebellum." $\mathrm{He}$ also noted (p. 316) that: "Toluidin-blue series of Chrysemys show the two nuclei as quite distinct dorsally, but ventrally they are joined by a bridge of cells." While this is essentially true at the more anterior levels of their extent (and is well shown in his figure 15), it is scarcely the case more caudally, at least in the series of Chrysemys available for study (see p. 122; also figs. 1, 2, 6; and the account of this mass in the snake, p. 127).

As has been seen (p. 112), the caudalmost level of the medial cerebellar nucleus in Chrysemys is considered to be in the same plane as the caudal pole of the lateral nucleus, both passing over into the nucleus vestibularis dorsolateralis. However, the medial nucleus lies in a considerably more dorsal position than the lateral cerebellar nucleus and is not so compact a mass at these more caudal levels. Throughout its rostrocaudal extent it is most definitely a cerebellar nucleus (figs. 1, 2), being at all times, except perhaps most caudally, an integral part of the cerebellum. Despite the fact that it lies in the stream of afferent fibers to the cerebellum throughout its extent, it appears to be a fairly compact mass of cells. Ventrally it is bounded by the nucleus lateralis cerebelli; laterally, by the long ascending paths to the cerebellum ; medially, by the IVth ventricle and the granular layer of the cerebellum; and dorsally, by the granular layer of the cerebellum, and these relations remain about the same throughout its extent (figs. 1, 2, 6, 7, 16, 17, 23, 24). Its rostralmost extent slightly exceeds that of the lateral cerebellar nucleus. 
Its characteristic cells are relatively large and fairly dark staining, being oval or bipolar in type (figs. 1, 2, 6, 7), although many of them appear to have at least three processes. These cells are very nearly the same size as the Purkinje cells in this form, although the largest of them seem just a shade larger than most of the Purkinje cells (this apparent difference in size has been considerably enhanced in the turtle illustrations so that these would show up well). It is these larger cells that provide the chief criterion for dividing a medial from a lateral nucleus in cell preparations. There is a large component of smaller cells, which appear very similar to the neurons making up the lateral cerebellar nucleus and which may be functionally equivalent to these latter.

Larsell ('26) has described a nucleus medialis cerebelli in Anniella and Gerrhonotus, and noted that it is smaller than the lateral cerebellar nucleus and but poorly separated from it; in other respects, it resembles the turtle condition. Shanklin ('30) has labeled and described the nucleus medialis cerebelli of this report as a nucleus lateralis cerebelli.

The medial cerebellar nucleus, in both the smaller and larger lizards, has essentially the same relations noted for the turtle (fig. 8). However, the nucleus is not so compact as in the turtle, its cells being scattered among the granular cells of the cerebellum laterally (Shanklin, '30). The size of its characteristic cells relative to the Purkinje cells agrees with the condition in the turtle, although both types are actually smaller here than in the turtle. This mass seems to differ from the homologous group in Gerrhonotus and Anniella (Larsell, '26) in being fully as large as, or even larger than, the lateral cerebellar nucleus.

In snakes, the medial cerebellar nucleus agrees perfectly with Larsell's ('26) description for the garter snake, and resembles that of the smaller lizards quite closely, as he noted.

In Thamnophis this nucleus is relatively much smaller than the lateral cerebellar nucleus and very intimately associated with it (fig. 11). The large cells, slightly larger than the 
Purkinje cells as a rule, are found intermingled with the granular cells of the cerebellum, being very few and scattered in most sections.

In Alligator mississippiensis this nucleus (fig. 13) agrees closely with the nucleus medialis cerebelli of Caiman sklerops (van Hoevell, '16), with the exceptions noted on page 125, as well as with Ariëns Kappers' ('21) brief description based on Crocodilia. It also resembles the homologous nucleus in Chrysemys, except that it does not extend relatively so far rostralward, and in the lizards to the extent that the large cells are rather diffusely scattered among the basal cells of the granular layer, lying between the fascicles entering the cerebellum, and the typical cells are much larger than the Purkinje cells.

Lateral reticular gray. This term embraces the smallcelled, mostly rather diffuse gray masses in close contact with the cerebellar nuclei laterally and ventrally in all the forms discussed, as is particularly well shown in sagittal and in horizontal series (figs. 1, 8, 11, 13). The more caudal and lateral portion of the reticular gray (just rostral to the most cephalic extent of the vestibular complex) lies in direct continuity with the nucleus lateralis cerebelli, and follows it dorsally and medially as it creeps around the lateral angle of the IVth ventricle (fig. 1 ). This more caudal portion of the reticular gray seems to be intercalated among the fiber bundles swinging out of (possibly also into) the cerebellum (figs. 6 and 23 , not labeled).

More anteriorly the small-celled portion of the nucleus isthmi lies in approximately the same relation to the anterior part of the medial cerebellar nucleus, being more split up by the afferent fibers to the cerebellum and seemingly continuous with the smaller cells of the cerebellar nuclei and with the granular cells of the cerebellum. Farther anteriorly (at the very anterior limits of the cerebellar plate), the most medial extension of the nucleus isthmi pars parvocellularis seems to be continuous forward into the mid-brain as the cell mass labeled nucleus precerebellaris (fig. 6). 
Thus it is possible to think of the cerebellar nuclei as the apex of a fan-like mass of smaller reticular cells, the rays of which, concave medially, diverge rostrally into the mid-brain and caudally into the medulla oblongata, apparently being threaded by both afferent and efferent cerebellar fibers.

\section{Description of cerebellar cortex}

It is fully realized that this report has little to contribute concerning the structure of the cerebellar cortex among reptiles, although the scope of the study demands at least a brief consideration of it. For a detailed account of its embryological development, the significance of its various sulci, and its subdivisions, the reader is referred to the excellent studies of Ingvar ('19) and Larsell ('26 and '32), and, more in general, to the accounts of Tilney ('23), Herrick ('24), and Hausman ('29). For details of the histology of the separate elements, the work of Ramón y Cajal ('11) and especially of Larsell (' 32 ; in this connection his papers on the amphibian cerebellum are also interesting) is referred to, the more so since this latter observer had a very rich collection of Golgi material at his disposal.

The cerebellum of reptiles is essentially a plate of nervous tissue. This plate, as has been readily recognized in all reptilian forms studied, and by practically every investigator who has even glanced at this region, is composed of three rather definite layers, which in turn have a distinct intrinsic histologic character.

In Chrysemys (figs. 1 to 7 ), where the relations are perhaps as simple as they are found anywhere among the reptiles, there is a more superficial, lighter staining area, with diffuse, faintly stained, round cells, the molecular layer (see all figures on the turtle). This occupies almost half of the thickness of the plate except laterally, in the auricular lobe (Larsell's, '32, floccular lobe), where it is considerably thinned out relative to the granular layer (fig. 3). Transverse sections, particularly rostrally, seem to make it appear relatively thicker. 
Approximately the deeper half of the plate is taken up by an exceptionally deeply staining, closely packed mass of small, round or oval cells, the granular layer (see all figures of turtle). This also remains about the same thickness throughout the plate, but laterally, as was the case with the molecular layer, it thins slightly (fig. 3). From the cerebellooblongata junction forward it is not quite so compact ventrally, the cells being split apart by the fiber bundles entering (and leaving) the cerebellum. It also appears to be hollowed out ventrally and caudally, near the base of the cerebellum, to make room for the cerebellar nuclei and the cerebellar commissure. Here, as in the molecular layer, more rostral transverse sections appear to demonstrate a relatively enormously thick granular layer, but this is due to the necessarily oblique plane such sections have followed. In the midline there is a rather constant, fairly cell-free area, quite variable in distinctness and often occupied by a blood vessel.

Lying between these two layers, and taking up most of the remaining small portion of the cerebellar plate, is the layer of Purkinje cells (see all figures on the turtle). These are fairly large, bipolar, deeply staining, and very obvious cells, seldom more than three or four cells deep and usually not more than two cells deep (although transverse series appear to dispute this for the reasons noted above). Between this layer and the granular cells is a rather thin, relatively cellfree area, which is readily seen, in silver or Weigert material, to be occupied by a tangled fiber mass (figs. 17, 18, 23, 24, 26). The layer of Purkinje cells also thins out laterally (in Larsell's, '32, floccular lobe), being reduced there to a single layer or scattered single cells (fig. 3 ).

The above relations hold throughout the reptilian forms examined, provided necessary allowances are made for the changes in shape and complexity of the simple plate as described above in Chrysemys. For instance, in lizards (see figs. 8 and 26A) the varying degree of eversion causes the granular layer to appear most superficial and the molecular layer deeper, thus apparently causing a reversal of these 
relations as described in the turtle. The relations in the snake (figs. 11, 12, 26C) are very similar to those in Chrysemys, except that there is but a small auricular lobe and no layer of Purkinje cells excepting caudally, these cells being scattered irregularly throughout the molecular layer (figs. $11,12,26 \mathrm{C}$ ). In Alligator (see figs. 13, 14, 15, 26B) the cerebellar plate is folded into three parts: an anterior vertical part, attached to the anterior medullary velum and showing a tendency toward eversion; a more horizontal middle part; and a more caudal vertical part. In these forms some troublesome transverse pictures are encountered, enhanced somewhat by the so-called ventriculus cerebelli, merely a dorsal extension of the IVth ventricle, which in some transverse planes seems to be a true cerebellar ventricle. In Alligator apparently the granular layer occupies slightly more than the half of the plate allotted to it in Chrysemys.

FIBER CONNECTIONS OF THE VESTIBULAR REGION

Direct root fibers of the acoustico-facial complex

Just caudal and dorsal to the entrance of the Vth nerve, a comparatively large bundle of nerve fibers can be readily observed entering the medulla oblongata in gross preparations of Chrysemys marginata. This bundle can be divided quite easily, microscopically, into four roots, two of which belong to the VIIth nerve. Here, this whole mass of entering nerve roots (figs. 19 and 25) is designated as the entering acoustico-facial complex, and although this communication is not concerned with all of this complex, all portions of it will receive brief consideration.

Sensory root of the VIIth nerve. This consists of a bundle of fine fibers which runs almost directly medialward to near the ependyma of the IVth ventricle (fig. 22), having a slight inclination from dorsal to ventral, and being split into fascicles by the longitudinally coursing tracts through which it passes nearly at right angles (fig. 25). This necessarily takes it between the cells of the nucleus vestibularis ventrolateralis, which it helps to divide into a pars dorsalis and a pars ventralis (fig. 4). Upon approaching the IVth ventricle, the 
sensory VIIth root turns abruptly caudalward (fig. 22), occupying the same relative position as does the fasciculus solitarius (fig. 20), with which it becomes directly continuous caudally (as Ariëns Kappers, '21, noted in Crocodilia, forming thus a pre-vagal component of that fasciculus; and as Tuge, '32, likewise showed in Chrysemys elegans; see also Barnard, '36). No collaterals or stem fibers could be traced to any of the nuclei at its level of entrance.

At the point where it turns caudalward, a few fine fibers course rostralward (fig. 22). These are rather difficult to identify in any but the most favorable preparations. The greater number appear to be contributed from more caudal levels, possibly coming from the IXth and Xth nerves (fig. $22)$. Those from the sensory VIIth root are even more difficult to identify; nor could it be determined whether these represent stem fibers or collaterals. It is most difficult to trace this bundle rostrally, due to its intermingling with the cerebello-tegmental system of fibers near the ventricle (fig. 22 ), which are of the same caliber and staining reaction. They could be identified no farther rostralward than the point where the mesencephalic root of the Vth nerve reaches the dorsolateral angle of the ventricle, even in certain especially favorable horizontal preparations. (These are doubtless homologous to Beccari's, '12, VIIth fibers to the cerebellum. More probably they pass to the much disputed secondary gustatory nucleus, if such a nucleus be present here.)

No significant differences appear in the several lizards studied (fig. 25B), which agrees with the results of Beccari ('12), Ariëns Kappers ('21), Shanklin ('30), and Frederikse ('31). In the snake, this root does not lie nearly so close to the ventricle as in the turtle, where it causes an elevation on the ventricular wall, but lies lateral to the nucleus vestibularis ventromedialis (fig. 25C). Furthermore, it enters the medulla oblongata more dorsally, due to the relatively poor development of the cochlear root in the snake. Papez ('29) figured such a bundle, labeling it the fasciculus solitarius. The alligator resembles the turtle except in the position which this 
root occupies with reference to the ventricle, wherein it resembles the snake more closely, although here the sensory VIIth root is not so easy to separate from the other longitudinally running systems with which it is crowded closely together, probably due to the extreme development of the cochlear nuclei in crocodiles. Ariëns Kappers ('21) has noted its presence in the crocodile and Hindenach ('31) figured and labeled a comparable root in Sphenodon.

Motor root of the VIIth nerve. The coarse, heavily medullated and fairly compact fascicles observed at the ventral and anterior level of entrance of the ventral VIIIth root make up the motor root of the VIIth nerve (figs. 4, 19, 23 to 25). From this point they arch dorsomedially toward (and finally into) the commissural fibers lying just beneath the floor of the IVth ventricle, being split up somewhat by the longitudinally coursing bundles of the descending $V$ th root (figs. 19 and 25D). The dorsalmost fibers lie very near to the ventralmost vestibular fibers, to which they are very similar. The fascicles course rostromedially through the commissural fibers at a sufficient angle to be fairly readily separable, until the dorsolateral portion of the fasciculus longitudinalis medialis is reached, when they turn abruptly caudalward (being apparently a part of the medial longitudinal fasciculus in transverse sections; figs. $19,20,25 \mathrm{D}$ ), and descend in that relation until about the level of entrance of the IXth nerve (fig. 20). Here they leave this position, a few fibers at a time, and course ventrolaterally to their nucleus of origin. Some of the fibers of this root cross to the opposite side before turning caudally, presumably originating from the opposite nucleus, particularly in lizards.

This root was very similar in the other reptilian forms studied (see figs. 10,12, 14, 15, 25), its extent depending somewhat upon the slightly variable position of the motor nucleus of the VIIth nerve. Tuge ('32) figured this root in Chrysemys essentially as noted above; as did Hindenach ('31) for Sphenodon, Beccari ('12), Ariëns Kappers ('21, also in the snake and the crocodile), and Frederikse ('31) 
for lizards; and Papez ('29) for the water snake. However, Shanklin ('30), in Chameleon vulgaris, noted the motor root of the VIIth nerve as being in close relation with the motor root of the Vth nerve at the latter's emergence; in fact, lying dorsal to the motor root of the Vth here (see his fig. 26). None of the lizard material examined agrees with Shanklin's figure nor with his description of this root. However, such a condition may be present in Chameleon, exaggerated perhaps, by the plane of section.

Acoustic nerve. The VIIIth nerve enters the medulla as two fairly distinct roots; a dorsal root, which obviously is related chiefly to the more dorsal (cochlear) group of nuclei, and a ventral root, which is apparently entirely related to the vestibular nuclei. In the turtle both these roots are composed of rather coarse fibers with essentially the same staining reaction. Practically all investigators who have examined the VIIIth nerve among Reptilia, since the time of Stieda (1875), have noted these two roots.

Dorsal (cochlear) root of the VIIIth nerve. The dorsal, posterior, or cochlear root, as it has been variously termed, is of primary interest here only insofar as it carries a vestibular component (Retzius, 1881-1884 and de Burlet, '29). It enters the medulla oblongata dorsal and caudal to the sensory root of the VIIth nerve (figs. 19, 21, 23, 24, 25D).

Various observers (Holmes, '03; Beccari, '12; Ariëns Kappers, '21; and others) have recognized that a considerable component of this root exhibits vestibular connections. Beccari ('12) termed this the posterior vestibular root, which led to some confusion when used in conjuction with the more inclusive term of posterior root. This vestibular component will be considered in detail along with the ventral or purely vestibular root.

The distribution of the purely cochlear portion of the dorsal root has been well described by Holmes ('03), Beceari ('12), Ariëns Kappers ('21), Huber and Crosby ('26), and others, most of these observers agreeing that the direct root fibers are distributed chiefly to the cochlear nuclei (nucleus 
angularis, nucleus laminaris, and nucleus dorsalis magnocellularis). Holmes ('03) found secondary cochlear fibers joining his acoustico-cerebellar tract and was unwilling to definitely exclude direct cochlear fibers from this tract, although he was likewise unable to demonstrate their presence in his Weigert material. Ariëns Kappers ('21) noted, and later Huber and Crosby ('26) verified, secondary cochlear fibers to the cerebellum, which coursed in their cochleovestibulo-cerebellar tract, which have been fully confirmed (Larsell, '26 and '32; Shanklin, '30; Frederikse, '31; and others). Beccari ('12) has apparently stressed more the direct cochlear fibers to the cerebellum, which he described and figured quite fully.

Transverse series of the turtle showed the cochlear root entering the medulla oblongata and passing almost directly to all the cochlear nuclei present, but chiefly to the nucleus dorsalis magnocellularis, since the other cochlear nuclei are poorly developed (figs. 21 and 24). Near these nuclei, the direct cochlear fibers become so intermingled with secondary fibers that it is practically impossible to determine definitely their further course. In adult series cut in other planes, particularly horizontal, it appears that certain fibers course rostrally for a considerable distance, intermingled with the secondary cochlear and vestibular fibers running in the same direction, although even here one can do no more than did Holmes ('03), when he recorded that he was unwilling to state definitely that no direct cochlear fibers joined the complex which he labeled the tractus acustico-cerebellaris. However, in series of very young Chelhydra serpentina (3 days after hatching) cut, with intent, in an oblique frontal plane, and very well and differentially impregnated after the pyridine-silver method (Huber and Guild, '13), the whole sweep of the entering cochlear fibers was very evident (fig. 21). Here unquestionable cochlear root fibers could be traced so far into the base of the cerebellum at the cerebello-oblongata junction that it was practically certain that they ended there. This confirms, at least in some measure, the observation of Beccari ('12) in this respect. Such fibers were not 
very numerous, being far outnumbered by the secondary cochlear fibers accompanying them. All the other material examined, particularly in sagittal and horizontal series, exhibited some evidence of such root fibers to the cerebellum, but nowhere else could they be so conclusively demonstrated as in the young Chelhydra material. They appeared least obvious in the alligator, and were difficult to find in the snake material, probably due to the difference in form relations in the region. It should be emphasized that it is far from proven that all the fibers entering with the cochlear portion of the dorsal root in these forms are in reality cochlear in function. This seems questionable as well from the relatively small development of the cochlear portion of the middle ear (except among the Crocodilia) as from the debatable part the sense of hearing actually does play in the life of these animals. It is apparently true that practically all reptiles are capable of uttering some sort of sound, at least during the mating season (see Gadow, '01; Ditmars, '10; Reese, '15). Consequently, they must possess a certain degree of hearing. However, it seems quite as likely that a considerable number of the so-called cochlear fibers may be neither truly cochlear nor truly vestibular at this stage of phylogeny (or ontogeny, in young forms), but mediate, rather, more of an undifferentiated vibratory type of sensibility which may be useful in orienting the animal in space, perhaps making up in some measure for the loss of the lateral line organs. An objection that could well be raised here is the fact that no direct cochlear fibers have been reported among the Amphibia, either embryo or adult. However, this does not entirely deny their existence.

It is likewise entirely possible that some of them may be purely vestibular in function. While the presence of such fibers in the cochlear root in the numbers observed passing directly to the cerebellum does not appear very probable, still, if true, such fibers could be readily explained as direct vestibular fibers to the cerebellum running with the cochlear root. 
It would seem significant that this system comprises so few fibers as to be most apparent only in very young forms where the nervous elements appear not yet to have reached their full development. It is further of interest to note that such fibers become less obvious in the Crocodilia, in which, among reptiles, are found the best developed cochlea and the largest relative number of cochlear fibers, and where, consequently, one should expect to find such a tract best developed were it an important functional component of the cochlear system. Probably these facts and the differences of opinion cited regarding the distribution of the direct cochlear fibers to the cerebellum can best be coordinated by considering that primitively (as evidenced by their presence in very young material) such direct fibers are present and rather numerous (particularly in forms where the cochlear nuclei show relatively little differentiation), probably originating from undifferentiated endings having to do with orientation in space; from such endings one would expect direct fibers to the cerebellum. As these endings differentiate either into receptors for purely cochlear or purely vestibular stimuli, their fibers entering the central nervous system would seek centrally either a cochlear or a vestibular center (another application of Ariëns Kappers', '08, principle of neurobiotaxis).

Thus as the cochlea (and consequently the cochlear nuclei) becomes progressively more differentiated, and the cochlear root larger, such direct cochlear fibers to the cerebellum become more and more interrupted by the increasingly large development of the cochlear nuclei, so that such fibers become fewer in number, both ontogenetically and phylogenetically, looking toward the condition in birds and even in mammals, where they have not yet been reported.

Among the smaller lizards (as well as the snake) the cochlear fibers are finer in caliber than the vestibular fibers, as Beccari ('12) noted, although in Varanus and Heloderma they appear to be of the same size. In lizards this root has been figured and briefly described by Shanklin ('30), Frederikse ('31), and others. Papez ('29) noted it in the water 
snake, where it resembles the turtle, provided due allowance is made for the much reduced condition of the cochlear nuclei and their differences in position (figs. 12 and 25C). This reduction in size also serves to obscure the direct cochlear fibers to the cerebellum, since they become mixed with the vestibular and secondary cochlear fibers almost at once after their entrance into the medulla oblongata. Holmes ('03), Ariëns Kappers ('21), and Huber and Crosby ('26) have considered this root in the crocodiles, and are in essential agreement with the foregoing description. In these forms, also, the cochlear fibers are slightly finer in caliber than the vestibular fibers (see fig. 25A).

Ventral (vestibular) root of the VIIIth nerve. This, the remaining component of the entering acoustico-facial complex, has been variously referred to as the anterior, ventral, or vestibular root of the VIIIth nerve. It carries fibers exclusively from that part of the auditory apparatus concerned primarily with equilibrium (Retzius, 1881-1884; de Burlet, '29). The vestibular component of the cochlear root (the posterior vestibular root of Beceari, 12) will also be considered here.

The neuraxes of the vestibular ganglion cells form a rather closely packed root which enters the medulla oblongata between the two root of the VIIth nerve (figs. 23 and 25D), and slightly ventral to the cochlear root. After their entrance, these fibers run almost directly medialward, with a slight ventral tilt. The vestibular component of the cochlear root pursues a similar course, though this lies dorsal to the level of the sensory VIIth root (figs. 23, 25D). Transverse silver series of Chrysemys readily demonstrate the following possibilities of distribution:

1. Many of the fibers come into relation with both the large and the small cells of the nucleus vestibularis ventrolateralis (fig. 25D).

2. A considerable number pass into the commissural band of fibers lying ventral to the IVth ventricle (fig. 25D). Here it is next to impossible to determine accurately what proportion are secondary and what proportion are primary 
vestibular fibers, though probably the former predominate (p. 149). However, such direct vestibular fibers may: a) cross the midline and pass to the opposite vestibular nuclei (these appear to have lost their medullary sheaths before they reach the inferolateral angle of the ventricle); b) turn into the fasciculus longitudinalis medialis, either contra- or homolaterally and pass either caudally or cephalically within that bundle; c) after reaching the inferolateral angle of the ventricle, turn ventrally, in considerable numbers, into the homolateral reticular gray.

3. Sagittal and horizontal series demonstrate conclusively that many of the entering vestibular fibers run medially to near the IVth ventricle and then arch rostrolaterally and slightly dorsally, a relation noted many years ago by Stieda (1875). These constitute the direct vestibular fibers to the cerebellum (fig. 22).

4. Many fibers curve caudolaterally and slightly ventrally, making up the descending vestibular root, which forms part of the vestibulo-spinal tract (fig. 22).

5. A considerable number course directly to a position near the IVth ventricle, where they bifurcate, one branch ascending and the other descending in company with the ascending and descending vestibular roots (fig. 22). This is not always the case, since either one or both branches may terminate on the cells of the vestibular nuclei, or one branch may be added to the commissural fibers noted above. The impression was received that the ascending and descending vestibular roots account for a relatively very large number of the direct vestibular fibers, at least in the turtle (see fig. 22), where the nucleus tangentialis is very small, although some of its cells showed the cup or spoon type of ending noted first by Ramón y Cajal ('08) in fishes (see also Pearson, '36), and later by Beccari ('12) in Lacerta muralis.

6. It was also possible to demonstrate a few spoon or cup type endings about the smaller cells of the nucleus vestibularis ventrolateralis, which supports the idea that (although very small) a functionally homologous nucleus tangentialis 
may be present here in the turtle. In the other reptiles, it was very evident that the large fibers of the vestibular root, especially, formed spoon- or cup-shaped terminations about the cells of the nucleus tangentialis, particularly in lizards. Some of these fibers end completely on these cells; others continue in part toward the commissural fibers, which they help to form; still others pass rostrally to add to the ascending vestibular root, or caudally to add to the descending root.

7. A few of the vestibular fibers, or their collaterals, quite certainly break up around the cells of the nucleus vestibularis ventromedialis, although these are very difficult to be certain of due to the many diverse fibers coursing through this nucleus.

8. Fibers from the vestibular component of the cochlear root appear to break up in relation to the cochlear nuclei, particularly the nucleus laminaris, although these may be aberrant cochlear fibers.

The direct ascending vestibular fibers arch rostrolaterally and with somewhat of a dorsal inclination (fig. 22). This course brings them out around (and under) the lateral recess of the IVth ventricle, then upward and apparently into relation with the granular cells of the auricular lobe of the cerebellum (Larsell's floccular lobe, '32). This would seem to correspond to the brief description of the vestibulofloccular tract of Larsell ('26 and particularly '32). This tract appears to carry the major portion of the direct ascending vestibular fibers (fig. 22). Not all of the direct vestibular fibers follow this course, as Larsell ('32) has noted (see p. 152). Some secondary fibers accompany this tract. These direct fibers to the cerebellum are in relation laterally with the long ascending cerebellar tracts; in relation dorsally (mixed to some extent) with the cochleo-vestibulo-cerebellar tract (Ariëns Kappers, '21; Huber and Crosby, '26); and in relation medially with the tractus cerebello-spinalis and the periventricular gray. Thus they pass dorsolateral to the nucleus vestibularis superior, though quite possibly they are in relation with that nucleus via collaterals. These fibers 
are in continuous relation with the cells of the nucleus vestibularis dorsolateralis, excepting farther rostrally, where that nucleus passes over into the cerebellar nuclei. Here there is a strong possibility of synaptic relation with the cerebellar nuclei, particularly the medial nucleus, although not demonstrable in the material available. Some of these fibers appear to pass into the cerebellar commissure (p. 151).

The descending vestibular root curves in a caudolateral direction with a slight inclination ventrally, eventually coming to lie rather far laterally, and in relation ventrally with the descending Vth root (fig. 22). It is closely applied to the nucleus vestibularis descendens throughout the extent of the latter (fig. 22), and is relatively a fairly large group of fibers among the turtles. These fibers could not be followed very far caudally since it appears that most of them terminate in relation to the caudal portion of the nucleus vestibularis ventrolateralis and the nucleus vestibularis descendens. Any fibers which course beyond the caudal limits of the latter nucleus would do so in company with the tractus vestibulospinalis, and will be considered with that tract. It should be emphasized here that from the material available the existence of very many direct vestibular fibers farther caudalward than the caudalmost limits of the nucleus vestibularis descendens is questionable, although perhaps a few of the decussating fibers which pass down in the medial longitudinal fasciculus are of this nature, a point impossible of determination from the material. Certainly no direct vestibular fibers can be traced into a position analogous to that which Beccari ('12) figured as a direct vestibulo-spinal tract (p. 148).

For the most part, the above description obtains in all other forms studied. However, where a well-developed nucleus tangentialis is present many more of the vestibular fibers (variable in size) are seen ending in relation to it. The direct vestibular fibers, particularly the ascending, are not relatively so numerous.

The foregoing account of the vestibular root fibers is similar, in general, to the previous accounts of Holmes ('03), 
de Lange ('17), Ariëns Kappers ('21), Huber and Crosby ('26), Larsell ('26 and '32), Papez ('29), and others. For a detailed account and analysis of the vestibular system, reference is made to Beccari's ('12) excellent study, with which the above account is in essential accord, although much of the finer detailed histology of endings, bifurcations, etc., as Beccari described them, could not be verified completely. This was due partially to the lack of embryonic material and also because all the material available was prepared more for the study of fiber tracts than for that of the finer histology of the synapses.

\section{Trigeminal root fibers to the cerebellum}

The presence of direct trigeminal fibers to the cerebellum, in reptiles, is a point concerning which considerable difference of opinion exists. Banchi ('03) described such fibers in turtles, snakes and lizards. Beccari ('12) also observed their presence (see his figure 4, p. 663). De Lange ('16) doubted their existence in Crocodilia, although he stated that such fibers appeared to be present in that form, as did Ariëns Kappers ('21, fig. 369), who noted further that they accompanied the dorso-spino-cerebellar tract (with which are closely associated nucleo-cerebellar and secondary trigemino-cerebellar fibers). Huber and Crosby ('26) also found evidence of such fibers, noting particularly their close relation to the nucleo-cerebellar system. Larsell ('26) found some indication of their presence in lizards and snakes. Although most of the above statements of opinion were in the affirmative, most of these observers likewise noted that the actual evidence left much to be desired in the way of conclusiveness. However, Larsell ('32) described and figured a tract in an embryo of Chrysemys which he considered as distinct evidence for the presence of such direct fibers, and noted supporting evidence in his adult turtle and alligator material (see also p. 143). Such fibers have also been reported by Woodburne ('36). 
The first evidence of direct trigeminal fibers to the cerebellum appeared in a transverse Weigert series of Chrysemys. Here well-myelinated fibers, which unquestionably left the Vth nerve, could be followed dorsalward and slightly rostralward in company with the dorso-spino-cerebellar and nucleocerebellar fibers, up to the base of the cerebellum. These were never very numerous in any one section, and often could not be followed so far toward the cerebellum, but their total number seemed relatively quite large (fig. 26D). Silver material verified the presence of such fibers, although they could not be traced so far nor so easily here.

Weigert preparations of the horned toad and the snake seemed to demonstrate conclusively the presence of direct trigeminal fibers to the cerebellum (fig. 26A) in rather large numbers. The figures of these forms (figs. 26A and 26C) demonstrate such fibers completely enough so as to require no further description. In Alligator mississippiensis (fig. 26B) they are apparently much less numerous, considering the relatively large size of the trigeminal nerve, and here they could not be demonstrated so conclusively. However, as shown in figure $26 \mathrm{~B}$, fibers can be observed definitely leaving the Vth nerve and turning dorsofrontally in company with the fiber band lying along the dorsolateral side of the medulla oblongata, as Ariëns Kappers ('21, fig. 369) observed.

The exact distribution of these fibers in the cerebellum would require degeneration preparations, but they appear to distribute chiefly homolaterally and to end particularly in relation with the granular cells of the lateral portion of the cerebellum, probably chiefly in the auricular lobe (floccular lobe of Larsell, '32), though this interpretation may not account for all of them.

Reference to Larsell's ('32) figure 31 indicates that the direct $V$ th fibers of the above description are considerably more laterally located than those so designated in his figure of a Chrysemys embryo. It is interesting in this connection to note that in Beccari's ('12) figure 4, page 663, of an embryo of Lacerta muralis, there are direct trigemino-cerebellar 
fibers labeled which lie considerably more laterally than the same in Larsell's figure, apparently agreeing more with the position of these fibers as they are here described (see fig. 26). However, in view of the lack of adequate embryological material, it is not possible to venture an opinion as to whether the tract which Larsell ('32) labels the ascending Vth root is homologous to that tract as described in the foregoing account or not, since very possibly such a tract could become forced more laterally with the further development and elaboration of the gray of the region, and hence come to correspond, in the adult, to its position as noted in this account.

\section{Secondary afferent connections of the vestibular region}

In Chrysemys, in addition to receiving the direct vestibular root fibers, the vestibular region receives impulses originating in the cerebellum and in lower bulbar and cord centers as well. It receives these not only through the stem fibers of tracts which primarily interrelate such centers with the vestibular gray, but also by way of the very rich and widespread dendritic ramifications it maintains in close relation with many other tracts coursing through and near the region, as well as with contiguous nuclear masses.

Tractus cerebello-vestibularis. This tract (figs. 18, 23 to 26) courses in part with the tractus vestibulo-cerebellaris and in part with the tractus cerebello-spinalis, and will receive detailed consideration along with those two tracts (pp. 151 and 169).

Tractus spino-vestibularis. This tract will receive more detailed consideration along with the tractus vestibulo-spinalis, together with which it runs (figs. 20, 22, 23; p. 145). Very likely this tract makes up the largest component of the fiber system usually designated as the tractus vestibulospinalis in reptiles. Its origin could not be definitely determined in the available material. Apparently such origin, for the most part, is in the spinal cord, but the possibility of bulbo-vestibular fibers must be kept in mind, though such could not be definitely demonstrated and are probably not very numerous. 
Certain other secondary afferent connections. It appears in pyridine-silver and Golgi preparations that the cells of nearly all the vestibular nuclei are similarly oriented. Hence, practically throughout this region their dendrites can be observed passing laterally into relation with the more laterally coursing tracts to.the cerebellum. In fact, Golgi preparations show a rather dense network of these dendrites among such tracts in places where the impregnation has been good. Other dendrites pass dorsally into the cochlear gray and its associated fiber tracts (though not to so great an extent in Alligator, where the cochlear region is highly developed), and still others pass ventrally into the reticular gray and the fiber tracts of that region. In addition, dendrites pass both rostrally and caudally (and quite possibly across the midline), thus subserving internuclear functions, as do certain dendrites observed passing into the periventricular gray.

The richness and extensiveness of this dendritic ramification is best developed among the cells of the nucleus vestibularis ventrolateralis (as Beccari, '12, noted), where it is not at all unusual to encounter six and seven processes to a cell of that nuclear mass, each accompanied by numerous fine, unmedullated fibers which seem to be following along these processes to enter into the pericellular synaptic net noticeable about each of these cells. The above is not true for the tangential nucleus, the dendrites of which are inevident or very small, nor is it the case to so marked an extent in the nucleus laminaris or the nucleus vestibularis ventromedialis.

Secondary efferent connections of the vestibular region

Tractus vestibulo-spinalis. The account of this tract in Chrysemys includes also a description of the spino-vestibular and of the direct vestibulo-spinal path (p. 141), these three being so intermingled that they are impossible of accurate delimitation in the absence of degeneration material.

In transverse series the tract is very obvious (fig. 20) and is closely intermingled with the cells of the nucleus vestibularis descendens (fig. 22). Laterally it is in relation with 
the ascending cerebellar tracts and with secondary cochlear fibers; dorsally, with the cochlear gray and its associated fiber system; medially, with the tractus cerebello-spinalis (which may carry a small vestibulo-spinal component, particularly from the pars dorsalis of the nucleus vestibularis ventrolateralis, figs. 20 and 23 ), and with the nucleus vestibularis ventromedialis and the fasciculus solitarius; ventrally, with the descending root of the Vth nerve and its nucleus. Its fibers appear to intermingle somewhat with those of the adjacent tracts. Followed caudally, it seems to decrease considerably in size, probably due to the direct component terminating in relation with the nucleus vestibularis descendens, and to intermingling with contiguous fiber tracts, particularly the mediodorsal portion of the descending Vth root. This intermingling becomes more evident and the tract more difficult to delimit from the descending Vth root as it is followed caudally, where it also appears to amalgamate with the cerebello-spinal tract. Caudal to the entrance of the $X$ th roots, little fascicles of the tractus vestibulo-spinalis can be noted detaching themselves from the dorsomedial border of the descending $V$ th root and running ventrally and slightly medially (through and medial to the nucleus of the descending Vth root) to become lost in the ventral part of the reticular formation. These little fascicles are no longer evident at the junction of the spinal cord and the medulla oblongata, though it is easy to determine that the tract continues over into the cord. However, such fascicles do not seem to account for all the fibers of this tract, and one is thus forced to the conclusion that a considerable component of the tract is still intermingled laterally with the descending Vth root and adjacent tracts, or else has ended, little by little, in relation to some of the nuclei of the brain stem.

The nucleus vestibularis descendens appears to be most intimately associated with this tract, and while absolute proof was not attainable, it is probable that the larger part (if not all) of the descending vestibular root ends in relation to its cells, and that this relation holds for the spino-vestibular 
component of the tract also. Furthermore, it would seem that the vestibulo-spinal component proper (which does not appear to be very large or obvious, if present at all) is contributed principally by the nucleus vestibularis ventrolateralis, pars ventralis; the nucleus vestibularis descendens adding but little, if any, to this tract, but discharging by way of the medial longitudinal fasciculus. It appears doubtful whether any of the vestibular nuclei rostral to the nucleus vestibularis ventrolateralis contribute to the vestibulo-spinal tract, and conversely, whether the spino-vestibular component proper contributes to the vestibular nuclei farther rostralward than the entering vestibular roots, though this observation could not be verified satisfactorily. Very likely this tract also carries a vestibulo-bulbar component, which would distribute to the motor nuclei of the brain stem. Regarding such a connection, Tuge ('32) has noted collaterals from this tract to the small neurons of the XIIth nucleus, as well as dendrites of the XIIth nucleus ramifying among the fibers of the vestibulo-spinal tract (p. 148). This latter observation has been verified in the material available, and this fact is equally true for the dendrites of the Xth nucleus, as well as for those of the nucleus of the descending root of the Vth. The above description is applicable also to the alligator and the snake.

In lizards it is possible to find a vestibulo-spinal tract fully comparable to the above. In addition, there is a very noticeable vestibulo-spinal tract somewhat more medially, lying ventral to the level of the entering motor VIIth root and slightly ventrolateral to the inferolateral angle of the IVth ventricle (fig. 25B). This tract is almost entirely made up of the relatively large, dark staining neuraxes of the large cells of the nucleus vestibularis ventrolateralis. A few neuraxes appear to be contributed by cells of the nucleus tangentialis, though these are very unusual and it is uncertain how far they accompany this tract. The tract can be readily followed caudally into the spinal cord, in its course moving ventromedially and lying finally just lateral to the 
medial longitudinal fasciculus. It has been impossible to verify such a tract in any of the other forms studied. However, in the other forms, particularly in the turtle and the alligator, there is a relatively large vestibulo-reticular connection in the same relation (p. 139). This tract in lizards might be justifiably termed a Deiterso-spinal path and be considered homologous to the ventrolateral vestibulo-spinal path of higher forms. This is the tract which Beccari figured for embryos of Lacerta muralis ('12; figs. 7 and 8, fascio vestibolo spinale-diretto) as a direct vestibulo-spinal path, though he briefly described a vestibulo-spinal path as originating from the cells of Deiters' nucleus. However, he showed (in his fig. 8) a descending vestibular root conforming in its relations to the description here given of the vestibulo-spinal path (of which it is here considered a component).

The vestibulo-spinal tract has received brief mention by some of the earlier workers (Edinger, '08, and earlier; Holmes, '03; and others). De Lange ('16) and Ariëns Kappers ('21) noted it in Alligator; Papez ('29) labeled and briefly described it in the snake, essentially as given in the above account. Shanklin ('30) described the vestibulo-spinal tract as consisting of two parts, a direct vestibulo-spinal path (corresponding in its relations to the one described above for the turtle), and a Deiterso-spinal tract, originating in Deiters' nucleus (nucleus vestibularis ventrolateralis). This latter appears to be homologous to the tractus cerebellospinalis of this report, which probably carries a small vestibulo-spinal component, and becomes amalgamated with the vestibulo-spinal tract caudally. Frederikse ('31) figured a descending vestibular root in a position analogous to that of the present account. Tuge ('32) labeled a tract in Chrysemys in the general region of the vestibulo-spinal tract which is homologous in position with Beccari's direct vestibulospinal path in Lacerta.

Commissural fibers. From all the vestibular nuclei fibers pass toward the inferolateral angle of the IVth ventricle, 
where they enter into the band of commissural fibers (figs. 19 and 25) which passes below the ventricle and toward the midline. This is also true of vestibular root fibers (p. 138). The nucleus vestibularis ventrolateralis is the largest contributor, although the nucleus vestibularis descendens also gives rise to a considerable number. Fibers from the cochlear nuclei and from the chief sensory nucleus and the nucleus of the descending root of the Vth help make up this commissural system; these are usually of smaller caliber. In addition, decussating motor fibers of the Vth nerve and the motor root of the VIIth nerve are also present, their concentration depending somewhat on the level of the section. From the above diverse list, it can readily be understood that a considerable degree of error might easily creep into any attempt at an exact evaluation of their further course. However, the following statements may be made with some degree of confidence.

Certain of the secondary vestibular fibers which enter into the commissural group can be observed to cross the raphe and pass to the vestibular gray of the other side, hence serving for coordination of the two sides. A questionable number of these fibers are doubtless direct vestibular root fibers. These last appear relatively more numerous in lizards and snakes, being overshadowed in the turtle and the alligator by the marked development of the secondary cochlear fibers crossing here. Most of the commissural fibers quite evidently run into the medial longitudinal fasciculus, where the larger number appear to pass caudally, in the contralateral fasciculus, down into the cord regions, as many observers have noted, probably corresponding to the medial vestibulo-spinal tract of higher forms. Certain of these secondary fibers pass rostralward or caudalward in the homolateral medial longitudinal fasciculus.

The relative proportion of fibers which follow these varions courses and their exact nucleus of origin are difficult of accurate determination. Certainly the nucleus tangentialis is a large contributor, as is the nucleus vestibularis ventro- 
lateralis, although all the vestibular nuclei here seem to contribute some fibers to the medial longitudinal fasciculus. Very probably those from the nucleus vestibularis dorsolateralis and the nucleus vestibularis superior are more concerned with the motor portion of the IIIrd and with the IVth nuclei, and would then correspond to what has been designated the vestibulo-mesencephalic system (Papez, '29, for snake; Tuge, '32, for Chrysemys; and others).

Certain of the commissural fibers, after crossing the midline, pass lateroventrally into the reticular gray. The nucleus of the VIth lies right in the midst of these commissural fibers, and some of them appear to end in relation to its cells. Certainly the observations of Tuge ('32), that some of the dendrites of the VIth nucleus pass around the inferolateral angle of the ventricle and get into the vestibular gray, can be readily verified.

Another component is the rather numerous group of secondary vestibular fibers that courses toward the inferolateral angle of the ventricle as though to add to the commissural fibers, but just before reaching that position turns ventrally into the homolateral reticular gray, where the fibers appear to terminate (figs. 19 and 25). These vestibuloreticular fibers are quite numerous, excepting among the lizards. Most of these fibers are contributed by the nucleus vestibularis ventrolateralis. Some of them apparently pass into relation with motor nuclei at appropriate levels, notably the motor Vth and motor VIIth nuclei, and it is possible that some may pass caudally, without synapse, in the reticular substance to lower motor centers in the cord, but these could not be demonstrated in forms other than lizards (p. 147).

As observed by Beccari ('12), Tuge ('32), and many others, the dendrites of the reticular cells pass up and into relation with these commissural fibers, as well as into relation with the vestibular gray. All the above statements have been quite well substantiated and carefully checked through a study of Golgi material. 
It should be noted that in large part the above account verifies the more general observations of many of the earlier workers (Edinger, '08 and earlier; Holmes, '03; Beccari, '12; and others). Various parts of the above account have been either briefly noted or expressed in figures by Papez ('29), Ariëns Kappers ('21 and '29), Shanklin ('30), Frederikse ('31), Tuge ('32) and others.

Tractus vestibulo-cerebellaris. The direct vestibular component of this system has already been considered briefly (p. 140 ; also fig. 22) and will be more fully reviewed here. Intermingled with this tract are a considerable number of cerebello-vestibular fibers (p. 169).

The secondary vestibular component of this tract is composed chiefly of fibers which originate, apparently, from the cells of the nucleus vestibularis ventrolateralis and the nucleus vestibularis dorsolateralis. Some of these fibers may be carrying impulses which originally reached the medulla oblongata via the vestibular nerve of the opposite side (and perhaps it is these which cross in the cerebellar commissure). It is possible that some of the crossed vestibular fibers contributed by the nucleus tangentialis and the nucleus vestibularis descendens add to this tract, but if present, such a component is very small. In addition, the nucleus laminaris contributes a noticeable component to this tract, which is included in the tractus cochleo-vestibulo-cerebellaris of Ariëns Kappers ('21) and Huber and Crosby ('26), and the tractus lamino-cerebellaris of Shanklin ('30).

From the level of the entering vestibular roots, caudally, to the base of the cerebellum, rostrally, the vestibulo-cerebellar tract occupies a large part of the middle and inferior portion of the lateral limb of the medulla (figs. 18, 19, 22, 23, 25 and 26). It is limited dorsally by the cochlear gray and cochlear fiber paths; medially, by the dorsal arcuate system (more caudally, and the cerebello-tegmental system, more rostrally); ventrally, it borders on the chief sensory nucleus and the nucleus of the descending root of the Vth, part of the descending root of the Vth, more caudally, and 
the reticular gray, more rostrally; laterally, it runs in company with the ventral superficial arcuate, spino-cerebellar and direct trigemino-cerebellar systems, and is intermingled with these to some extent, particularly rostrally. Some nucleocerebellar fibers, notably from the chief sensory nucleus of the Vth, seem to accompany the fibers of the vestibulo-cerebellar tract (fig. 25). Followed rostrally, the tract curves laterally (always closely applied to the scattered cells of the nucleus vestibularis dorsolateralis, which are concentrated in part on its medial side), at the same time sweeping dorsally. This course brings it lateral and ventral to the lateral recess and up and into the more caudal part of the cerebello-oblongata junction. It can readily be seen that such a course would carry it dorsolateral to the nucleus vestibularis superior. As noted, the direct vestibular root fibers follow a similar course, and a considerable portion of them pass to the auricular lobe, the rest of them distributing to other portions of the cerebellum. It must be emphasized that in the absence of degeneration preparations it is not possible to be dogmatic about the exact termination or the relative number of the direct root fibers, since it would be very possible that a large number of them terminate on the cells of the nucleus vestibularis dorsolateralis and continue onward from there as secondary fibers (which is probably the case, to some extent at least). However, in addition to the component to the auricular lobe (which is secondary in part, accompanied by direct and secondary cochlear fibers, doubtless the greater portion of the tractus cochleo-vestibulo-cerebellaris, see $p$. 151), the larger number of vestibular fibers swing up and back distributing to the granular layer of the cerebellum, where they spread laterally and caudally, as Larsell ('32) has noted; this agrees with Ingvar's ('19) observation on the crocodile. Much of the tract is in relation with the medial cerebellar nucleus, where some of its fibers appear to terminate-an appearance due in part to the fact that the accompanying cerebello-vestibular component originates here. Some of the fibers pass into the more caudal portions of the cerebellar 
commissure, and probably reach the opposite side, in part, no doubt, cerebello-vestibular, with origin in the opposite nucleus medialis cerebelli, but possibly contributed to by the axones of Purkinje cells, both homo- and contralateral, despite certain experimental observations on higher forms to the contrary.

In the smaller forms, such as the lizard and the snake, due partially to the relatively smaller rostrocaudal extent of the region, and, in the case of the lizard, to the eversion of the cerebellum (which tendency in Alligator leads to similar relations there), there is a sharper ventrodorsal gradient to the course of this tract, particularly near its termination, though actually the significant relations as noted are very similar throughout.

In many respects the foregoing account is but little different from previous descriptions of this tract (Edinger, '08 and earlier; Holmes, '02; Beccari, '12; Ariëns Kappers, '21 and elsewhere; Huber and Crosby, '26; Larsell, '26 and '32; Papez, '29; Hindenach, '31; Shanklin, '30; Frederikse, '31; and others).

\section{FIBER CONNECTIONS OF THE CEREBELLUM}

Afferent cerebellar connections

Tractus spino-cerebellaris. Due to the many times this tract has already been described (Edinger, '08 and earlier; de Lange, '16; Ariëns Kappers, '21; Huber and Crosby, '26; Larsell, '26, and others), another detailed description of it would be superfluous, particularly in view of the complete consideration Larsell ('32) has given to this system. Our material agrees essentially with the greater part of his description at least so far as based on adult material.

Briefly, then (based on Chrysemys), the spino-cerebellar system can be followed forward from the junction of the medulla oblongata with the spinal cord, occupying a ventrolateral position near the periphery of the bulb. Slightly rostral of the entering Xth roots some of the more dorsally situated of these fibers begin to edge laterally around the 
descending Vth root, a few at a time, mixed somewhat with the more rostral nucleo-cerebellar fibers. It is these former fibers which compose the dorsal spino-cerebellar tract. They come to lie just dorsal to the descending Vth root, continually recruiting more from below, until about the level of the entrance of the Vth roots, when they swing dorsalward into the cerebellum, distributing much as Larsell ('32) noted (figs. 17 to $23,25,26)$. Larsell ('32, p. 336) says of it: "In its course through the bulb the tract under consideration lies just dorsal to the spinal Vth bundle and arches dorsally just caudad of the level of the Vth root." The material studied is in agreement with this only to about the level of entrance of the Xth root caudally, caudal to which it lies more ventrolaterally and in company with the ventral spino-cerebellar tract (see also p. 159).

The more ventrally lying component of the spino-cerebellar system continues forward, moving slightly more dorsolaterally as the dorsal spino-cerebellar fibers swing around the descending $V$ th root, until at about the level of entrance of the VIIIth roots it lies mostly ventral to the descending root of the Vth (figs. 19 and 26). It maintains this relation as it passes forward, until about the level of the entrance of the Vth roots, when it curves dorsally and rostrally, in part passing through the more ventrally entering Vth roots (figs. 16 to $18,26)$ to form a considerable part of the cerebellar commissure. This is the ventral spino-cerebellar tract which, throughout much of its course, is very intimately related ventrally and medially to the spino-mesencephalic system and the lateral lemniscus.

Where the ventral spino-cerebellar tract curves dorsally to enter the cerebellar commissure, several rather obvious fascicles swing abruptly ventrofrontalward from its more dorsal portion (shown best in Weigert sagittal series). No especial effort has been made to identify these, but they seem to originate mostly from the chief sensory nucleus of the $V$ th and might be the homologue of Wallenberg's (1898, '03) quinto-frontal path in birds. 
In subscribing to the terms dorsal spino-cerebellar and ventral spino-cerebellar as Larsell ('32) uses them, no homologies are necessarily implied with higher forms (see also Larsell, '32), and further no definite line of demarcation exists between these two tracts morphologically, particularly in the absence of evidence regarding their origin in the cord (Huber and Crosby, '26), although such a general division does make it easier to describe the system and is essentially in accord with the anatomic relations encountered. These fibers (particularly the ventral spino-cerebellars) are in very close anatomic relation to the cerebellar nuclei, especially the medial nucleus (as Huber and Crosby, '26, noted for this tract in the alligator).

The alligator appears to show a considerable relative diminution in the size of the spino-cerebellar system, particularly of the ventral spino-cerebellar tract. It is this relatively (as compared with turtle) smaller bundle of fibers which Huber and Crosby ('26) described as accompanying the spino-mesencephalic fibers and then entering the cerebellum in the alligator, and considered as the possible homologue of the mammalian ventral spino-cerebellar system. Larsell ('32) verified that observation in these forms. Perhaps this disparity in size is partially due to the tendeney toward eversion of the rostral part of the cerebellar plate. This would force the spino-cerebellar fibers to adopt a steeper ventrodorsal gradient near the rostral part of their course in order to attain their objective, and consequently more of them would pass dorsal to the entering $V$ th roots or through these roots, thus causing the apparent marked decrease in size, more particularly of the ventral spino-cerebellar component. This emphasizes that the main distinction between these two tracts in reptiles appears to be their relation to the entering $V$ th roots- $a$ variable relation largely associated with differences in the form of the cerebellar plate. However, there still obtains a relative decrease in the whole spino-cerebellar system in the alligator, considering the much larger size of the cerebellum (and especially the fact that it 
is being compared with the turtle, a form where there is probably little, if any, contribution from trunk regions), for which another explanation must be sought. Perhaps the alligator is approaching the avian condition, where many intersegmental fibers are present in the cord, forming there a considerable component of the spino-cerebellar system, but being spino-spinal rather than spino-cerebellar, so that, despite the relatively larger muscular development, the tract in the alligator does not show the same relative progressive increase from caudal to rostral portions of the cord as is the case in the higher mammals, particularly. It should be noted, however, that the spino-cerebellar system is relatively much larger in birds, in spite of the loss of this intersegmental component throughout the cord, and this is doubtless correlated with the larger size of the cerebellum, both being central expressions of the necessarily highly developed proprioceptive mechanisms incident to flight.

Nucleo-cerebellar system. Here are included all the contributions to the cerebellum from bulbar centers caudal to the vestibular complex. In most of the literature these fibers have been included with the spino-cerebellar system, under the term tractus spino-cerebellaris (de Lange, '16; Ariëns Kappers, '21; and others), or tractus spino-cerebellaris dorsalis (Larsell, '26; Hindenach, '31; and others), these latter observers in many cases considering the term dorsal spinocerebellar as synonymous with bulbo-cerebellar, being a rather loose usage of terminology, which has led to some confusion (p. 159). Here the term nucleo-cerebellar is applied to the diverse fibers originating from various bulbar centers, including ventral superficial arcuate, olivo-cerebellar (if present), and reticulo-cerebellar fibers, as well as fibers from the more caudal sensory nuclei of the brain stem which are related to the cerebellum (these last mediate impulses brought in over the descending root of the $V$ th and the somatic sensory vagal component, which, after synapse, as Huber and Crosby, 26, observed, run to the cerebellum). 
Ventral superficial arcuates. At the very caudalmost levels of the medulla oblongata, particularly noticeable in transverse Weigert series of Chrysemys, though quite well developed in all the forms studied, many fibers cross the midline in the more ventral portions of the raphé. After decussation, these become grouped into little fascicles, and pass dorsalward and slightly frontalward, lying at the very periphery of the medulla oblongata. Many of these fibers originally swing ventromedially out of the nuclei funiculi posterioris (which in these forms have been homologized with the mammalian nucleus gracilis and nucleus cuneatus, Zeehandelaar, '21), curve down to cross in the raphé at varying levels and continue as noted above, apparently being homologous to the ventral superficial arcuates of higher forms. Added to these are many fibers derived from the reticular nuclei.

Followed forward, the ventral superficial arcuates eventually occupy the very dorsolateral angle of the lateral limb of the medulla oblongata (at about the level of entrance of the Xth nerve, fig. 20), retaining that position until the caudal part of the cerebello-oblongata junction is reached, when they turn dorsalward into the lateral part of the cerebellum, apparently distributing, along with the reticulo-cerebellar, olivocerebellar, part of the trigemino-cerebellar, and dorsal spino-cerebellar systems, to the more lateral (including the auricular lobe) and caudal parts of the cerebellum (figs. 17, 18, 26). This whole complex that swings up into the cerecellum is homologous to the inferior cerebellar peduncle or restiform body of higher forms, as has been observed previously (Edinger, '08; Ariëns Kappers, '21; Larsell, '26 and '32; and others).

Banchi ('03) was the only observer who noted a ventral superficial arcuate system among reptiles, although his brief description is couched in such general terms that it is difficult to be certain that he did not include with it the whole of the nucleo-cerebellar system of this account.

Olivo- and reticulo-cerebellar fibers. It has been impossible to demonstrate satisfactorily an inferior olive and a consequent olivo-cerebellar tract. True, it is possible to identify 
a more or less well-defined group of cells in the region where the inferior olive is alleged to be, but so far as can be determined, on the basis either of cell type or connections, this mass can equally as well (and probably even better), be considered as a group of reticular cells; like the other reticular cells they contribute fibers to the cerebellum. Practically all of the workers on the reptilian cerebellum and bulb have noted an inferior olive and olivo-cerebellar fibers (not, however, with the same degree of assurance), though practically all are agreed that the olivo-cerebellar fibers become intermingled with the nucleo-cerebellar and dorsal spino-cerebellar component as herein described, and cannot be traced separately to the cerebellum. Certainly if any one of the reticular cell masses located in the caudoventral portion of the medulla oblongata is considered an inferior olive, such a course for its fibers as just noted can be readily verified in the material studied. However, it is of interest that Kooy ('17) noted that the inferior olive in reptiles is not evident, and that Tuge ('32) was unable to identify it satisfactorily in Chrysemys. Among those who maintain the existence of an inferior olive and olivo-cerebellar fibers in these forms may be mentioned Ariëns Kappers ('21), Larsell ('26 and '32), and others. It appears that an inferior olive and olivo-cerebellar fibers have yet to be conclusively demonstrated in reptiles. It is difficult to determine what criteria can be used in these forms to conclusively differentiate an inferior olive from the various reticular gray masses scattered throughout this part of the bulb. Possibly one way this might be definitely settled would be by means of a study of the embryology of this region in reptiles, side by side with a similar study in mammals.

Certain other nucleo-cerebellar connections. From brain stem levels caudal to the entrance of the VIIIth nerve and rostral to the XIIth nucleus, fibers can be observed still crossing the midline and following the superficial path noted above for the ventral superficial arcuates. These seem to be chiefly contributions from the nucleus of the descending root of the $V$ th and the reticular gray, as well as other sensory nuclei 
of the region (p. 156). The contribution from the nucleus of the descending root of the Vth nerve can be considered as the caudal portion of the ventral trigemino-cerebellar system of Huber and Crosby ('26), though here it is included with the nucleo-cerebellar system (p. 156).

The above, then, make up the strictly bulbo- or better, nucleo-cerebellar system. A fairly good indication of its size can be obtained at about the level of the Xth nerve entrance, at which point but few (if any) dorsal spino-cerebellar fibers have become intermingled with it (fig. 20). The whole system runs forward with the tractus spino-cerebellaris dorsalis and distributes as noted previously (figs. 17 to 26 ). It seems to be homologous with the bulbo-cerebellar system of Herrick ('14, '14 a, '30) and Larsell ('20, '23, '25, '31, '32) for Amphibia.

Tractus trigemino-cerebellaris. The various secondary trigemino-cerebellar connections have been well described by Huber and Crosby ('26) and their interpretation has been verified in the material studied. There is a dorsal trigeminocerebellar tract (fig. 26, tr.trig.cer.rect.), from the homolateral chief sensory nucleus of the $V$ th and passing dorsomedially, in relation with the cerebello-tegmental and vestibulo-cerebellar tracts, to the region of the cerebellar commissure, where its fibers become lost. Fibers of similar origin appeared to pass dorsolaterally and frontally in company with the nucleo-cerebellar and dorsal spino-cerebellar fibers already discussed (fig. 26). Following this course, these fibers necessarily come into fairly close relationship with the cerebellar nuclei.

The ventral or cruciate trigemino-cerebellar path (figs. 16, 17) is crossed and is contributed to both by the nucleus of the descending root and by the chief sensory nucleus of the Vth nerve. The more caudal portion of this tract is considered with the nucleo-cerebellar system (p. 156). To this is added more rostrally the fibers from the chief sensory nucleus of the Vth nerve. The contribution from the more dorsal part of the trigeminal lemniscus (Huber and Crosby, '26) passes into the 
base of the cerebellum, where it becomes lost (fig. 17). This last contribution seems relatively larger in the snake, but is so intermingled with other fibers to the cerebellum that it is difficult to truly evaluate its development.

Larsell ('26) noted no secondary trigemino-cerebellar fibers in snakes and lizards. Shanklin ('30) briefly noted a small bundle of secondary $V$ th fibers to the cerebellum. However, Larsell ('32) mentioned trigemino-cerebellar fibers in the turtle and the alligator, but stressed more their commissural nature. These appear to be homologous to the dorsal trigemino-cerebellar system of Huber and Crosby ('26) and of this account, and possibly in part to the contribution from the trigeminal lemniscus. Larsell's results are based to a considerable extent on embryological material, and hence could not be verified in the material available; consequently, although unquestioned trigeminal fibers can be traced into the region of the cerebellar commissure, we are not prepared to state whether or not they are merely commissural in nature.

Tractus tecto-cerebellaris. As a prelude to taking up the tecto-cerebellar system, the possibility of an isthmo-cerebellar connection might well be considered. The nuclei isthmi, lying one on each side at the junction of the medulla oblongata and the mid-brain, and at the periphery of the brain (except in snakes, where this nucleus is not obvious), are interconnected by finely medullated commissural fibers, passing both through the anterior medullary velum and the cerebellar commissure. These proceed from the more dorsomedial portion of the pars magnocellularis of the nucleus isthmi (fig. 27). Fibers can also be noted swinging into the cerebellar commissure from more ventral and caudal levels of the nucleus. Consequently, there is a strong probability of an isthmo-cerebellar connection, which, if present, might be considered an indirect tecto-cerebellar connection (i.e., a tecto-isthmo-cerebellar connection). Some of the fibers of the tecto-isthmal system which pass to this region appear to turn caudomedially, without synapse, and add to the dorsal 
part of the cerebellar commissure, hence probably adding to the tecto-cerebellar system (fig. 27).

Tecto-cerebellar fibers were first definitely demonstrated in reptiles by Huber and Crosby ('26) in the turtle. Since then they have been observed among lizards (Larsell, '26; Shanklin, '30); in Sphenodon (Hindenach, '31), in the turtle (Larsell, '32), and again noted by Huber and Crosby ('33), who verified, in lizards, Shanklin's ('30) observation for Chameleon that there exists a crossed as well as an uncrossed component. Due to the rich collection of exceptionally wellimpregnated pyridine-silver material, it has been possible to verify this tract in all the forms examined (fig. 27).

The tecto-cerebellar fibers are of two main types, crossed and uncrossed. The uncrossed component (chiefly thinly medullated) can be seen swinging out of the stratum album centrale, passing beneath the decussating fibers of the IVth nerve, and coursing on the dorsal surface of the anterior medullary velum to swing up and into the cerebellum (fig. 27D). Certain of them turn deeper into the cerebellar commissure; others reach the region of the nucleus medialis cerebelli, where they are lost; still others pass into the granular layer. A few have been followed rather far into the molecular layer, a fact suggestive of their termination as climbing fibers (which have been demonstrated in the reptilian cerebellum; Ramón y Cajal, '11; Larsell, '32). These fibers are difficult to see at all in any but sagittal sections, and from such sections a good conception of their number and extent cannot be obtained. When it is considered that they can be identified from near the midline to the plane of the dorsomedial extremity of the nucleus isthmi pars magnocellularis, even though but few fibers appear in any one section, the sum total makes up a rather large tract. A considerable number of the coarsely medullated fibers of the stratum album centrale are also observed following a similar course (fig. 27). In addition, the fine, superficially placed fibers which Huber and Crosby ('33) observed in Weigert series and traced into the stratum griseum et fibrosum 
superficiale (thus forming a cerebello-tectal path) have been verified, in the silver material of the turtle, the alligator, and the larger lizards, but were not demonstrable in the smaller lizards nor in the snake (fig. 27). However, none of these fibers could be positively traced to their cells of origin or to their exact termination.

The uncrossed tecto-cerebellar tract has been known in Amphibia for some time. Herrick ('25, fig. 39, p. 477), especially, noted it and considered that it had origin from the corpus posticum (the amphibian homologue of the inferior colliculus). Golgi material of turtle demonstrates, as Huber and Crosby ('33) have shown, that fibers from the reptilian inferior colliculus add to the tecto-cerebellar system, but this component does not appear to be very large, since silver preparations show by far the larger number of fibers swinging out of the stratum album centrale and passing over the top of the inferior colliculus.

Regarding the relative contribution from the two colliculi, the following facts are very interesting. It is noteworthy that in the bony fishes, particularly, where the optic tectum is very highly developed, the tecto-cerebellar system from the optic tectum is very large. In Amphibia, where the optic tectum is relatively less developed and the corpus posticum of good size, the tecto-cerebellar tract is largely, if not entirely, a contribution from the corpus posticum. In reptiles, where the optic tectum is well developed and the inferior colliculus developed to a variable degree, both types of tectocerebellar fibers are present, the main contribution coming from the optic tectum. In mammals, with the relative decrease in importance of the optic tectum as a sensory correlation center, the main contribution of tecto-cerebellar fibers is apparently from the inferior colliculus. From the above it can be seen that the term tecto-cerebellar has been used for two entirely different sets of connections, very often interchangeably, which has led to some confusion in the literature.

Finely medullated fibers from the stratum album centrale can be observed crossing in the caudal part of the tectum and 
then almost immediately turning downward and caudalward over the top of the anterior medullary velum, mixed with the more medial part of the uncrossed component and distributing similarly (fig. 27). A larger number of fibers of this crossed component insinuate themselves between the decussating IVth nerve fibers and then pass into the cerebellar commissure more medially.

The very rich periventricular connection between cerebellum and tectum (fig. 27) has been observed by Huber and Crosby ('26 and '33), who noted ('33) that this system is afferent with respect to the tectum, thus composing a cerebello-tectal system of connections. The origin of such fibers is still in doubt. Some have been traced into the region of the medial cerebellar nuclei, but a great many more have been followed well up into the cerebellar plate; a few to very near the layer of Purkinje cells. This system of fibers is closely interwoven with those periventricular fibers noted beneath the ependymal lining of the IVth ventricle throughout its extent. Not enough evidence is at hand regarding this system to attempt an interpretation of its functional significance at this time.

Here should be mentioned the quite obvious mesencephalic Vth fibers which appear to run into the cerebellum (see fig. 27D). These are very clear in some of the alligator and snake material. In Sternotherus a few of them have been traced into the medial cerebellar nucleus, and others far into the granular layer before they were lost. The strong possibility of such a connection was noted by Weinberg ('28) and others, but the earlier evidence was not very conclusive.

\section{Efferent cerebellar paths}

Cerebello-tegmental system. The efferent cerebellar pathways are described here under a terminology slightly different from that in current use. This appears the more advisable and justifiable since in certain instances the same terminology does not appear to include the same group of fibers to different observers, and also since some of the current 
terminology seems to imply at the same time both too much and too little in the way of homology with mammalian forms.

Here all the efferent cerebellar tracts are considered as the cerebello-tegmental system excepting the cerebello-tectal, the cerebello-vestibular, and the cerebello-spinal fibers, which latter two seem to correspond to the hooked fasciculus of Russell (1894) for mammals. This includes the fibers which curve ventrally out of the inferior portion of the cerebellar commissure, fanning out rostralward and caudalward as rather discontinuous, small bundles which lie at various levels from near the periphery to near the ventricle (figs. 16, 17, $21,22)$. The cerebello-tegmental system is then arbitrarily subdivided into a portion passing rostrally to mid-brain regions (the tractus cerebello-motorius et tegmentalis mesencephali), and a portion passing caudally to bulbar regions (the tractus cerebello-motorius et tegmentalis bulbaris). Each of these may be rather imperfectly separated into a tractus cerebello-motorius (either bulbaris or mesencephali) and a tractus cerebello-tegmentalis (either bulbaris or mesencephali) for these two regions, wherever such a subdivision serves to make the description more comprehensible. The term cerebello-motorius is restricted to that component more strictly concerned with the motor nuclei of the cranial nerves, insofar as such a component is capable of differentiation, and the term cerebello-tegmentalis is restricted to that component (the larger) which distributes largely to the more highly specialized gray of the tegmental region, such as the red nucleus. These components overlap to a considerable extent. Such a terminology leaves much to be desired, but appears to be sufficiently general to permit of ready adaptation to other forms, and at the same time specific enough so that there can be little question of the portion of this large system under discussion at any time.

Tractus cerebello-motorius et tegmentalis mesencephali. This portion is less easily separated into motor and tegmental components than is the bulbar part of the system. Certainly if there is a mammalian homologue of the brachium con- 
junctivum in these forms it is this portion of the cerebellotegmental system. However, just as certainly this tract is not homologous to the brachium conjunctivum as the term has apparently been used in much of the literature on reptiles, where it is restricted to the strictly cerebello-rubral part of the system, which is only a part of the tractus cerebello-tegmentalis mesencephali. However, if the term brachium conjunctivum is used in the sense of the literature on mammalian forms, notably human, it is in most respects homologous to the tractus cerebello-motorius et tegmentalis mesencephali of this account, varying in the relative development of its components. In other words, here is a superior cerebellar peduncle surprisingly homologous to the mammalian superior cerebellar peduncle.

Leaving the more frontoventral part of the cerebellar commissure and passing ventrolaterally and frontally, chiefly dorsolateral to the mesencephalic root of the Vth nerve (which separates this component from the tractus cerebellomotorius mesencephali) and ventromedial to the nucleus isthmi pars magnocellularis, a rather thin, discontinuous sheet of fibers (chiefly medullated) can be readily observed, particularly in sagittal sections (excepting in snakes, in which the nucleus isthmi is inevident, where these fibers simply course through the fiber tracts in that region at an angle, having otherwise the same relations). Following this course, the tractus cerebello-tegmentalis mesencephali passes through, and largely dorsal to, the bundles of the tractus cerebello-tegmentalis bulbaris (fig. 16, 17, 24). In exceptionally favorably cut sections of young Chelhydra and of the alligator, the whole sweep of these fibers can be seen and are found to be more concentrated rather far laterally in the mid-brain (figs. 21 and 22). They curve ventrally and medially, mostly crossing the midline rather far ventrally and at varying rostrocaudal levels, after which many turn forward and certainly come into relation with the large reticular cells of this region (which in part lie in the relation de Lange, '12, noted for the red nucleus in Testudo), though it has not 
been possible to find an unqestioned termination of such fibers on these cells. Others seem to disappear in the general reticular gray of the region. Some uncrossed fibers might easily get into relation with the large reticular cells above noted (figs. 21 and 22). Many of the fibers of this tract do not swing so far lateralward, but oceupy a more medial position in the tegmentum of the mid-brain at variable distances from the ventricle, and in part (the more medially lying fibers) come into relation with the IIIrd and the IVth nerve nuclei, either homolateral or contralateral, as well as with the tegmental gray. Some of them appear to pass into the medial longitudinal fasciculus and probably run in that bundle to the motor nuclei of this region or possibly to higher centers. This more medial portion overlaps to some extent the tractus cerebello-motorius mesencephali.

The tractus cerebello-motorius mesencephali (figs. 21 and 22 ) is quite small and consists of that part (largely unmedullated) of the tractus cerebello-motorius et tegmentalis mesencephali which courses medial to the mesencephalic root of the Vth nerve (and in part through it), lying fairly close to the ventricle, and runs medially, erossing high up in the raphé, either to end directly on the nucleus of the IVth nerve or to run forward, probably to the nucleus of the IIIrd nerve, by way of the medial longitudinal fasciculus. In part it passes to the tegmental gray either crossed or uncrossed and overlaps the more medial (and dorsal) portion of the tractus cerebello-tegmentalis mesencephali. This system is quite small as compared to the tegmental component and is directly continuous caudally with the tractus cerebello-motorius bulbaris, which may also contribute to the nuclei of the IIIrd and IVth nerves by way of the medial longitudinal fasciculus.

The origin of the tractus cerebello-motorius et tegmentalis mesencephali seems to be largely homolateral, chiefly from the nucleus lateralis cerebelli, though there is a considerable addition, particularly to the tegmental portion, from the nucleus medialis cerebelli as well as from the cerebellar plate, probably from Purkinje cells. There is a strong possibility 
of a small contralateral component, more particularly as regards the cerebello-tegmental part.

The large reticular cells of the mid-brain (wherein has been located a red nucleus) stand out exceptionally well in the series of young Chelhydra. In practically all cases where an evident neuraxis could be observed, it crossed the midline (about the middle of the raphé) almost immediately after leaving the cell body. Such fibers then turned caudally and became collected into small fascicles, just lateral and ventral to the medial longitudinal fasciculus, which soon became lost among the other longitudinally coursing paths in this region. Such fibers probably constitute a rubro-spinal tract, a system which has been assumed to exist among reptiles, but one which needs further documentation.

The tractus cerebello-motorius et tegmentalis mesencephali can be identified with little variation in all the forms studied, varying in size with the size of the brain. In the alligator and the lizard (to some extent in the snake) the larger part of the tegmental portion crosses rather more dorsally than the above description would indicate. It is quite significant that such facts agree well with the relative dorsoventral position of the red nucleus as de Lange ('12) has located it in these various forms.

The above system appears to have been included (in large part at least) by Huber and Crosby ('26) under the term tractus cerebello-tegmentalis mesencephali. They homologized this to Ariëns Kappers' ('21) brachium conjunctivum anterius of Crocodile and to Larsell's ('23) brachium conjunctivum of the frog. Larsell ('26) briefly noted a brachium conjunctivum in lizards and snakes. Papez ('29), Shanklin ('30), Hindenach ('31), and Frederikse ('31) also noted a similar tract as the brachium conjunctivum. Larsell ('32) observed such a tract both in the turtle and the alligator.

Tractus cerebello-motorius et tegmentalis bulbaris. Coursing in the ventral and caudal portion of the cerebellar commissure, apparently in part contralateral in origin, a large bundle of medullated fibers swings out of that commissure 
and turns ventrally, passing over the dorsal part of the mesencephalic Vth root and spreading out into numerous fascicles which course ventrally and caudally (certain of them rostrally). Here these fascicles lie medial to the afferent cerebellar systems and the lateral lemniscus, though laterally they intermingle with them. Continuing this course, they become lost among the other longitudinally coursing fibers of the region and can be followed no farther than to about the level of entrance of the VIIIth nerve, although they probably do reach more caudal levels. A small portion of the fibers seem to swing more medially and cross the raphé, and the more medial part of this bundle certainly comes into relation with the motor nucleus of the Vth nerve (figs. 16 to 18,23 to 25 ).

This tract contains a considerable contralateral component the origin of which could not be definitely determined. It receives a large contribution from the homolateral nucleus lateralis cerebelli and probably some from Purkinje cells. A few questionable fibers appear to join it from nucleus medialis cerebelli.

This system appears to be in part the efferent fibers lying in the inferior cerebellar commissure noted by Ariëns Kappers ('21). It is included in the cerebello-tegmental system of Huber and Crosby ('26) and others. Larsell ('32) verified the findings of Huber and Crosby ('26) to which he apparently added the tractus cerebello-motorius of this account, considering it the representative of Russell's fasciculus in these forms.

The tractus cerebello-motorius bulbaris is that portion which remains mostly medial to (in part passing through) the mesencephalic $V$ th root as the tract leaves the cerebellar commissure. It carries many thinly medullated fibers, particularly at its more caudal levels of origin. Coursing ventromedially, this tract turns more medially toward the raphé, where it crosses just beneath and to some extent through the medial longitudinal fasciculus (figs. 17, 18, 26), to which it apparently contributes. It spreads into the tegmental regions 
of the opposite side, but is a very large contributor to the motor nucleus of the Vth nerve. Undoubtedly, as Huber and Crosby ('26) suggest, it also places the other bulbar motor nuclei under cerebellar control, in part through its connections by way of the medial longitudinal fasciculus.

This tract originates chiefly from the homolateral lateral cerebellar nucleus. It receives a considerable number of fibers which have crossed in the cerebellar commissure, and a few direct fibers out of the cerebellar plate. More rostrally it may receive a few fibers from the medial cerebellar nucleus. The tract lies close to the ventricle throughout its extent, but cannot be definitely followed any farther caudalward than can the tegmental portion. It appears to correspond to the tractus cerebello-motorius of Ariëns Kappers ('21) for Crocodilia and to a part of the cerebello-tegmental system of Huber and Crosby ('26) and of Larsell ('32). It is probably included, at least in part, when the term Russell's fasciculus or the fasciculus uncinatus has been used for reptiles (Ariëns Kappers, '21; Papez, '29; Larsell, '32).

Tractus cerebello-spinalis (et cerebello-vestibularis). This tract could be considered with the cerebello-tegmental system, but it appears to answer most nearly to the description of Russell's (uncinate or hook bundle) fasciculus in higher forms, especially when considered together with the cerebellovestibular fibers coursing in company with the vestibulocerebellar system.

The tractus cerebello-spinalis (et cerebello-vestibularis) appears to be principally a contribution from the medial cerebellar nucleus, receiving no additions from the homolateral lateral cerebellar nucleus. In addition, it carries a large component from the cerebellar plate as well as fibers which have crossed in the cerebellar commissure. These components become grouped together at the more caudodorsal part of the cerebellar commissure and immediately hook around the lateral recess of the IVth ventricle in the caudomedial part of the cerebello-oblongata junction, lying considerably dorsal to the main part of the tractus cerebellomotorius bulbaris, and very close to the ventricle (fig. 24). 
At this point the tract lies in close juxtaposition to the incoming vestibulo-cerebellar tract and its cerebello-vestibular component, but as it passes caudally, remaining near the ventricle, it becomes grouped by itself as a noticeable bundle, distinct even in transverse series (figs. 18 to 20,24, 25). It is best followed in a sagittal silver series of Chrysemys. In the vestibular region it lies near the ventricle, ventral to the cochlear gray and dorsolateral to the prevagal component of the fasciculus solitarius; being in relation laterally with ascending vestibular fibers, anteriorly, particularly with the cochleo-vestibulo-cerebellar system; and with descending vestibular fibers, posteriorly (vestibulo-spinal tract). As it reaches the caudal parts of the vestibular region, it loses its compactness and, a few at a time, its fascicles become intermingled with the vestibulo-spinal (and spino-vestibular) path, until about the level of entrance of the Xth nerve, when it cannot be further distinguished from that tract. In its course through the vestibular region it is very obvious that fascicles leave this tract and break up in the vestibular gray, and some can even be followed farther ventrally into the reticular gray of the region. In passing through the vestibular region the cerebello-spinal tract comes into particularly close relation to the pars dorsalis of the nucleus vestibularis ventrolateralis, and seems to receive a small vestibulo-spinal component from that nucleus. It could not be traced separately into cord levels, but there was a suggestion in the material that it did reach such levels, hence the name.

This tract is most distinct in the turtle, although in none of the other reptiles does it constitute a large component. In the smaller forms and in those with a marked eversion, it does not form the compact bundle noted in the turtle.

From the literature it does not appear that this path has received the consideration due it as a distinct efferent system. Either it has been included under the terms cerebello-motorius or cerebello-tegmentalis (Ariëns Kappers, '21; Larsell, '32), or it accompanies some ascending vestibular system (such as the cochleo-vestibulo-cerebellar or the vestibulo-cerebellar 
tract), or a descending vestibular system such as the Deiterso-spinal tract (Shanklin, '30). In the alligator, as a result of the enormous cochlear development, this tract is crowded somewhat ventrolaterally and easily confused with the ascending vestibular systems in that region. In snakes it does not lie so near the ventricle as in turtles, and is considerably mixed with the vestibulo-cerebellar systems due to the small size of the cochlear region in these forms. (The tract so labeled for the snake, fig. $25 \mathrm{C}$, contains a large component of vestibular fibers.)

Connections of the cerebellar plate. At present the amount of Golgi material available does not permit any added contribution to the interconnections of the cerebellar plate components in reptiles. Consequently no attempt will be made here to consider such connections, though in this respect reference might well be made to Larsell's ('32) paper, where a considerable contribution to the present knowledge of such connections is contained. However, it is felt that a study of pyridine-silver material of all the reptilian forms available warrants the impression that a considerable component of all of the efferent cerebellar paths is contributed by fibers, evidently not commissural, passing out of the cerebellar plate, which very likely are the neuraxes of Purkinje cells, though this conclusion could not be satisfactorily verified.

\section{SUMMARY AND DISCUSSION}

So intimate a relation exists between the cerebellar and vestibular regions in reptiles that an adequate analysis of one region is dependent upon a thorough understanding of the other.

The vestibular nuclear complex in reptilian forms may be divided into the following nuclei: 1 ) the nucleus vestibularis ventrolateralis (Deiters'), the very obvious, large-celled, highly developed nucleus situated at the level of entrance of the VIIIth nerve; 2) the nucleus tangentialis, a variably developed nuclear mass lying intercalated among the entering vestibular fibers, external to the nucleus vestibularis ventro- 
lateralis ; 3) the nucleus vestibularis ventromedialis, a smallcelled, poorly delimited cell group situated internal to the nucleus vestibularis ventrolateralis, near the inferolateral angle of the ventricle; 4 ) the nucleus vestibularis descendens, another small-celled mass, variably developed, and situated most caudally in the vestibular region; 5) the nucleus vestibularis dorsolateralis, the small-celled, rostral continuation of the nucleus vestibularis ventrolateralis, very intimately related rostrally to the cerebellar nuclei ; 6) the nucleus vestibularis superior, a differentiation of the last named nuclear mass, obvious only in turtles. Associated with these nuclei is the nucleus laminaris, which may be partly vestibular but appears to be mainly cochlear in function. While all these vestibular nuclei, excepting the nucleus vestibularis superior, are present in all the reptilian forms, they present certain interesting variations. Although well developed in all reptiles, the nucleus vestibularis ventrolateralis reaches its highest development in the alligator, where it forms one of the most conspicuous cell masses of the medulla oblongata. In all these forms its constituent neurons are of the large, multipolar, efferent type, with a rich dendritic network spreading to all parts of the vestibular region. The largest neurons, and relatively the smallest number of them, are found in the snake. These two facts presumably are correlated with each other and related to the type of locomotion found here, for it seems probable that fewer larger neurons with more numerous collaterals might well supply adequately a larger group of the ventral horn neurons related to trunk muscles than of those related to the functionally more specifically specialized extremity muscles. The tangential nucleus is least developed in turtles, best developed among lizards, and reaches an intermediate stage of development in the snake and the alligator. There seems to be an interesting correlation between the relative development of this nucleus and the degree of trunk movements encountered in these forms (p. 176). For an adequate analysis of the nucleus vestibularis ventromedialis, degeneration preparations are required, for while this nucleus 
certainly receives vestibular impulses, it is also certain that it receives fibers of passage, chiefly trigeminal, cochlear and vagal. The degree of development of the consistently smallcelled nucleus vestibularis descendens is in inverse relation to the development of the nucleus tangentialis, since it is relatively largest in turtles and smallest in lizards. The nucleus vestibularis dorsolateralis foreshadows the comparable nuclear complex in avian forms, and, as is to be expected, is best differentiated in lizards and crocodiles, but in no reptile is it highly specialized. The nucleus vestibularis superior is present only in turtles, which suggests that its development is in inverse relation to the development of the nucleus vestibularis dorsolateralis, and that it is included in this latter mass as that grows larger.

The gross morphology of the cerebellum is of considerable interest in reptiles since it affects to a marked degree the relations of closely associated cell masses and fiber tracts. The smaller cerebella are found among the small lizards and snakes, though due to marked differences in shape it is diffcult to evaluate properly the relative differences in cerebellar size between these forms and to determine which of the forms has the smaller. The Crocodilia possess the largest cerebella, those of the turtles being intermediate in size. These facts agree with Larsell's ('26 and '32) observation that the auricular lobe is least developed in the snake and much better developed in the reptiles which make use of extremities in locomotion, although this agreement in the observed facts does not necessarily imply an agreement with his interpretation of these facts. The cerebella of certain lizards show a marked eversion, while indications of such an eversion are found in other reptilian forms, particularly in Sphenodon, and to a lesser extent among the crocodilians. The cerebellum consists of a cerebellar cortex and a cerebellar nuclear complex. Its nuclear complex is incompletely divided into a larger-celled, more medial and a smaller-celled, more lateral cell mass, the medial and lateral cerebellar nuclei, both of which are directly continuous caudally with the vestibular 
gray. The differences in form relations of these nuclei are related to the degree of eversion of the cerebellar plate, the effect of such an eversion being to crowd the nuclei rostrocaudally and slightly mediolaterally, and to spread them out dorsoventrally, causing also a relatively greater intermingling of the medial and lateral nuclei of the same side. The cerebellar cortex shows the usual division into a molecular, a Purkinje, and a granule cell layer, the latter two, particularly near the junction of the cerebellum with the medulla oblongata, enclosing a variably developed stratum fibrosum.

The vestibular connections may be considered under four headings; entering vestibular root fibers, internuclear connections, secondary afferent connections, and secondary efferent connections. The root fibers of the vestibular nerve distribute: 1) to the homolateral cerebellum terminating chiefly in the auricle, and passing to the corpus cerebelli and the cerebellar nuclei, as well as entering the cerebellar commissure in part, presumably to reach contralateral cerebellar areas ; 2) to all of the homolateral vestibular nuclei; 3) probably to certain of the contralateral vestibular nuclei by way of decussating fibers at the level of entrance of the root; 4) to the spinal cord in company with the homolateral vestibulo-spinal tract and possibly also in company with both the medial longitudinal fasciculi. The proportionate distribution to the nucleus vestibularis ventrolateralis varies with the degree of development of the tangential nucleus. All the vestibular nuclei appear to be interconnected by short internuclear fibers, and there is likewise a close commissural internuclear connection relating them. The secondary afferent connections of the vestibular complex fall into two general groups. To the first group belong those paths which terminate within the nuclear complex either by way of pericellular synapses or by synaptic relations with short, intranuclear dendrites. To this group belong: 1 ) the cerebello-vestibular paths, chiefly from the medial cerebellar nucleus to the nucleus vestibularis ventrolateralis and the nucleus vestibularis dorsolateralis; 2) the spino-vestibular tract, which ends 
primarily in relationship with the neurons of the nucleus vestibularis descendens, but also has connections with the nucleus tangentialis and the nucleus vestibularis ventrolateralis; 3) certain secondary connections from various sensory centers of the medulla oblongata, such as cochlear, trigeminal, and vagal centers, to the nucleus vestibularis ventromedialis, giving to this nucleus an indeterminate functional character. The second group is formed by the spread of the dendrites of the vestibular nuclei into neighboring nuclear masses or along the course of various fiber paths and is well developed in all the forms studied. These constitute a very important source of excitation of certain of these nuclear groups in reptiles. To this group belong the various dendritic ramifications of the nucleus vestibularis ventrolateralis into the tegmental and cochlear regions and along the course of all of the afferent paths to the cerebellum, and a similar, although less widespread ramification of the dendrites of the nucleus vestibularis dorsolateralis into the tegmental region and along the afferent cerebellar paths. The major efferent paths of the vestibular area consist of: 1) connections with the medial longitudinal fasciculus, largely crossed and descending from the nucleus vestibularis ventrolateralis, the nucleus tangentialis, and the nucleus vestibularis descendens, and probably largely ascending and crossed from the dorsolateral vestibular nucleus; 2) vestibulo-spinal connections, chiefly from the nucleus vestibularis ventrolateralis and possibly added to by the nucleus vestibularis descendens; 3 ) vestibulocerebellar connections, largely, though possibly not exclusively, from the dorsolateral vestibular nucleus.

In all the forms studied there are two general types of vestibulo-spinal connections in addition to the one passing by way of the medial longitudinal fasciculus. The first of these, a more dorsolateral vestibulo-spinal path, is developed in all the forms. It lies in a dorsolateral position in the caudal part of the vestibular region, and becomes largely intermingled with the spino-vestibular path, these two together being the vestibulo-spinal path referred to in the literature. 
The second is, strictly speaking, a vestibulo-spinal path only in lizards. It lies slightly ventrolateral to the inferolateral angle of the ventricle, at least near its place of origin from the large Deiters' cells. In this position, in all the other forms, there is a large number of vestibulo-reticular fibers from Deiters' nucleus (not so numerous in the snake), and these may, after a synapse on reticular cells, reach the motor centers of the cord as reticulo-spinal fibers. It is interesting to relate these facts to the relative development of the extremities in reptilian forms. The lizard-particularly the smaller lizard-has by far the most use (and the most rapid movements) of its limbs. The snake, of course, has no limbs, while the turtle is very clumsy in respect to limb movements on land, such movements being relatively slow and studied. The crocodilians resemble the turtle in this respect. From this it is logical to assume that the vestibulo-reticulo-spinal path may mediate the relatively slow limb responses made by the turtle and the alligator on land, while in the lizard, with the much more rapid locomotion in these forms, the reticular phase of the path has been short-circuited, so to speak. Thus an obviously more efficient and direct vestibulo-spinal path is developed controlling these limb movements, probably more truly homologous to the ventrolateral vestibulo-spinal path of higher forms. It should be emphasized that the tangential nucleus appears to be developed coordinately with the development of the trunk musculature and contributes directly and almost entirely to the medial vestibulo-spinal path which runs as a component of the medial longitudinal fasciculus. In the lizard and the snake, where this nucleus is relatively best developed, there is marked coordination of the body musculature of the two sides in connection with locomotion. In the alligator the more sluggish movement is associated with a relatively smaller development of this nucleus and its descending tract, and in the turtle, where there is practically no trunk movement, there is likewise practically no tangential nucleus. 
The cerebellar connections, whether afferent or efferent, appear to be related largely to both the cerebellar cortex and the underlying gray. Various observers have considered that the neuraxes of Purkinje cells in mammals do not pass outside of the cerebellum, although there is not unanimous agreement on this. In reptiles there is an increasing body of evidence, though it is not conclusive, that the neuraxes of Purkinje cells do enter directly into the formation of the efferent cerebellar paths (see also Larsell, '32).

The afferent cerebellar fiber tracts demonstrated in the material were:

1. A dorsal spino-cerebellar. This tract is continued directly forward from the spinal cord along the periphery of the medulla oblongata and swinging dorsal to the descending Vth root to enter the cerebellum, where it terminates laterally and caudally in the body of the cerebellum, and possibly to a slight extent in the homolateral auricular lobe, also contributing to the cerebellar commissure.

2. A ventral spino-cerebellar tract. This bundle is accompanied by the foregoing tract along its dorsolateral border throughout the bulb and continuing forward to the level of the entering roots of the Vth nerve, where it turns dorsally, curving rostral to (and partly through) the Vth nerve roots, to pass to the homolateral medial cerebellar nucleus and, in large part, into the cerebellar commissure to distribute chiefly to the rostral portion of the contralateral part of the body of the cerebellum.

3. A nucleo-cerebellar system. This fiber system is composed of various tracts relating sensory centers of the medulla oblongata to the cerebellum, notably ventral superficial arcuate fibers from the contralateral nucleus funiculus posterior, a reticulo-cerebellar system from the general reticular gray of the medulla oblongata (which includes any olivo-cerebellar component that may be present), and a trigemino-cerebellar system from the nucleus of the descending root of the $V$ th nerve of the opposite side-this whole complex distributing to the lateral and caudal portions of 
the corpus cerebelli and possibly in small part to the auricular lobe.

4. A vestibulo-cerebellar system. This system consists of fibers arising chiefly in the nucleus vestibularis dorsolateralis, joined by fibers arising chiefly from the nucleus laminaris (cochleo-vestibulo-cerebellar or lamino-cerebellar), as well as by some direct vestibular root fibers.

5. A trigemino-cerebellar system. This system is composed of paths taking origin in the contralateral and homolateral chief sensory nuclei of the $V$ th nerve, both paths passing to the homolateral corpus cerebelli and into the region of the commissure.

6. Direct root fibers of cranial nerves. These consist largely of fibers from the vestibular and trigeminal roots, which in the turtle, at least, are supplemented by certain root fibers running in the cochlear root, all of these passing chiefly into the auricular lobe.

7. A tecto-cerebellar system. This system is a continuation of the stratum album centrale of the optic tectum which swings caudalward into the cerebellum through the region of the anterior medullary velum, supplemented by fibers from the inferior colliculus, and, in the turtle at least, possibly by a few fibers from the nucleus isthmi. This system is partly crossed and partly uncrossed in the cerebellar commissure, and can be traced in part to the homolateral medial cerebellar nucleus, in part into the granular layer, and in small part into the homolateral molecular layer of the cerebellum. This connection from the optic tectum deserves special notice in reptiles, since it appears to be more particularly developed here, where the optic tectum plays so dominant a role, than in subreptilian or even mammalian forms.

The efferent cerebellar fiber tracts demonstrated in the available material were:

1. A tractus cerebello-spinalis. This tract is presumably the reptilian equivalent of Russell's fasciculus or the hooked bundle, originating largely from both medial cerebellar nuclei, supplemented by Purkinje cell axones, and immediately after 
leaving its cells of origin hooking sharply around and under the lateral recess of the IVth ventricle. It runs caudally at about that same level, lying very near the ventricle, at least in turtles where it forms the most compact bundle. This tract distributes to the nucleus vestibularis ventrolateralis as well as to the other vestibular nuclei and tegmental gray of the region, though to a lesser degree, and continues caudally to become lost in the vestibulo-spinal tract, probably accompanying that tract into the spinal cord.

2. A tractus cerebello-vestibularis. This tract has an origin similar to the cerebello-spinal tract, together with which it might be included as Russell's fasciculus, and distributes to the more medial part of the nucleus vestibularis dorsolateralis and to the nucleus vestibularis ventrolateralis throughout.

3 and 4. A tractus cerebello-motorius et tegmentalis bulbaris and a tractus cerebello-motorius et tegmentalis mesencephali. These tracts really form a continuous cerebello-tegmental system of fibers, supplying the motor nuclei of the cranial nerves (the tractus cerebello-motorius bulbaris and the tractus cerebello-motorius mesencephali) and other tegmental regions of the bulb and mid-brain (the tractus cerebellotegmentalis bulbaris and the tractus cerebello-tegmentalis mesencephali). Of these the tract of particular interest from a phylogenetic standpoint is the tractus cerebello-tegmentalis mesencephali, which carries within it fascicles connecting the cerebellum with the reptilian primordial red nucleus, and is the forerunner, then, of the cerebello- or dento-rubro-thalamic path of higher forms, which is to play a conspicuous part in the development of forebrain centers.

5. A cerebello-tectal system. This fiber complex shows a significant differentiation into a superficial and a periventricular portion. The superficial portion apparently is very small, being a direct connection forward through the anterior medullary velum to the superficial layers of the optic tectum. The periventricular portion is surprisingly well developed; its fibers, apparently arising in part from Purkinje cells of the cerebellum, come into close relation with the ventricle, 
coursing beneath the inferior colliculus (to which they may contribute) to the periventricular fiber layer of the tectum, where they break up around the dendrites of the cells of the periventricular gray. There is considerable evidence from the literature (Huber and Crosby, '26 and '33) that these are joined by fibers from the hypothalamic region and from the inferior colliculus, all of which distribute to the neurons constituting the periventricular gray. Since such neurons, through their long dendrites, are in relation to numerous exteroceptive impulses entering the tectum near its periphery, it is obvious that this periventricular bundle provides a means of correlating proprioceptive impulses from the cerebellum with exteroceptive impulses from other sources.

In the arrangement of the paths to and from the cerebellum there is a tendency toward a grouping which is comparable to the formation of the superior and inferior cerebellar peduncles of higher forms. The term superior peduncle or brachium conjunctivum should not be limited to the cerebellorubral path, as is sometimes done, but should be used to include those systems to the tegmental regions and motor nuclei of the upper cranial nerves which are also recognized constituents of the brachium conjunctivum of mammalian forms.

We are not ready as yet to enter into a detailed comparison of the reptilian vestibular and cerebellar regions with those regions of lower or higher forms; yet some brief statement of the relative development of these areas as compared with those of amphibians and mammals may be of interest. Compared with the reptilian cerebellum the amphibian cerebellum (Herrick, '14, '24, '24 a ; Larsell, '20, '23, '25, '31) is much smaller and much more generalized in type. The cerebellar nuclear gray is represented by a single cell mass which extends relatively far down into the peduncle. In correlation with its less highly differentiated cerebellar structure, the amphibian vestibular area is smaller and shows less nuclear differentiation; a large celled nucleus comparable to the reptilian nucleus vestibularis ventrolateralis and usually other nuclear gray nearer the cerebellar gray have been recognized. 
The fiber connections of the amphibian and reptilian cerebellar and vestibular areas are comparable in type but are smaller and show less specialization in the former animals. The cerebellum and the cerebellar nuclei show a marked increase in specialization in avian (Ingvar, '19; Sanders, '29) as compared with reptilian forms. This is especially evident with regard to the cerebellar nuclei, which are particularly large and show marked cellular differentiation and characteristic folding in birds. Again in correspondence with this cerebellar development, is the increased specialization of the vestibular nuclear group, particularly noticeable in the avian region homologous to the nucleus vestibularis dorsolateralis of reptiles. In the present account of reptiles, however, it has been possible to recognize in these forms all the major nuclear divisions present in birds. There is difference of opinion with regard to the extent to which the mammalian cerebellar hemispheres find representation in the reptilian cerebellum. Many observers agree that the auricular lobe is the forerunner of the flocculus. Larsell ('26, '32) was of the opinion that a portion of the so-called neocerebellum, as represented by the lobulus ansiformis, found representation in his pars lateralis of the reptilian cerebellum. Ingvar ('19) considered this portion of the cerebellum to make its first appearance in mammals. It is felt that further evidence is necessary before judgment can be passed regarding the interpretation of Larsell in this respect. Perhaps the most that can be said in an attempted comparison of reptilian and mammalian cerebellar nuclei is that these nuclei in reptiles are differentiating toward the nuclear configuration seen in mammalian forms, but that such differentiation is neither structurally nor functionally complete. A comparison of the vestibular area of reptiles and mammals is a matter of some difficulty. It is probable that in a general way the reptilian nucleus vestibularis ventrolateralis, the nucleus vestibularis descendens, and the nucleus tangentialis are homologous to the similarly situated vestibular nuclei of mammalian forms. Whether either or both the ventromedial vestibular nucleus 
or the dorsolateral vestibular nucleus are homologous to the mammalian medial vestibular nucleus, or merely substitute nuclear groups, it is impossible to state at present. From position and general relations it seems that the superior vestibular nucleus of turtles marks the beginning of a mammalian superior vestibular nucleus.

The foregoing description of the reptilian vestibular and cerebellar systems and the résumé of its nuclear masses and fiber connections illustrate the similarity of pattern which underlies the diverse differentiation within the nervous system, and emphasize again the possibility of understanding the more specialized vertebrate nervous systems through a study of the relations and connections in the simpler forms.

\section{LITERATURE CITED}

All references quoted in the text which are not included in the following bibliography may be found in the bibliographies at the ends of the appropriate chapters of the first reference listed below.

Ariëns Kappers, C. U., G. Carl Huber and Elizabeth C. Crosby 1936 The comparative anatomy of the nervous system of vertebrates, including man. The Macmillan Company, New York.

Banchi, A, 1903 Sulle vie di connessione del cervelletto. Arch. ital. di anat. e di embriol., vol. 2 , p. 426.

Beccari. N. 1912 La constituzione, i nuclei terminali e le vie di connessione del nervo acustico nella Lacerta muralis, Merr. Arch. ital. di anat. e di embriol., vol. 10, p. 646.

Ditmaks, R. L. 1910 Reptiles of the world. Sturgis and Walton Co., New York.

Frederikse, A. 1931 The lizard's brain: An investigation of the histological structure of the brain of Lacerta vivipara. C. C. Callenbach, Nijkerk (Holland).

GADOW, H. 1901 Amphibia and reptiles. Cambridge Natural History. The Macmillan Company, New York.

Hindenach, J. C. R. 1931 The cerebellum of Sphenodon punctatum. J. Anat., vol. 65, p. 283.

Houmes, G. M. 1903 On the comparative anatomy of the nervus acusticus. Tr. Roy. Irish Acad, vol. 32, sec. B, p. 101.

Huber, G. Cari and Eutzabeth C. Crosbr 1926 On thalamic and tectal nuclei and fiber paths in the brain of the American alligator. J. Comp. Neur., vol. 40, p. 97 .

DE LANGe, S. J. 1916 Das Hinterhirn, das Nachhirn, and das Rückenmark der Reptilien. Fol. Neurobiol., Bd. 10, S. 385 . 
LARSELL, O. 1926 The cerebellum of reptiles; lizards and snake. J. Comp. Neur., vol. 41 , p. 59 .

1932 The cerebellum of reptiles: chelonians and alligator. J. Comp. Neur., vol. 56, p. 299.

Reese, A. M. 1908 The development of the American alligator. Smith. Mise. Coll., no. 1791, Washington, D. C.

1910 The development of the brain of the American alligator. The paraphysis and hypophysis. Smith. Mise. Coll., no. 1922, vol. 54, Washington, D. C.

1915 The alligator and its allies. Putnam, New York.

vaN HoEvelL, J. L. D. 1916 The phylogenetic development of the cerebellar nuclei. Kön. Akad. v. Wetensch. te Amsterdam, Proc. sec. sc., vol. 18, p. 1431.

\section{LIST OF ABBREVIATIONS}

a, commissural fibers of nucleus isthmii a.coch., area cochlearis

ang.lat.v.IV, angulus lateralis ventriculi quarti

aq.S., aqueductus Sylvii

b, decussation of tractus cerebellomotorius bulbaris

c, afferent cerebellar fiber systems

cell.Purk., Purkinje cells

col.inf., colliculus inferior

com.cer., commissura cerebelli

d, efferent cerebellar fibers (in large part at least)

dec.r.mo.N.V, decussatio rami motorii nervi trigemini

dec.N.V, decussatio nervi trigemini

dec.tr.cer.teg.mes., deeussatio tractus cerebello-tegmentalis meseneephali

e, vestibulo-reticular fibers

f, mixed nueleo-cerebellar, dorso-spinocerebellar, vestibulo-eerebellar, and direet $V$ and VIII fibers

fase.sol., fascieulus solitarius fib.are.dors., fibrae arcuatae dorsales fib.arc.vent.superf., fibrae arcuatae ventrales superficiales

fib.coch., fibrae cochleares

fib.coch.sec., fibrae cochleares secundae

fib.com., fibrae commissurales

fib.perivent., fibrae periventriculares

f.l.m., fasciculus longitudinalis medialis

g, extension of ventral horn gray gang.vest., ganglion vestibulare gr.perivent., griseum periventriculare gr.ret., griseum reticulare

$h$, vestibulo-reticular fibers

junct.cer.obl., junctura cerebello-oblongata

1 , canalis centralis of spinal cord

l.aur., lobus auricularis

lem.lat, lemniscus lateralis

lem.trig., lemniscus trigeminalis

mes., meseneephalon

N.IV, nervus trochlearis

$\mathrm{N} . \mathrm{V}$, nervus trigeminus

N.VI, nervus abducens

N.VIII, nervus aeustieus

N.IX, nervus glossopharyngeus

N.X, nervus vagus

n.III, nueleus oculomotorius

n.IV, nucleus trochlearis

n.VI, nucleus abducens

n.coch., nucleus cochlearis

n.coch.dors., nucleus cochlearis dorsalis n.dors.magnocell., nucleus dorsalis magnocellularis

n.isth.p.magnocell., nucleus isthmii pars magnocellnlaris

n.isth.p.parvocell., nucleus isthmii pars parvocellularis

n.lam., nucleus laminaris

n.lam.p.dors., nucleus laminaris pars dorsalis

n.lat.cer., nucleus lateralis cerebelli n.med.cer., nucleus medialis cerebelli

n.mo.N.V, nucleus motorius nervi trigemini 
n.mo.N.VII, nuelous motorius nervi facialis

n.precer., nucleus precerebellaris

n.r.d.N.V, nucleus radicis descendentis nervi trigemini.

n.sens.prin.N.V, nucleus sensibilis prineipalis nervi trigemini

n.tang., nueleus tangentialis

n.vest.d., nucleus vestibularis descendens

n.vest.dors.lat., nucleus vestibularis dorsolateralis

n.vest.sup., nucleus vestibularis superior

n.vest.vent.lat., nucleus vestibularis ventrolateralis

n.vest.vent.lat.p.dors., nucleus vestibularis ventrolateralis pars dorsalis

n.vest.vent.lat.p.lat., nucleus vestibularis ventrolateralis pars lateralis

n.vest.vent.lat.p.vent., nucleus vestibularis ventrolateralis pars ventralis

n.vest.vent.med., nucleus vestibularis ventromedialis

ol.sup., oliva superior

pl.ch., plexus chorioidens

r.N.V, radix nervi trigemini

r.N.VI, radix nervi abducentis

r.N.IX, radix nervi glossopharyngei

r.N.X, radix nervi vagi

r.dors.N.VIII, radix dorsalis nervi acustici

r.mes.N.V, radix mesencephalica nervi trigemini

r.mo.N.VII, radix motoria nervi facialis

r.mo.N.V, radix motoria nervi trigemini

r.sens.N.V, radix sensibilis nervi trigemini

r.sens.N.VII, radix sensibilis nervi facialis

r.N.trig.ad cer., radix nervi trigemini ad cerebellum

r.vent.N.VIII, radix ventralis nervi acustici

r.asc.N.vest., ramus ascendens nervi vestibularis

r.N.coch.ad cer., ramus nervi cochlearis ad cerebellum

r.d.N.V, ramus descendens nervi trigemini
r.d.N.vest., ramus deseendens nervi vestibularis

r.N.fac.ad cer., ramus nervi facialis ad cerebellum

rec.lat., recessus lateralis

str.alb.cent., stratum album centrale

str.fib., stratum fibrosum

str.gran., stratum granulosum

str.mol,, stratum moleculare

str.Purk., stratum Purkinje

tect.op., tectum opticum

tr.cer.mo.bulb., tractus cerebello-motorius bulbaris

tr.cer.mo.et teg.mes., tractus cerebellomotorius et tegmentalis mesencephali

tr.cer.mo.mes., tractus cerebello-motorius mesencephali

tr.cer.teg.bulb., tractus cerebello-tegmentalis bulbaris

tr.cer.teg.mes., tractus cerebello-tegmentalis mesencephali

tr.cer.spin., tractus cerebello-spinalis

tr.cer.spin.(et tr.cer.vest.), tractus cerebello-spinalis (et tractus cerebellovestibularis)

tr.cer.vest., tractus cerebello-vestibularis tr.nuc.cer., tractus nucleo-cerebellaris

tr.spin.cer.dors., tractus spino-cerebellaris dorsalis

tr.spin.cer.dors.et tr.nuc.cer., tractus spino-cerebellaris dorsalis et tractus nucleo-cerebellaris

tr.spin.cer.vent., tractus spino-cerebellaris ventralis

tr.tect.cer., tractus tecto-cerebellaris

tr.trig.cer.cruc, tractus trigemino-cerebellaris cruciatus

tr.trig.cer.rect., tractus trigemino-cerebellaris rectus

tr.vest.cer.(et cer.vest.), tractus vestibulo-cerebellaris (et cerebello-vestibularis)

tr.vest.spin., tractus vestibulo-spinalis

tr.vest.spin.(et spin.vest.), tractus vestibulo-spinalis (et spino-vestibularis)

v.IV, ventrieulus quartus

v.IV (ang.inf.lat.), ventriculus quartus (angulus inferolateralis)

vel.med.ant., velum medullare anterius 

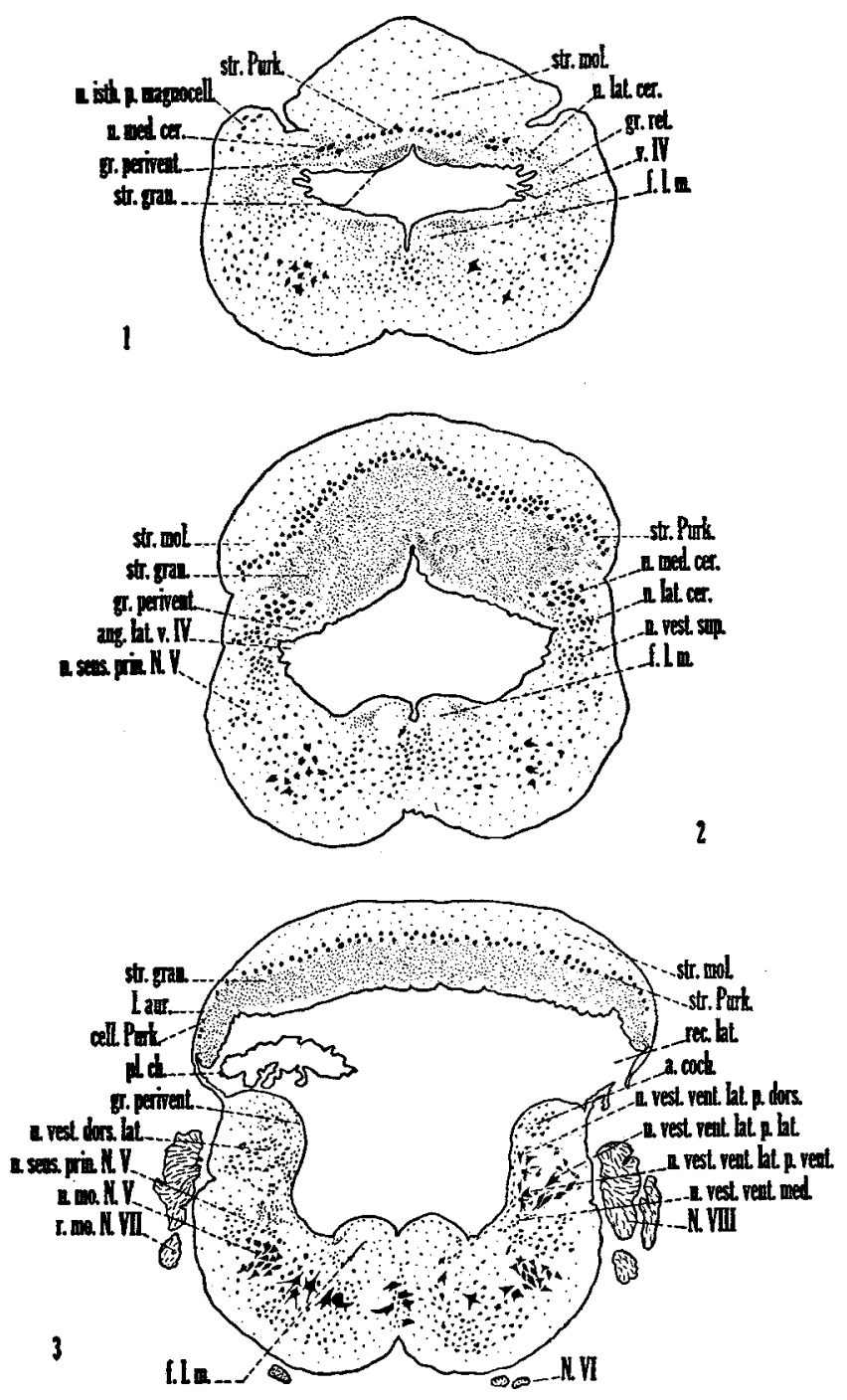

Fig. 1 Transverse section through the cerebellum at the rostralmost level of the cerebellar nuclei. Chrysemys marginata. Toluidin blue preparation. $\times 10$. Fig. 2 Transverse section caudal to previous figure. Chrysemys marginata. Toluidin blue preparation. $\times 10$.

Fig. 3 Transverse section just rostral to the entrance of the VIIIth nerve. Chrysemys marginata. Toluidin blue preparation. $\times 10$. 

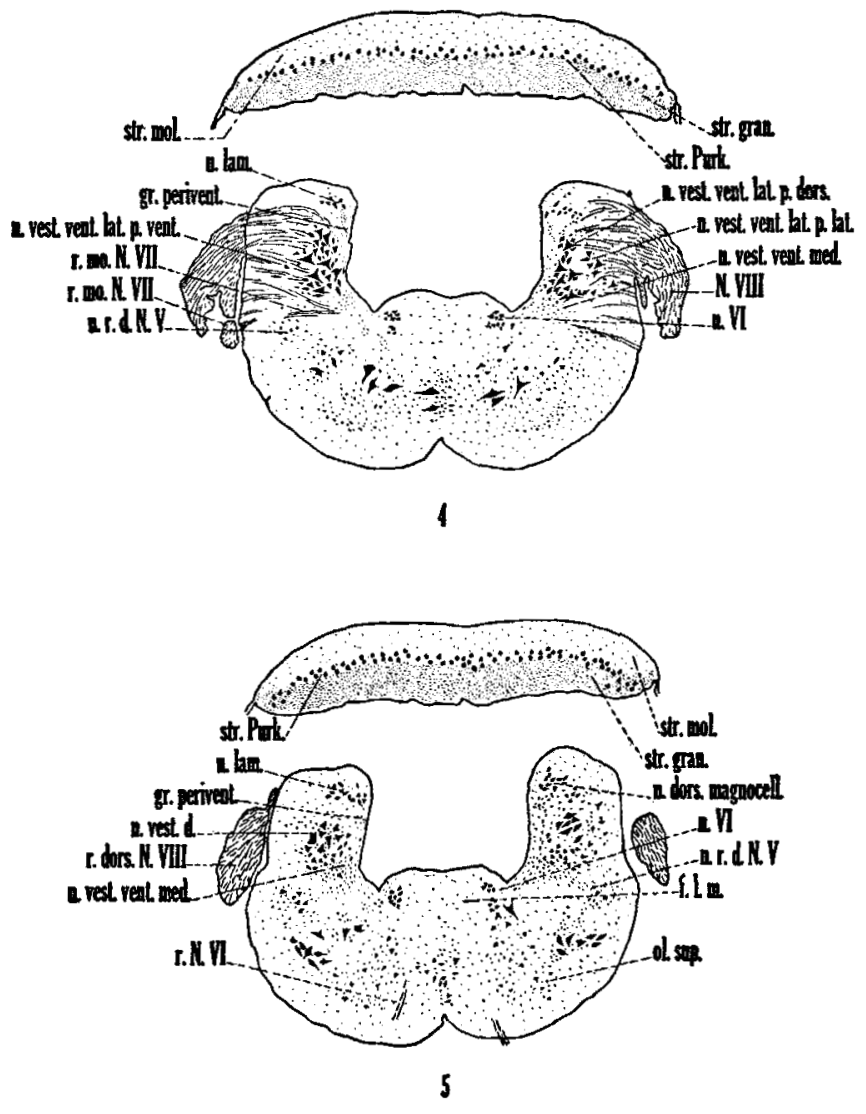

Fig. 4 Transverse section through the level of entrance of the VIIIth nerve. Note the cell grouping as well as the scattered small cells lying intercalated among the fibers of the entering VIIIth nerve. These latter are not labeled but are probably in part the representative here of the nucleus tangentialis. Chrysemys marginata. Toluidin blue preparation. $\times 10$.

Fig. 5 Transverse section just caudal to the entrance of the VIIIth nerve. This section is taken about at the transition level where the nucleus vestibularis ventrolateralis is passing over caudally into the nucleus vestibularis descendens and where the nueleus laminaris is passing over into the nucleas dorsalis magnocellularis. Note the obvious Deiters' cell mixed with the more medium sized ones of the nucleus vestibularis descendens. Chrysemys maginata. Toluidin blue preparation. $\times 10$. 

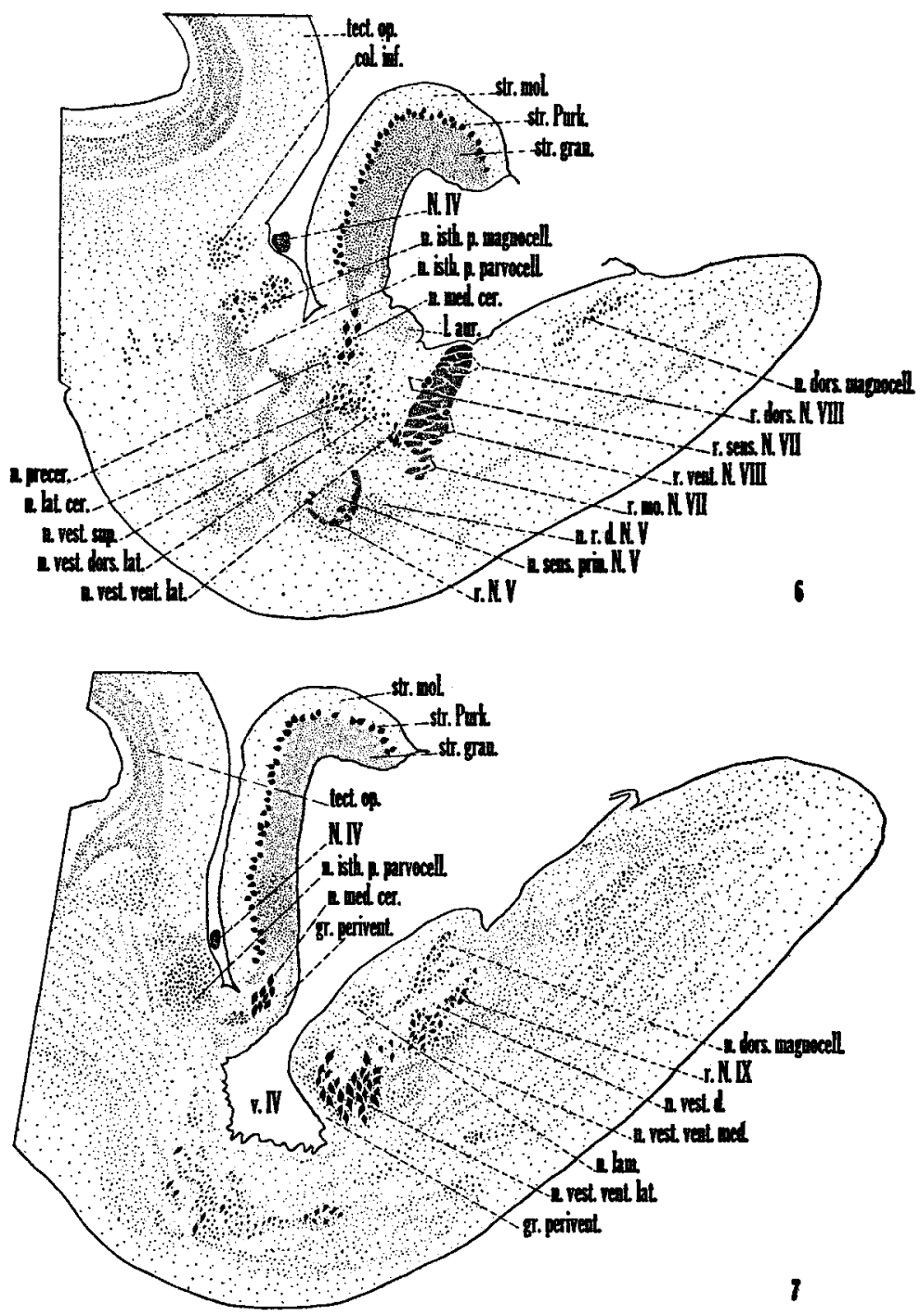

Fig. 6 Sagittal section just lateral to the lateral angle of the IVth ventricle showing quite well the relations of the cerebellar and vestibular nuclei to each other. Pseudoemys elegans. Toluidin blue preparation. $\times 10$.

Fig. 7 Sagittal section farther medialward than the preceding. This shows particularly the relations in the vestibular region. Pseudoemys elegans. Toluidin blue preparation. $\times 10$. 


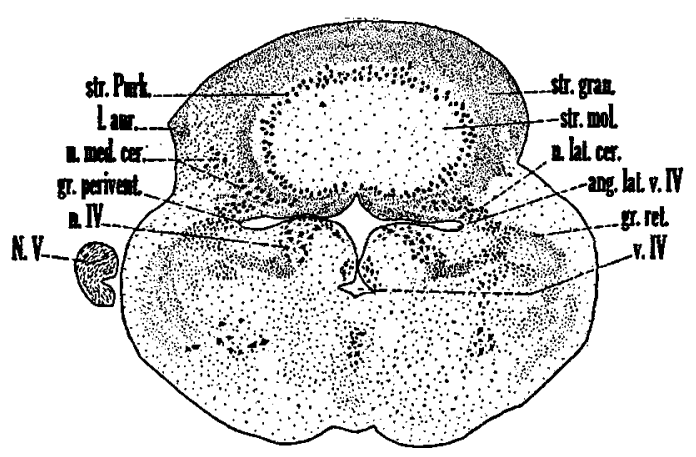

8

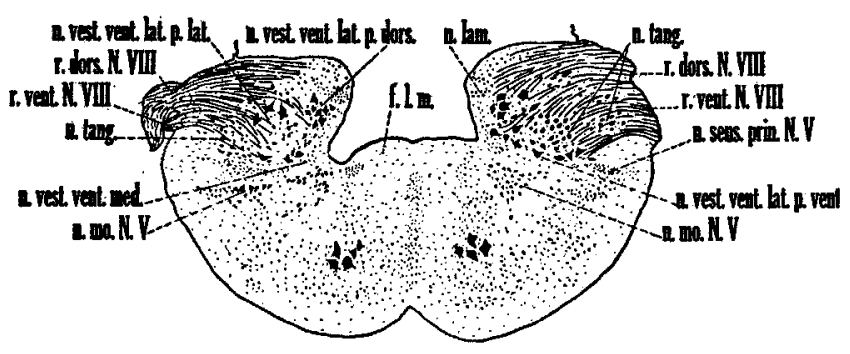

9

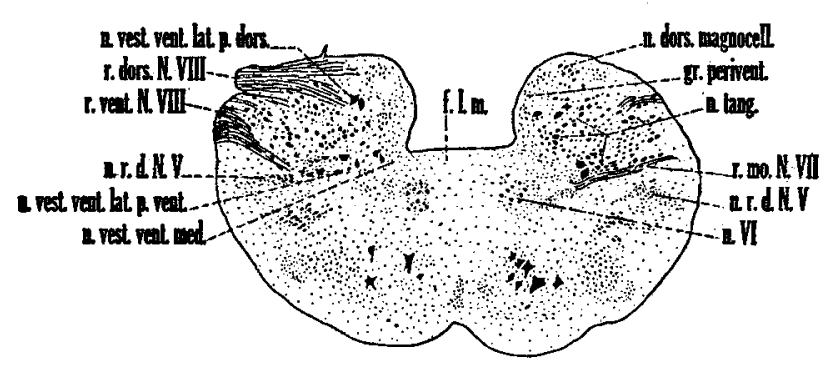

II

Fig. 8 Transverse section through the cerebellar region showing the cerebellar nuclei. Holbrookia. Toluidin blue preparation. $\times 20$.

Fig. 9 Transverse section through the nucleus vestibularis ventrolateralis. Holbrookia. Toluidin blue preparation. $\times 20$.

Fig. 10 Transverse section through the caudalmost portion of the entering roots of the VIIIth nerve. Holbrookia. Toluidin blue preparation. $\times 20$. 

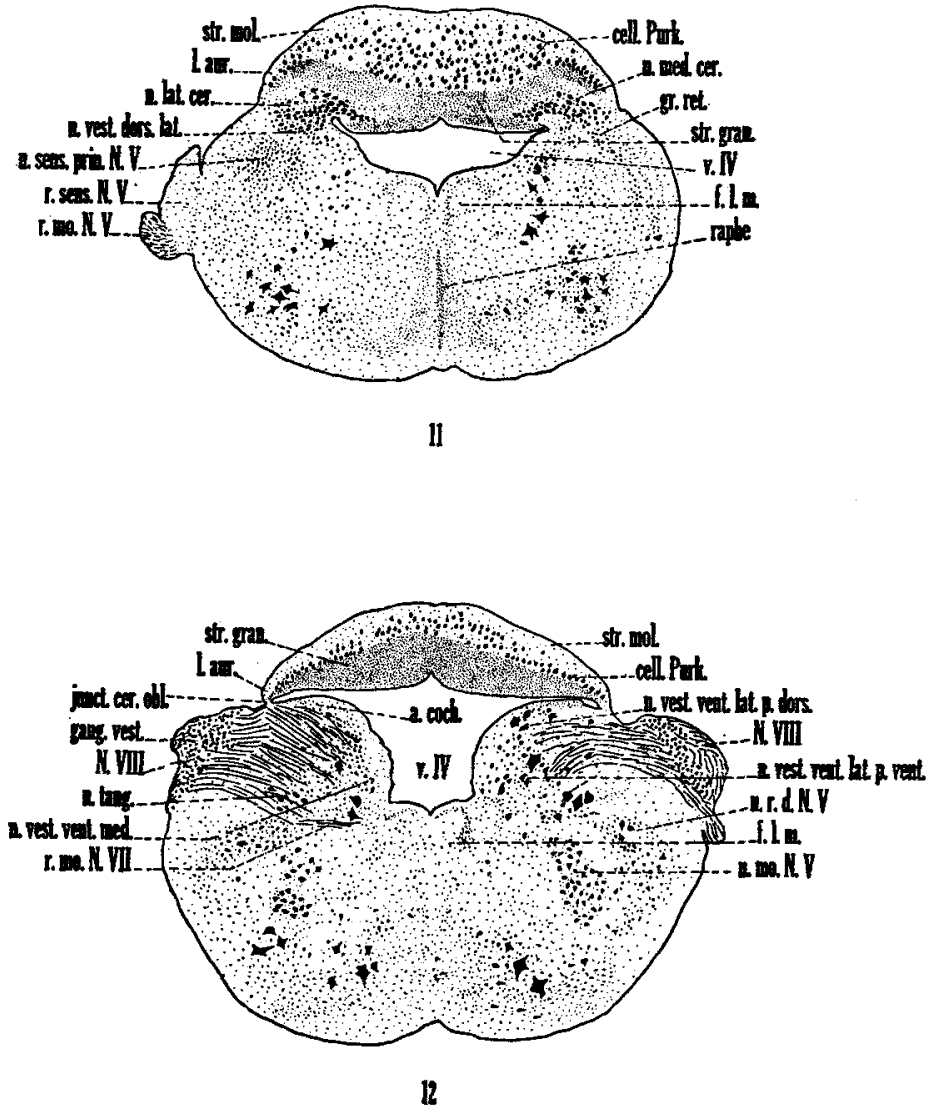

Fig. 11 Transverse section through the cerebellar region and the cerebellar nuclei of Thamnophis sirtalis. Note the resemblance of this figure to figure 15 of Larsell's ('32) account of the turtle. Note also how relatively slight is the separation between the cerebellar nuclei and between the lateral cerebellar nucleus and the nueleus vestibularis dorsolateralis. Toluidin blue preparation. $\times 20$.

Fig. 12 Transverse section through the vestibular region of Thamnophis sirtalis. Note particularly the small development of the cochlear region, the large nucleus tangentialis, and the relatively large size of the cells of the nucleus vestibularis ventrolateralis. Toluidin blue preparation. $\times 20$. 


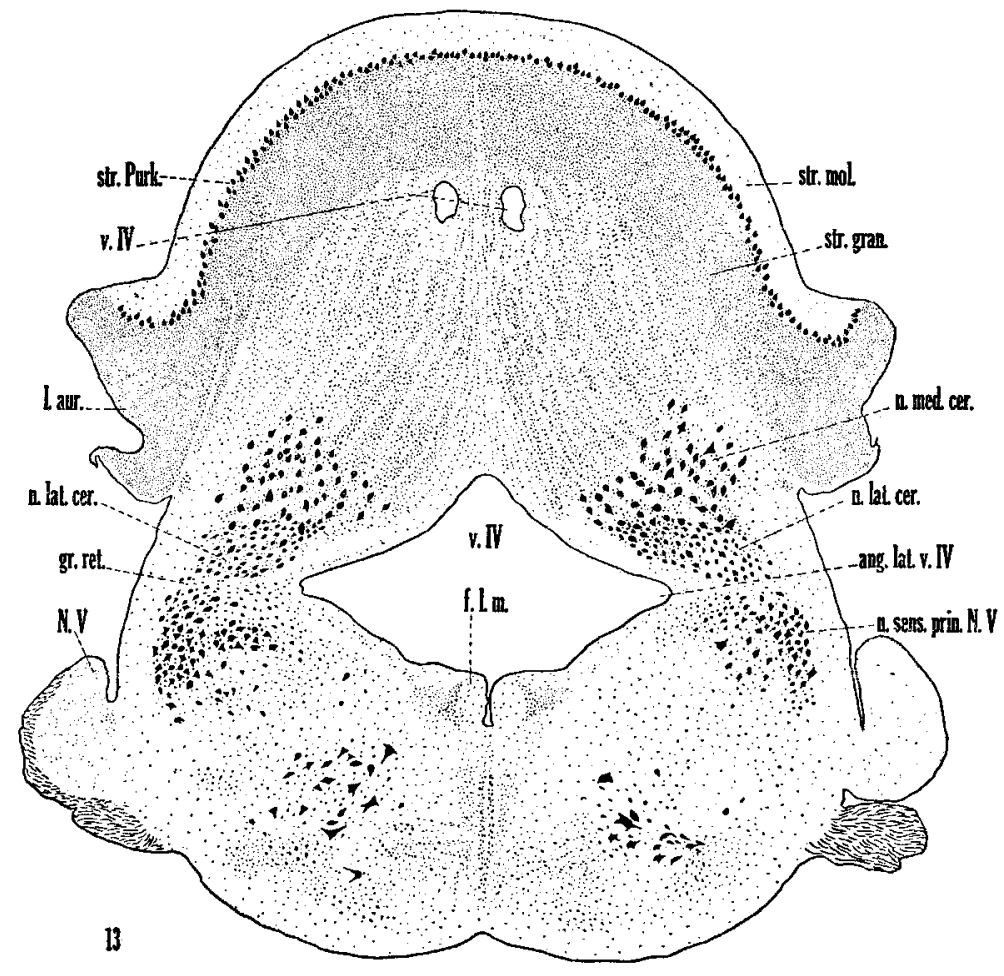

Fig. 13 Transverse section through the cerebellar nuclei of Alligator mississippiensis. Compare this with the figures of van Hoevell ('16). Note the scattered appearance of the nucleus medialis cerebelli-a result of the tendency toward eversion of the anterior third of the cerebellum here-and compare with the figures of the turtle. Toluidin blue preparation. $\times 10$. 


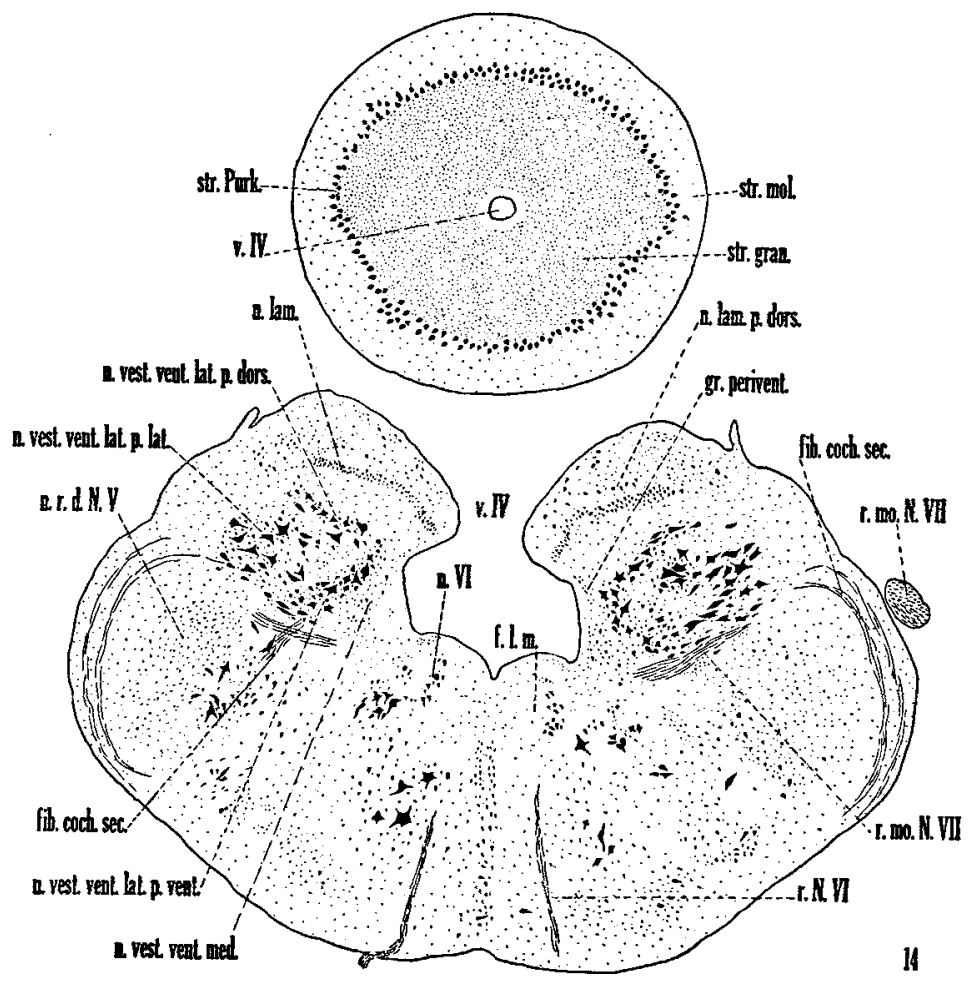

Fig. 14 Transverse seetion through the vestibular region of Alligator mississippiensis slightly rostral to the entrance of the roots of the VIIIth nerve. Note particularly the marked development of the nucleus vestibularis ventrolateralis and the subgrouping of the cells of the same. Observe also how the much larger cochlear region has inereased at the expense of the IVth ventricle. Toluidin blue preparation. $\times 10$. 


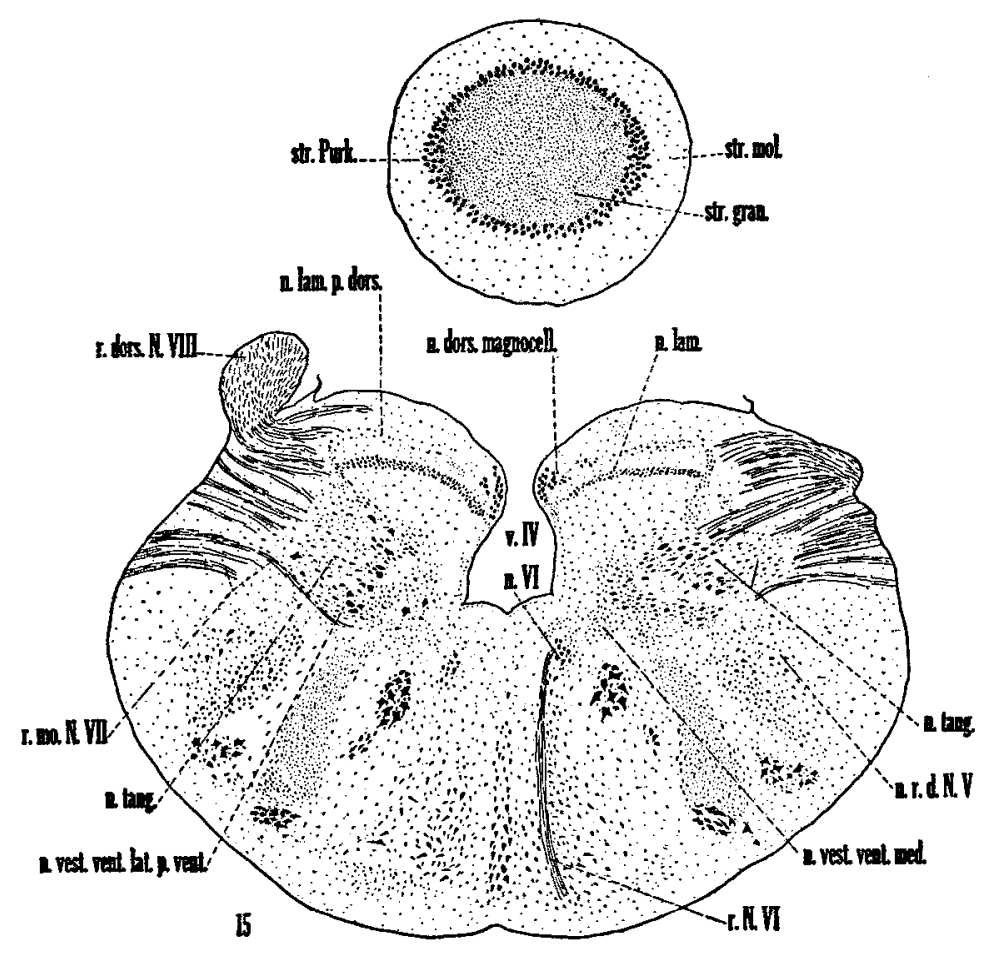

Fig. 15 Transverse section through the caudalmost level of entranee of the VIIIth roots in Alligator mississippiensis. Note the relative development of the nucleus tangentialis as compared with that of the lizard. Toluidin blue preparation. $\times 10$. 

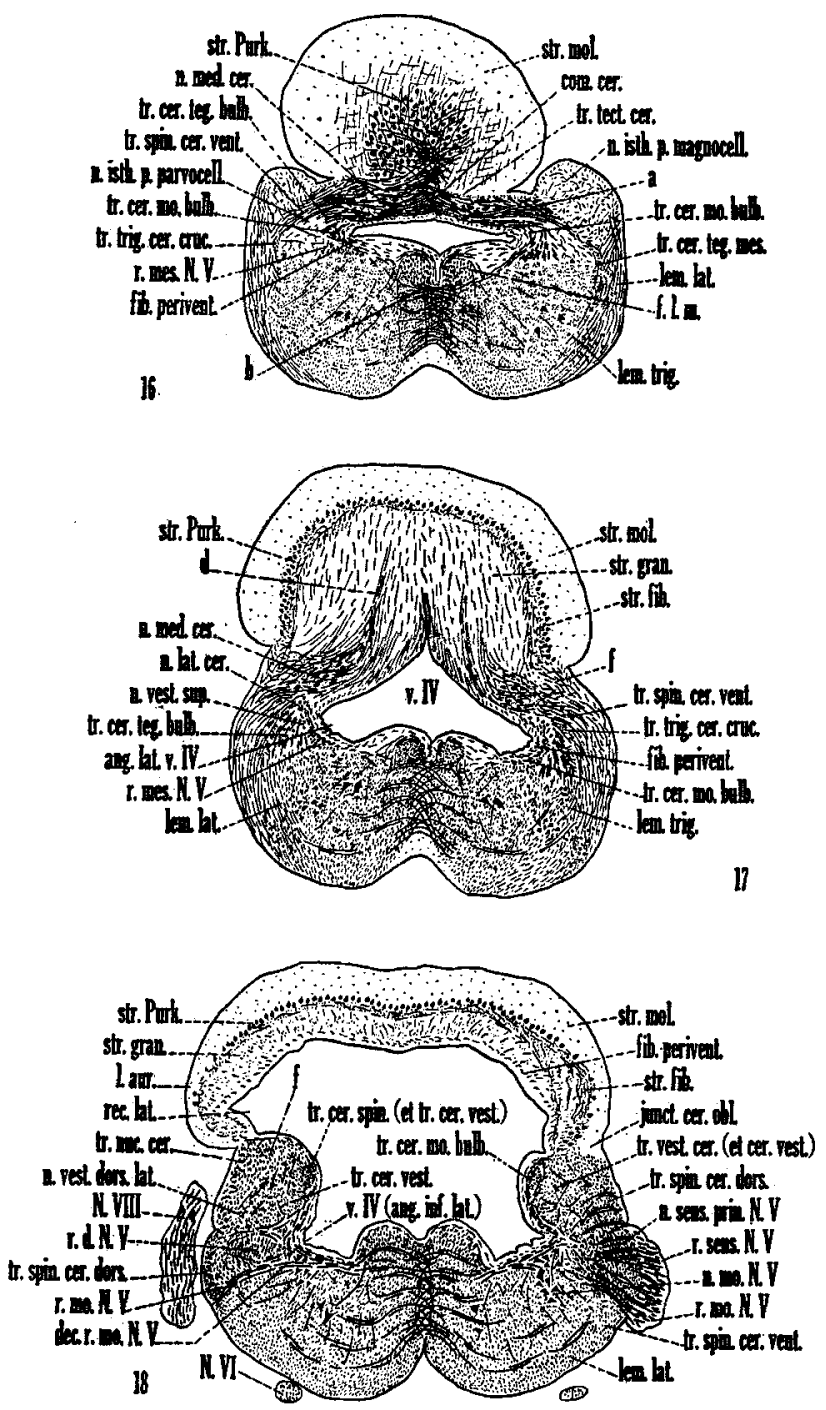

Fig. 16 Transverse section through the cerebellar commissure. Chrysemys marginata. Pyridine-silver preparation. $\times 10$.

Fig. 17 Transverse section through the brain stem just caudal to the cerebellar commissure. Chrysemys marginata. Pyridine-silver preparation. $\times 10$.

Fig. 18 Transverse section through the brain stem at the caudal level of the entrance of the roots of the Vth nerve. Note the motor root of the Vth nerve quite apparently erossing the midline. Chrysemys marginata. Pyridine-silver preparation. $\times 10$. 

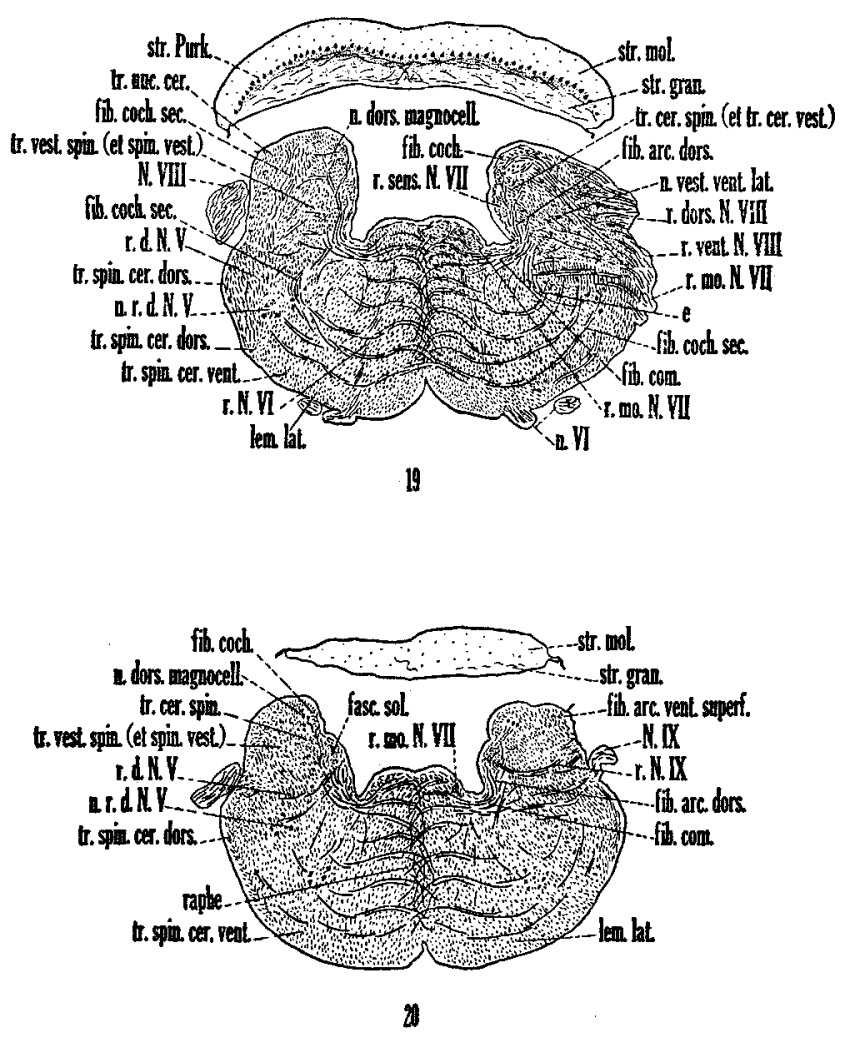

Fig. 19 Transverse section of the brain stem through the caudal levels of entrance of the VIIIth nerve and through the emergence of the root fibers of the VIth nerve. Chrysemys marginata. Pyridine-silver preparation. $\times 10$.

Fig. 20 Transverse section of the brain stem through the level of entrance of the IXth nerve. Note particularly the ventral superficial areuates and the vestibulo-spinal tract. Chrysemys marginata. Pyridine-silver preparation. $\times 10$. 

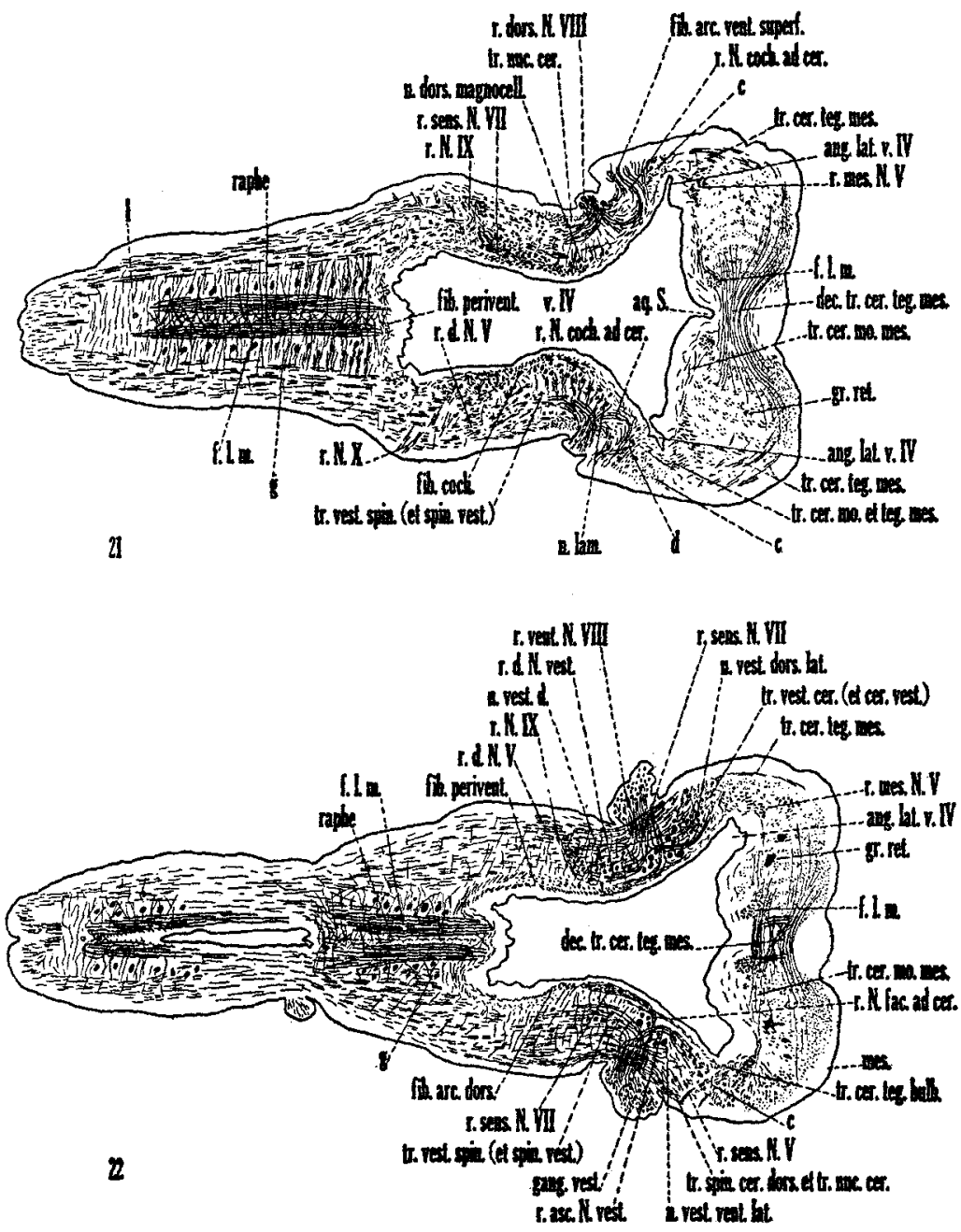

Fig. 21 Horizontal section cut in an oblique plane so that the rostral end is at a considerably more ventral level than the caudal end. Note particularly the direct ascending cochlear fibers to the cerebellum and how far laterally they swing to pass by the lateral recess of the IVth ventriele. Note also the course and relations of the tractus cerebello-motorius et tegmentalis mesencephali. Chelhydra serpentina (3 days after hatehing). Pyridine-silver preparation. $\times 20$.

Fig. 22 Horizontal section from same series as figure 21, but from a more ventral level. Note the ascending and descending direct VIIIth fibers as well as the bifurcating ones. Observe also the course of the sensory VIIth root. Chelhydra serpentina ( 3 days after hatehing). Pyridine-eilver preparation. $\times 20$. 

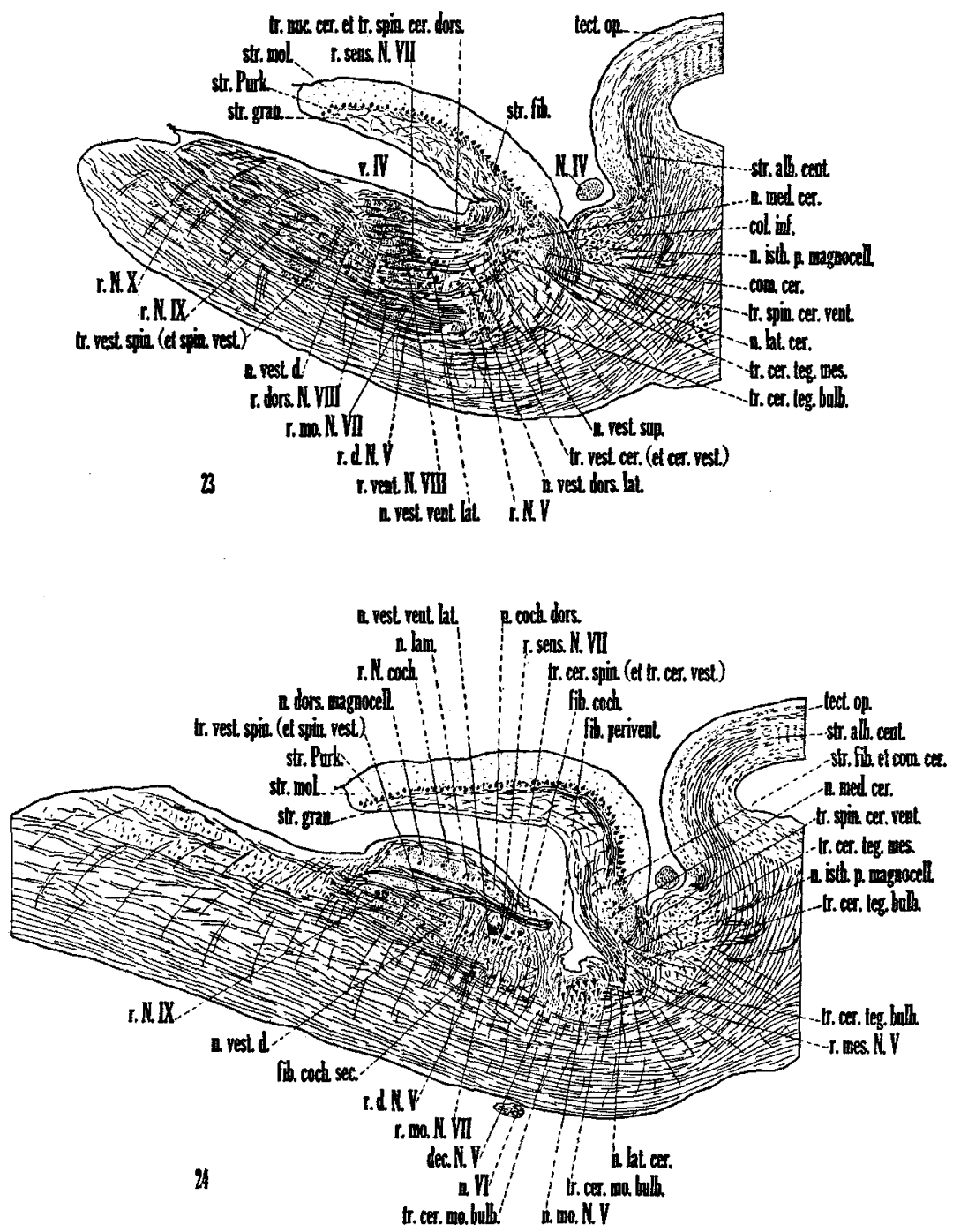

Fig. 23 Sagittal section through the brain stem of Chrysemys marginata at approximately the same level as figure 6. Note particularly the relations of the efferent cerebellar paths. Pyridine-silver preparation. $\times 10$.

Fig. 24 Sagittal section through the brain stem of Chrysemys marginata farther medial and through the vestibular region not far lateral to the ependymal lining of the IVth ventricle. Note particularly the relations of the efferent cerebellar paths, particularly the tractus cerebello-spinalis (et cerebello-vestibularis). Pyridine-silver preparation. $\times 10$. 


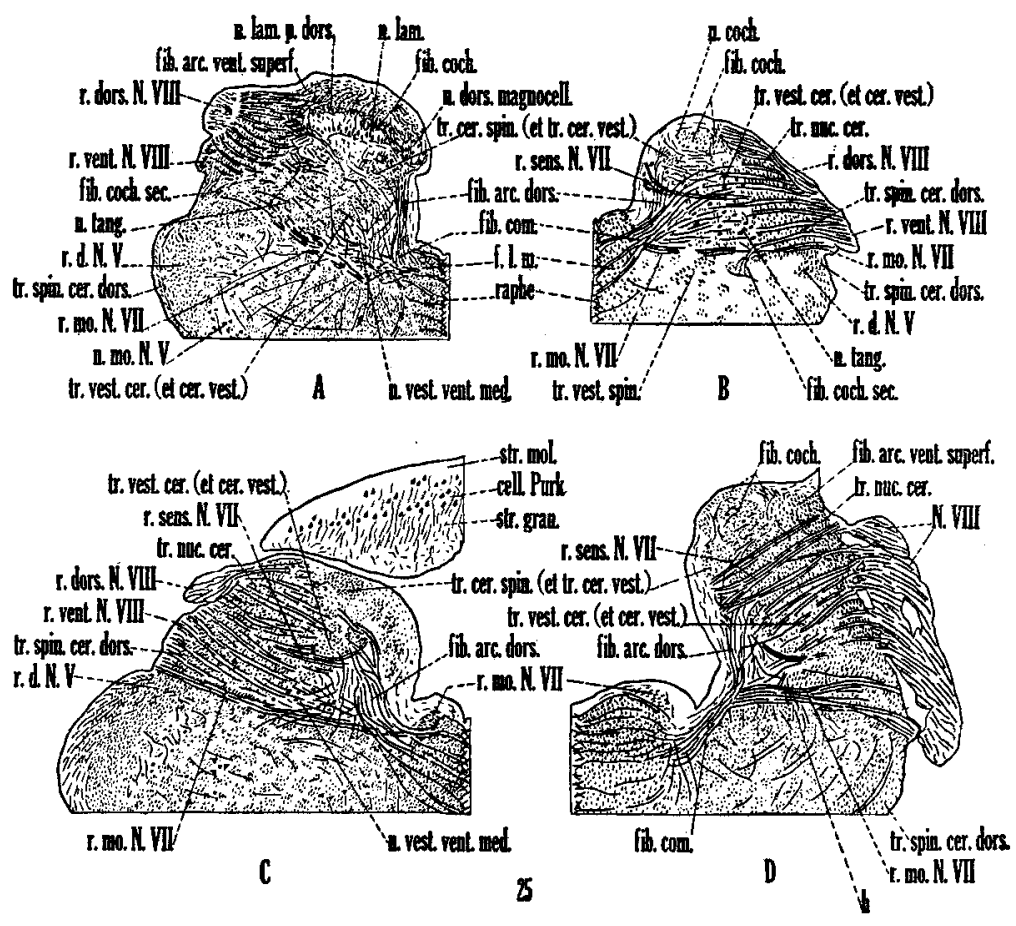

Fig. 25 Transverse Weigert sections through the level of entrance of the VIIIth nerve. Observe the various relations of the roots of both the VIIIth and the VIIth nerves. Note also as far as possible the secondary vestibular connections illustrated. A, Alligator mississippiensis. $\times 10$. B, Anolis caroinensis. Note tr.vest.spin. $\times 20$. C, Natrix. Here the fibers labeled tr.cer.spin. (et tr.cer.vest.) contain large numbers of secondary vestibular fibers, $\times 20$. $D$, Chrysemys marginata. The heavy black curved line represents a blood vessel. $\times 20$. 


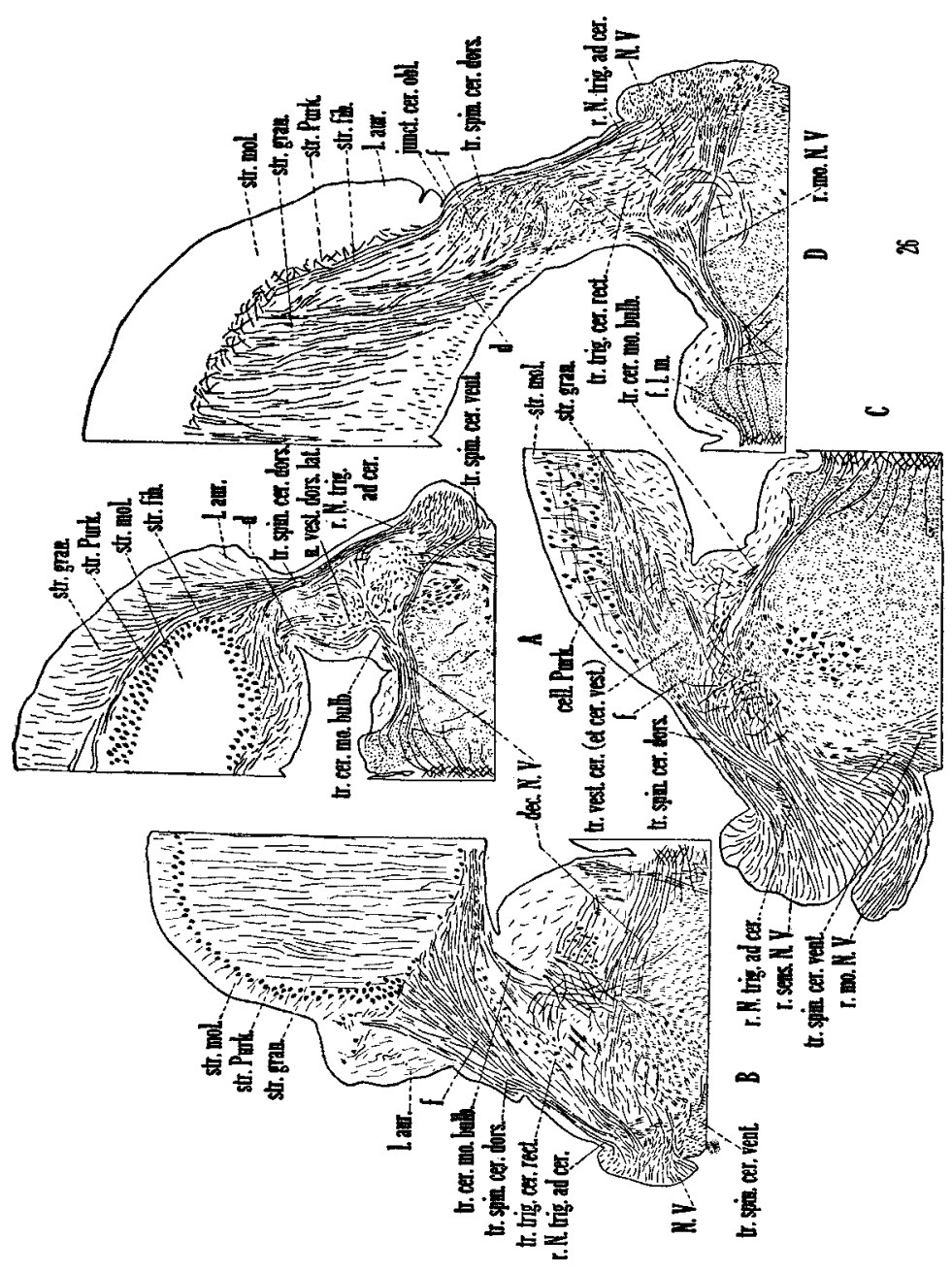

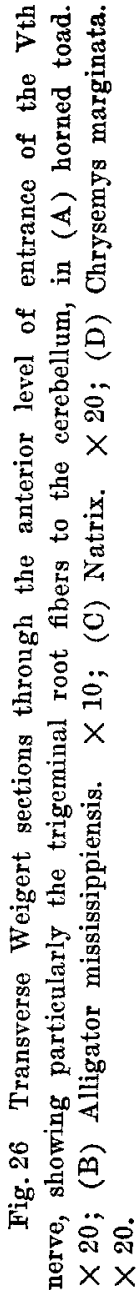




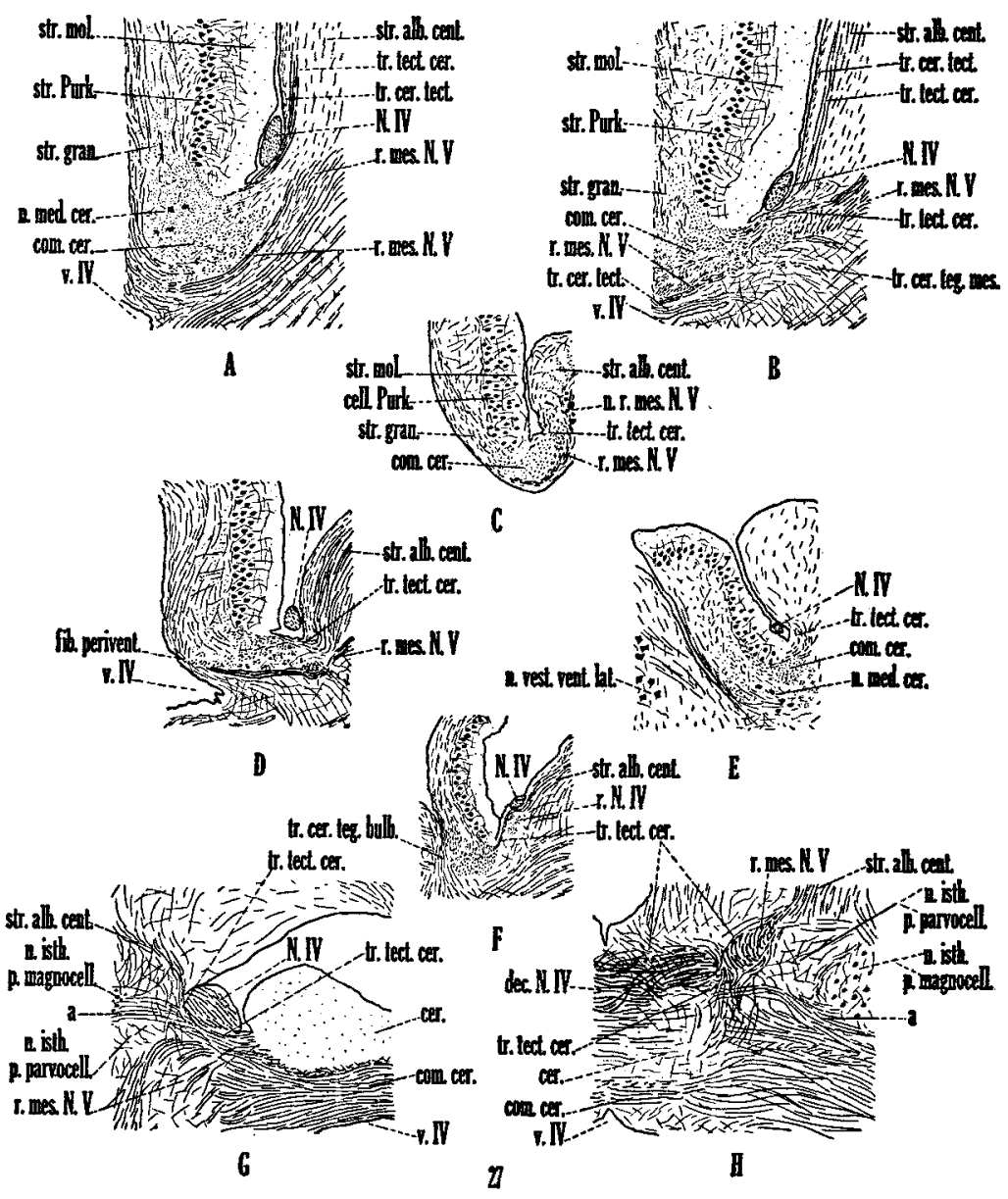

Fig. 27. Sagittal sections (except $G$ and $H$, horizontal) through the region of the anterior medullary velum to show the tecto-cerebellar system. $A$ and $B$, Alligator mississippiensis. $\times 10 . \mathrm{C}$ and E, Natrix. $\times 20 . \mathrm{D}$, Sternotherus. $\times 20$. F, Horned toad. $\times 20$. G, Alligator mississippiensis. $\times 20$. H, Chrysemys marginata. $\times 20$. 